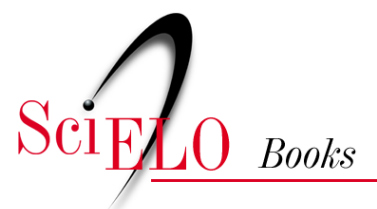

\title{
2. Análise da situação de saúde
}

Comissão Nacional sobre Determinantes Sociais da Saúde

\section{SciELO Books / SciELO Livros / SciELO Libros}

COMISSÃO NACIONAL SOBRE DETERMINANTES SOCIAIS DA SAÚDE. Análise da situação de saúde. In: As causas sociais das iniqüidades em saúde no Brasil [online]. Rio de Janeiro: Editora FIOCRUZ, 2008, pp. 23-130. ISBN: 978-85-7541-591-7. Available from: doi:

10.7476/9788575415917.0004. Also available in ePUB from: http://books.scielo.org/id/bwb4z/epub/comissao-9788575415917.epub.

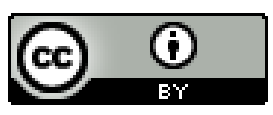

All the contents of this work, except where otherwise noted, is licensed under a Creative Commons Attribution 4.0 International license.

Todo o conteúdo deste trabalho, exceto quando houver ressalva, é publicado sob a licença Creative Commons Atribição 4.0. 


\subsection{Situação e Tendências da Evolução Demográfica, Social e Econômica do País}

O Brasil vem passando por grandes transformações econômicas, sociais e demográficas, particularmente nas quatro últimas décadas, com significativas repercussões nas condições de vida e trabalho da população e conseqüentemente em sua situação de saúde. Esta seção traça um esboço dessas transformações, destacando determinados processos, seus avanços, desafios e diferenciais segundo os diversos grupos sociais.

\section{Urbanização}

Conforme pode ser observado na Tabela 1 e no Gráfico 1, o censo demográfico de 1960 revelava que $55 \%$ da população economicamente ativa (PEA), portanto sua maioria, dedicavam-se à agricultura, ao passo que os restantes $45 \%$ se dedicavam aos setores secundário e terciário. Já na década seguinte, essa proporção se inverteu, com $54 \%$ da população empregada na indústria ou no setor serviços. Segundo o último censo de 2000 , apenas $19 \%$ da população estava empregada no campo, ou seja, uma queda de 55\% para $19 \%$ em quatro décadas. Nesse mesmo período, a população empregada pelo setor serviços passou de $27 \%$ a $60 \%$, ao passo que a dedicada à indústria, depois de uma ascensão de 17 a 29\% entre 1960 e 1980, caiu para $21 \%$, no censo de 2000.

Tabela 1 - Proporção de pessoas de 10 anos ou mais da PEA, por setor econômico. Brasil - 1940 - 2000

\begin{tabular}{c|ccc}
\hline \multirow{2}{*}{ Ano } & \multicolumn{3}{|c}{ PEA por setor de atividade econômica (\%) } \\
\cline { 2 - 4 } & Primário & Secundário & Terciário \\
\hline 1940 & 67 & 13 & 20 \\
1950 & 61 & 17 & 22 \\
1960 & 55 & 17 & 27 \\
1970 & 46 & 22 & 32 \\
1980 & 31 & 29 & 40 \\
1996 & 25 & 20 & 55 \\
2000 & 19 & 21 & 60 \\
\hline
\end{tabular}

Fonte: Censos Demográficos (1940 a 1980 e 2000) e Contagem da População (1996), Instituto Brasileiro de Geografia e Estatística (IBGE). 
Gráfico 1 - Evolução da proporção de pessoas de 10 anos ou mais de idade da PEA, por setor econômico. Brasil - 1940 - 2000

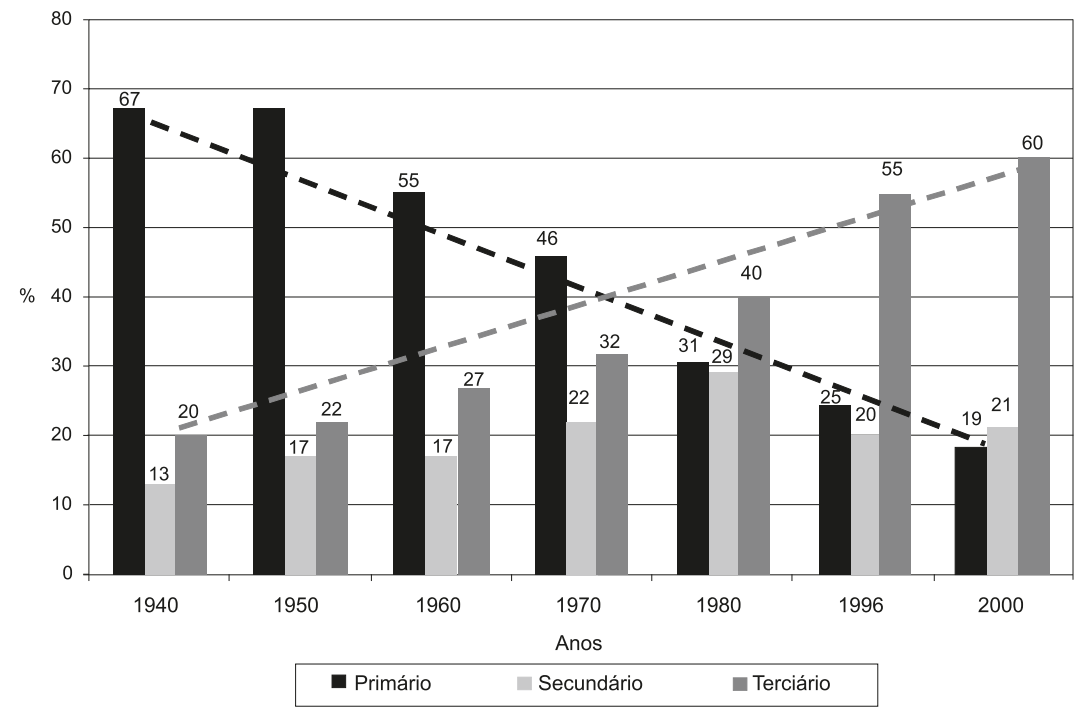

Fonte: Censos Demográficos (1940 a 1980 e 2000) e Contagem da População (1996), Instituto Brasileiro de Geografia e Estatística (IBGE).

Evidentemente, essa redistribuição acelerada da PEA do setor agrícola para os setores industriais e de serviços implicou um processo de urbanização também extraordinariamente acelerado. A Tabela 2 e o Gráfico 2 revelam que, em 1960, a maioria da população (55\%) possuía seu domicílio na zona rural. Na década seguinte, a proporção se inverteu, com $56 \%$ da população residindo na área urbana, proporção que cresce explosivamente desde então para atingir $81 \%$ em 2000. Em números absolutos, a população total do país era de 70.070.457 em 1960, sendo 31.303.034 na área urbana e 38.767.423 na área rural. Em 2000 , a população total cresceu para 169.610 .693 , sendo 137.775 .550 na área urbana e 31.835.143 na área rural, ou seja, no período de apenas quatro décadas a população rural diminuiu em 6.932.280, enquanto a população urbana cresceu em 106.472.516 milhões, um acréscimo de cerca de 2,7 milhões de pessoas por ano nas áreas urbanas, gerando uma enorme demanda por infra-estrutura e serviços.

A oferta dessa infra-estrutura e serviços urbanos não acompanhou a grande demanda, a tal ponto que, por exemplo, em 1980, havia 38,2 milhões de moradores em domicílios urbanos inadequados (neste ano a população total era de 119.002.706 habitantes, sendo 80.921.836 em áreas urbanas). Deve-se destacar que há uma diferença de mais de $75 \%$ nos níveis de mortalidade infantil entre crianças residentes em domicílios inadequados em relação aos adequados (Simões, 1985).

A urbanização acelerada, embora comum a todas as regióes do país, apresenta algumas variações, sendo mais precoce e mais acelerada na Região Sudeste, que em 2000 já contava com $91 \%$ da população vivendo em áreas urbanas. No outro extremo, situa-se a Região Nordeste, onde a população urbana apenas se torna majoritária no censo de 1991, atingindo $69 \%$ no ano 2000. 
Tabela 2 - População residente (\%), por situação do domicílio, segundo as grandes regiões. Brasil - 1940 - 2000

\begin{tabular}{|c|c|c|c|c|c|c|c|c|c|c|c|c|c|c|}
\hline \multirow{3}{*}{$\begin{array}{l}\text { Grandes } \\
\text { regiões }\end{array}$} & \multicolumn{14}{|c|}{ População residente (\%) } \\
\hline & \multicolumn{7}{|c|}{ Urbana } & \multicolumn{7}{|c|}{ Rural } \\
\hline & 1940 & 1950 & 1960 & 1970 & 1980 & 1991 & 2000 & 1940 & 1950 & 1960 & 1970 & 1980 & 1991 & 2000 \\
\hline BRASIL & 31 & 36 & 45 & 56 & 68 & 76 & 81 & 69 & 64 & 55 & 44 & 32 & 24 & 19 \\
\hline Norte & 28 & 31 & 37 & 45 & 52 & 59 & 70 & 72 & 69 & 63 & 55 & 48 & 41 & 30 \\
\hline Nordeste & 23 & 26 & 34 & 42 & 50 & 61 & 69 & 77 & 74 & 66 & 58 & 50 & 39 & 31 \\
\hline Sudeste & 39 & 48 & 57 & 73 & 83 & 88 & 91 & 61 & 52 & 43 & 27 & 17 & 12 & 9 \\
\hline Sul & 28 & 29 & 37 & 44 & 62 & 74 & 81 & 72 & 71 & 63 & 56 & 38 & 26 & 19 \\
\hline Centro-Oeste & 22 & 24 & 34 & 48 & 68 & 81 & 87 & 78 & 76 & 66 & 52 & 32 & 19 & 13 \\
\hline
\end{tabular}

Fonte: Censos demográficos (1940-2000). Instituto Brasileiro de Geografia e Estatística (IBGE).

Gráfico 2 - População residente (\%), por situação do domicílio. Brasil - 1940 - 2000

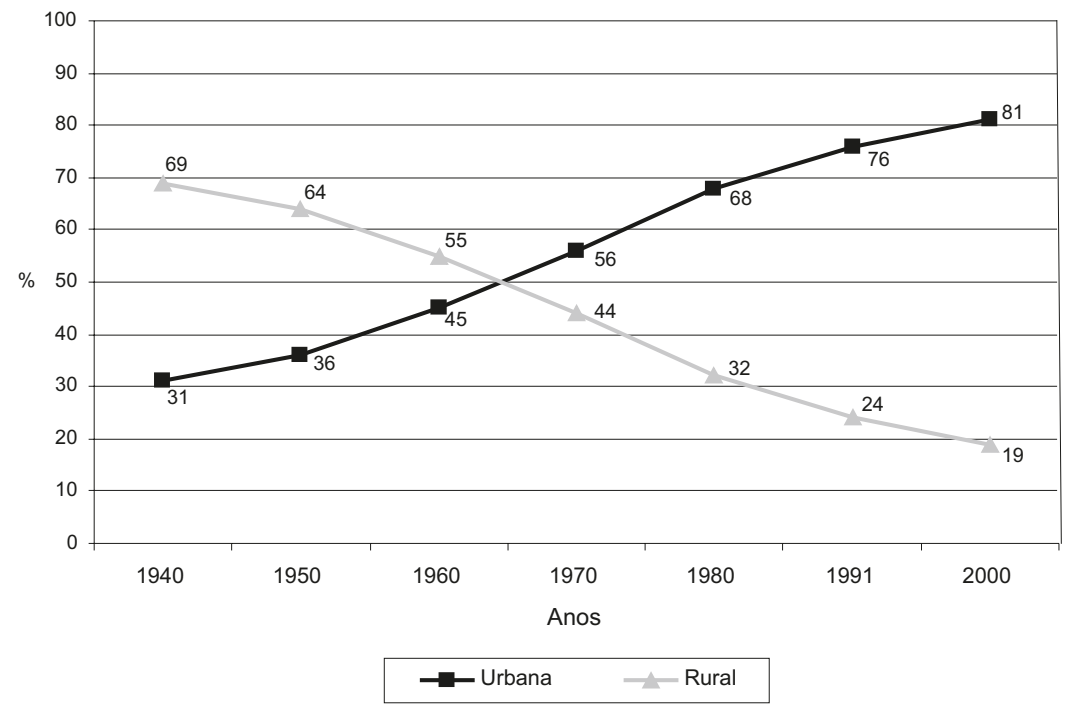

Fonte: Censos demográficos (1940-2000). Instituto Brasileiro de Geografia e Estatística (IBGE).

\section{Transição Demográfica}

Os processos de industrialização e urbanização acelerada foram responsáveis por importantes mudanças nos padrões de fecundidade da população. Segundo dados do censo, a taxa média geométrica de crescimento anual da população passou de 2,89\% no período 1960/1970 para 1,64\% no período 1991/2000. A taxa de fecundidade, que se mantinha estável desde 1940, passou a cair de maneira acelerada a partir de 1960. Como pode ser observado no Gráfico 3, também com dados censitários, a taxa de fecundidade, que era de 6,3 filhos por mulher em idade fértil em 1960, caiu para 2,3 em 2000, devendo situar-se em 2,0 em 2006, segundo projeções do IBGE. 
Gráfico 3 - Taxa de fecundidade. Brasil - 1940 - 2000

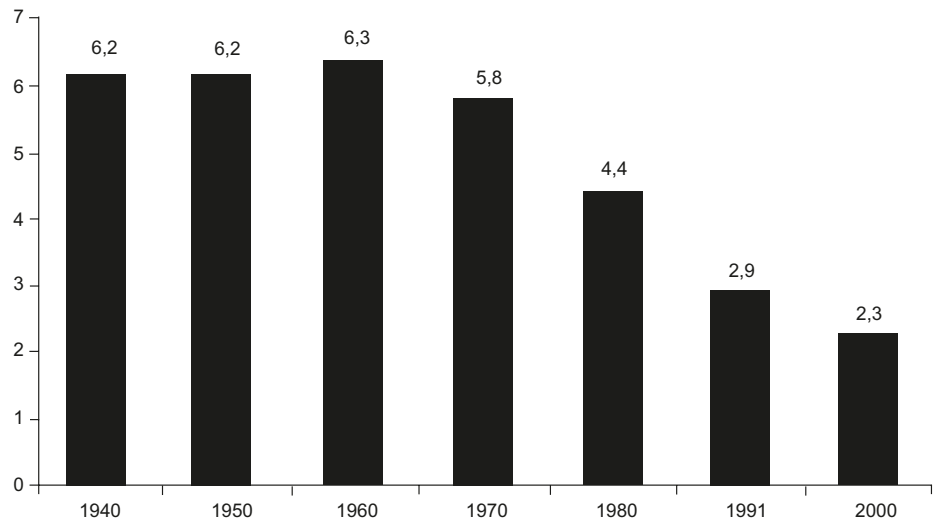

Fonte: Censo demográfico (1940-2000). Instituto Brasileiro de Geografia e Estatística (IBGE)

Essa importante queda da fecundidade ocorrida no Brasil nas últimas décadas é bem mais acelerada do que a observada nos países desenvolvidos. No Gráfico 4, observa-se que a queda da fecundidade experimentada por Itália e França é anterior e bem mais suave que a verificada no Brasil.

Embora a queda acelerada da taxa de fecundidade ocorra em todas as regiões do país, existem importantes diferenças segundo a escolaridade das mulheres. De acordo com dados da Pesquisa Nacional por Amostra de Domicílios (Pnad) de 2006, a taxa de fecundidade total, que em 2005 era de 2,1 filhos por mulher em idade fértil, variava de 4 para mulheres com até três anos de estudo a 1,5 para as que possuíam oito ou mais anos de estudo, como pode ser observado na Tabela 3.

Gráfico 4 - Taxa de fecundidade total. Brasil, França e Itália - 1900 - 2050

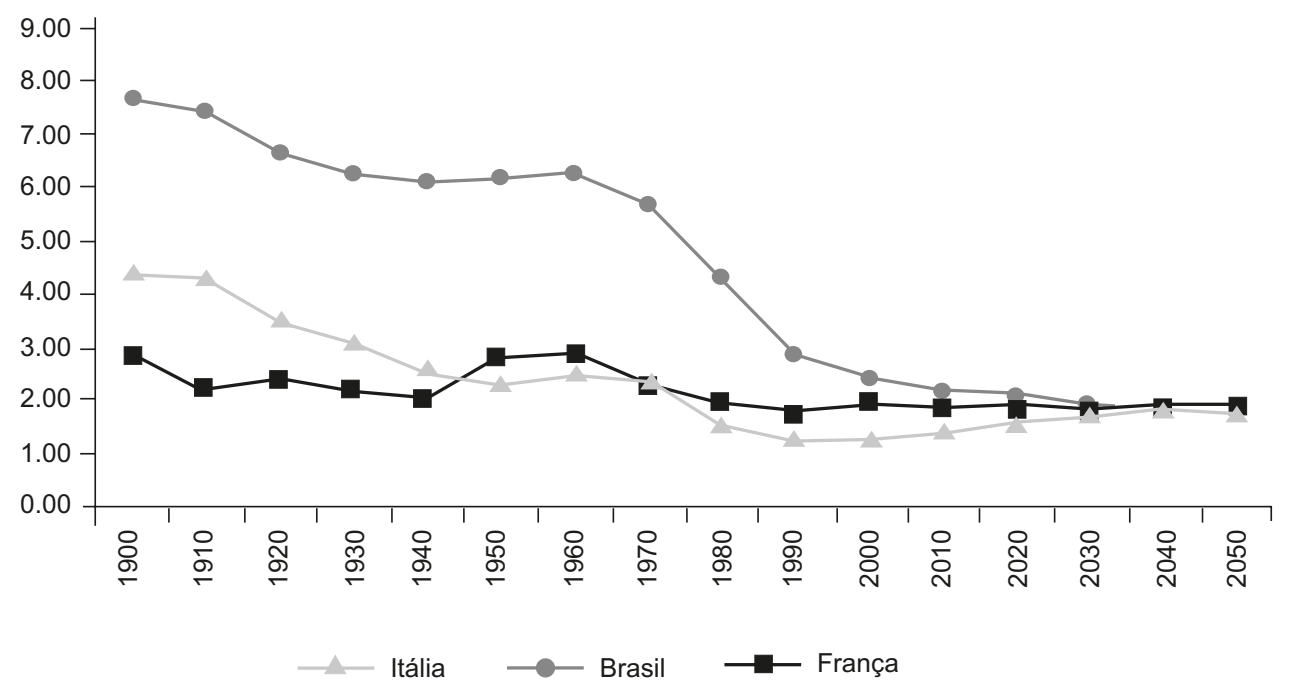

Fonte: ONU, Population Division of the Departament of Economic and Social Affairs of the United Nations Secretariat, World Population Prospects: The 2004 Revision; BACCI, 1999, p.137 e 167; FIBGE, 1990, p.33; IBGE, 2006, p34-36; IBGE, Censo demográfico de 1940, 1950, 1960 e 1970; IBGE/Diretoria de Pesquisas. Coordenação de População e Indicadores Sociais. Gerência de Estudos e Análises da Dinâmica Demográfica, 2004.

In: Brito, F. A Transição Demográfica no Brasil: as possibilidades e os desafios para a economia e a sociedade. Belo Horizonte: Cedeplar/UFMG, 2007. 
Tabela 3 - Taxa de fecundidade total por grupos de anos de estudo das mulheres, segundo as grandes regiões. Brasil -2005

\begin{tabular}{l|cccc}
\hline \multirow{2}{*}{$\begin{array}{l}\text { Grandes } \\
\text { regiões }\end{array}$} & \multicolumn{4}{|c}{$\begin{array}{c}\text { Taxa de fecundidade total, por grupos de anos de } \\
\text { estudo das mulheres }\end{array}$} \\
\cline { 2 - 5 } & TotAL $^{(1)}$ & Até 3 anos & 4 a 7 anos & 8 anos ou mais \\
\hline Brasil & 2,1 & 4,0 & 3,1 & 1,5 \\
Norte & 2,5 & 4,5 & 3,4 & 1,8 \\
Nordeste & 2,3 & 4,1 & 3,0 & 1,5 \\
Sudeste & 1,9 & 3,7 & 3,1 & 1,5 \\
Sul & 2,0 & 3,7 & 3,1 & 1,6 \\
Centro-Oeste & 2,0 & 3,4 & 3,1 & 1,5 \\
\hline
\end{tabular}

(1) Inclusive as mulheres sem declaração de anos de estudo.

Fonte: Pesquisa Nacional por Amostra de Domicílios 2005. Instituto Brasileiro de Geografia e Estatística (IBGE).

Importantes diferenças também são observadas de acordo com a renda. No Gráfico 5, construído a partir de dados de um trabalho de Berquó e Cavenaghi (2006), pode-se observar um nítido gradiente da taxa de fecundidade entre as diversas faixas de rendimento médio domiciliar per capita. A taxa para as mulheres que vivem em domicílios com renda per capita até um quarto do salário mínimo é mais de quatro vezes maior do que as que vivem em domicílios com cinco ou mais salários mínimos per capita.

Gráfico 5 - Taxa de fecundidade total, segundo rendimento médio mensal domiciliar per capita. Brasil 1991, 2000, 2004

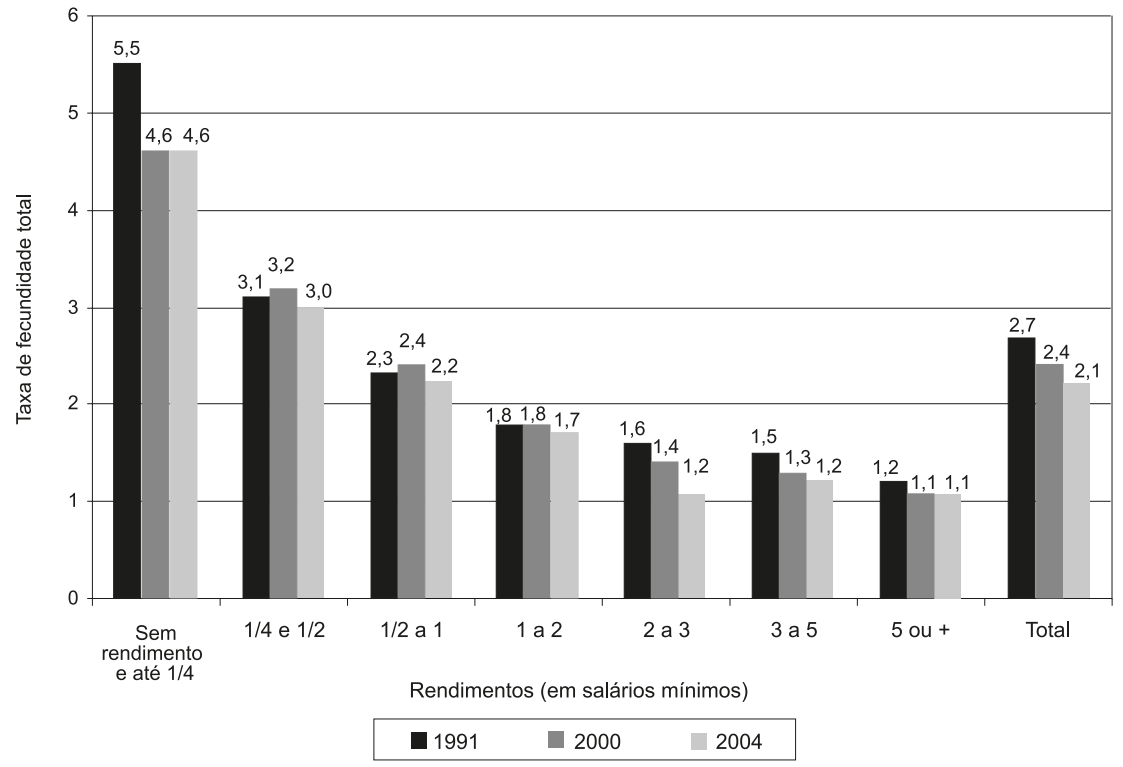

Fonte: Berquó, E.; Cavenaghi, S. Fecundidade em declínio: Breve nota sobre a redução no número médio de filhos por mulher no Brasil. Novos Estudos, Cebrap, 74, p. 11-15, março 2006. 
Importante observar o extraordinário aumento da contribuição das mulheres de 15 a 19 anos de idade na fecundidade total, em grande medida devido à redução da fecundidade das mulheres com idade mais avançada. Segundo dados do censo, no curto período de duas décadas, essa contribuição praticamente duplicou em todas as regiões do país, como pode ser observado no Gráfico 6.

Gráfico 6 - Contribuição da fecundidade das mulheres de 15 a 19 anos de idade na fecundidade total, por grandes regiões. Brasil - 1980 - 2000

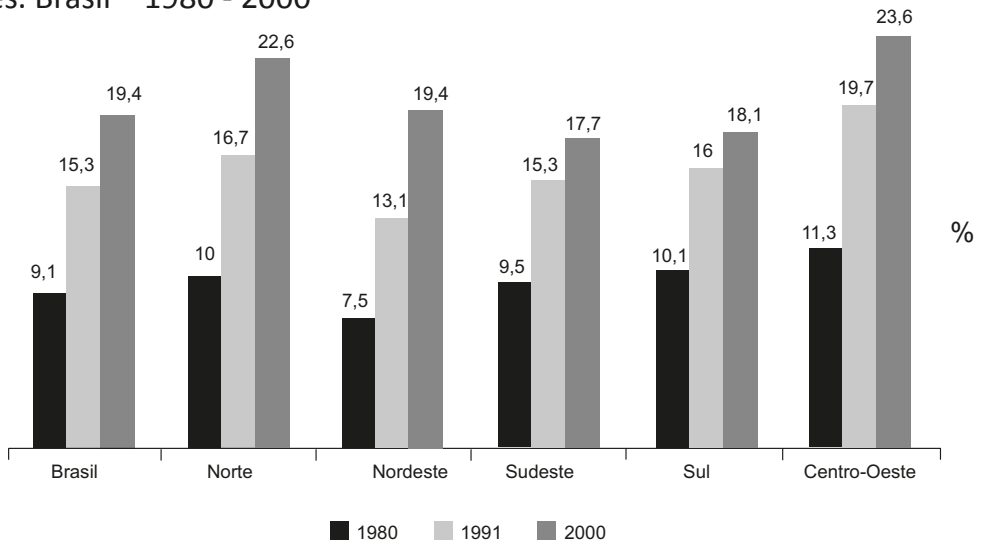

Fonte: Censo Demográfico 2000, Fecundidade e Mortalidade Infantil, Resultados Preliminares da Amostra. IBGE, 2002.

Apesar das baixas taxas atuais de fecundidade, a população brasileira ainda deve crescer de maneira expressiva nas próximas décadas, como resultado da fecundidade passada, como pode ser observado no Gráfico 7. O gráfico também mostra uma importante modificação na estrutura etária, com envelhecimento da população causado pela diminuição da fecundidade e aumento da expectativa de vida. A proporção de jovens de 0 a 14 anos que era de 42,6\% em 1960 passou para 30\% em 2000 e deverá atingir 18\% em 2050, ao passo que a de idosos maiores de 65 anos, que era de 2,7\% em 1960, passou para 5,4\% em 2000 e no ano de 2050 deverá superar a de jovens, alcançando 19\%.

Gráfico 7 - População total, segundo grandes grupos etários. Brasil - 1940 - 2050

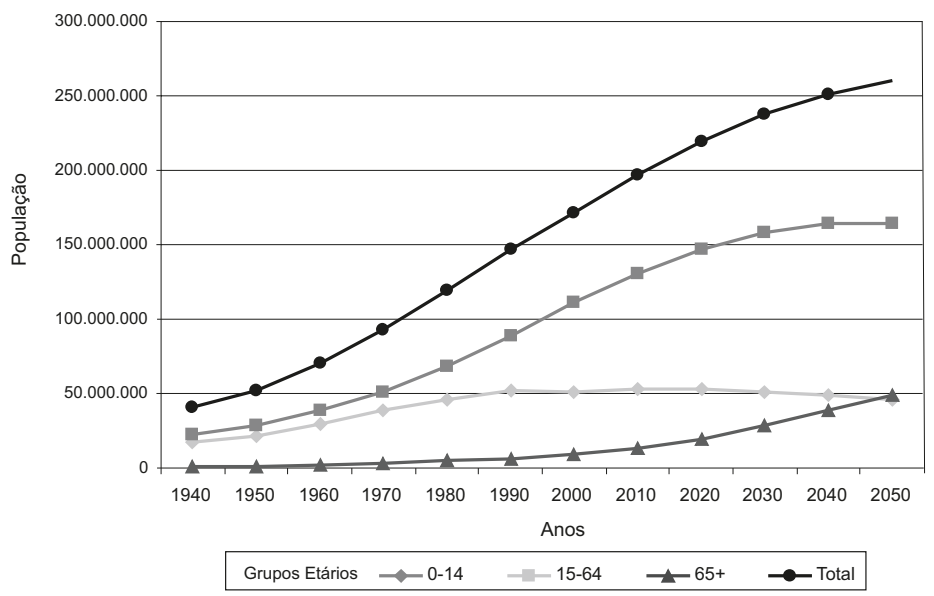

Fonte: IBGE.Censos Demogáficos de 1940, 1950, 1960 e 1980; IBGE/Diretoria de Pesquisas. Coordenação de População e Indicadores Sociais. Gerência de Estudos e Análises da Dinâmica Demoráfica, 2004.

In: Brito, F. A Transição Demográfica no Brasil: as possibilidades e os desafios para a economia e a sociedade. Belo Horizonte: Cedeplar/UFMG, 2007. 
As mudanças na estrutura etária, principalmente da maneira acelerada como vêm ocorrendo no Brasil, com um crescimento rápido do peso relativo dos idosos, têm um impacto importante na economia e na sociedade, obrigando a definição de políticas públicas que possam fazer frente a esse fenômeno sem paralelo na experiência mundial. Conforme salienta Brito (2007), essas políticas devem também levar em conta que, apesar do decréscimo relativo da presença dos jovens, seu número absoluto ainda é muito importante, devendo atingir o maior valor em 2010, para depois começar a decrescer também em termos absolutos.

Outro desafio para as políticas públicas é o fato de que as mudanças na estrutura etária ocorrem de forma desigual entre estados e regiões e entre os diferentes níveis de renda da população. O Gráfico 8 mostra as pirâmides populacionais do censo de 2000 para a população com renda familiar per capita de menos de meio salário mínimo, correspondente a $30 \%$ da população naquele ano, e para a população com mais de dez salários mínimos de renda familiar per capita, cerca de $3 \%$ da população.

Gráfico 8 - Pirâmides etárias dos grupos extremos, por faixa de renda familiar per capita em salários mínimos. Brasil - 2000 (\%)
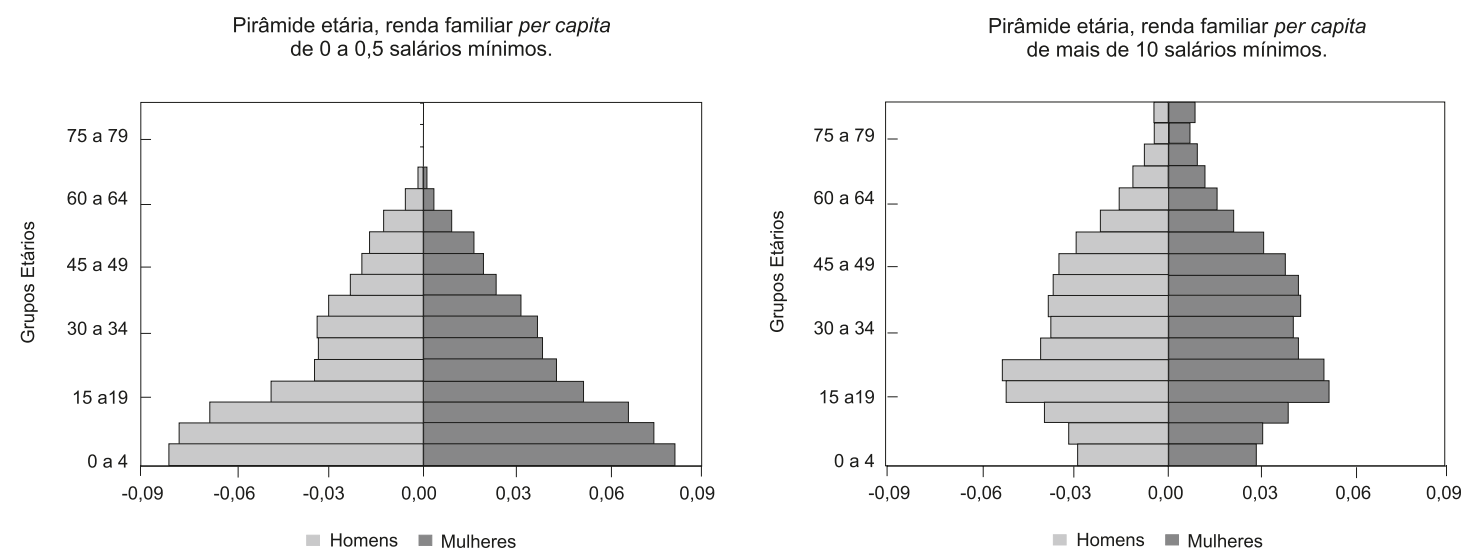

Fonte: IBGE.Censos Demogáficos de 1940, 1950, 1960 e 1980; IBGE/Diretoria de Pesquisas. Coordenação de População e Indicadores Sociais. Gerência de Estudos e Análises da Dinâmica Demoráfica, 2004.

In: Brito, F. A Transição Demográfica no Brasil: as possibilidades e os desafios para a economia e a sociedade. Belo Horizonte: Cedeplar/UFMG, 2007.

Outro elemento importante a ser tomado em conta pelas políticas públicas se refere à evolução da razão de dependência em função das mudanças na estrutura etária. Considerando que tanto a população de 0 a 14 anos como a de mais de 65 anos são dependentes da população em idade ativa de 15 a 64 anos (PIA), define-se a razão de dependência total (RDT) como a proporção da soma de jovens e idosos em relação à PIA. A RDT pode ser desdobrada em razão de dependência de jovens e razão de dependência de idosos, sendo a primeira a proporção dos jovens em relação a PIA e a segunda, a dos idosos. Como mostra a Tabela 4, em 1960, a RDT era de cerca de $83 \%$, ou seja, havia 83 dependentes para cada 100 pessoas na PIA, sendo que desses 83 dependentes, 78 eram jovens e 5 idosos. Entre 1960 e 2000, há uma queda importante da razão de dependência de jovens e um aumento da razão de dependência de idosos. A RDT caiu para 54\% em 2000, correspondendo a cerca de 46 jovens e 8 idosos para cada 100 pessoas da PIA. O índice de idosos, ou seja, a razão de idosos em relação aos jovens, triplicou nesse período, passando de 6,4 para 18,3. As projeções indicam que, a partir 
de 2000, a RDT deve manter-se relativamente estável até 2050, mas com uma importante mudança progressiva em sua composição, praticamente igualando-se nesse ano a razão de dependência de idosos $(29,7)$ e a de jovens $(28,2)$.

Tabela 4 - Razão de dependência total, de jovens e de idosos (\%), índice de idosos e idade mediana. Brasil - 1950 - 2050

\begin{tabular}{l|ccc|c|c}
\hline \multirow{2}{*}{ Período } & \multicolumn{3}{|c|}{ Razão de dependência } & \multirow{2}{*}{$\begin{array}{c}\text { Índice de } \\
\text { Idosos }\end{array}$} & $\begin{array}{c}\text { Idade } \\
\text { mediana }\end{array}$ \\
\cline { 2 - 3 } 1950 & TOTAL & Jovens & Idosos & 5,8 & 19,2 \\
1960 & 79,1 & 74,7 & 4,4 & 6,4 & 18,6 \\
1970 & 83,0 & 78,0 & 5,0 & 7,5 & 18,6 \\
1980 & 82,3 & 76,6 & 5,7 & 10,5 & 20,3 \\
1990 & 73,0 & 66,1 & 6,9 & 12,3 & 22,5 \\
2000 & 65,8 & 58,6 & 7,2 & 18,3 & 25,3 \\
2010 & 54,4 & 46,0 & 8,4 & 24,9 & 28,5 \\
2020 & 50,7 & 40,6 & 10,1 & 36,3 & 31,9 \\
2030 & 48,8 & 35,8 & 13,0 & 57,1 & 34,7 \\
2040 & 50,2 & 31,9 & 18,2 & 79,1 & 37,6 \\
2050 & 53,0 & 29,6 & 23,4 & 105,6 & 40,3 \\
\hline
\end{tabular}

Fonte: IBGE. Censos Demográficos de 1950, 1960 e 1970; IBGE/Diretoria de Pesquisas. Coordenação de População e Indicadores Sociais. Gerência de Estudos e Análises da Dinâmica Demográfica, 2004.

In: Brito, F. A Transição Demográfica no Brasil: as possibilidades e os desafios para a economia e a sociedade. Belo Horizonte: Cedeplar/UFMG, 2007.

Os demógrafos têm chamado a atenção para a necessidade de estabelecer políticas sociais e de emprego que aproveitem as oportunidades demográficas relacionadas com a queda na RDT e sua estabilidade entre 2010 e 2030. Nesse período, para 100 pessoas da PIA, teremos 50 jovens e idosos dependentes, com predomínio dos jovens, ou seja, uma relação de uma pessoa dependente para cada duas potencialmente produtivas. Um vez mais, vale o alerta de que essas políticas devem levar em conta que as oportunidades e desafios demográficos variam segundo as condições econômicas e sociais dos diversos grupos da população. Na Tabela 5 , pode-se observar que as razões de dependência e índice de idosos no ano 2000 são bastante diferentes de acordo com os níveis de renda familiar per capita. No grupo mais pobre, para cada 100 pessoas da PIA havia 82 dependentes, ao passo que no mais rico, para as mesmas 100 pessoas, havia 31 dependentes, 51 a menos. A composição dos dependentes é também bastante diferente, pois ao contrário da razão de dependência de jovens, a de idosos cresce com a renda. Dos 82 dependentes para cada 100 da PIA entre os mais pobres, 76 eram jovens e 6 eram idosos, ao passo que dos 31 dependentes dos grupos de maior renda, 17 eram jovens e 14 idosos, sendo a diferença no índice de idosos entre os dois grupos superior a dez vezes. 
Tabela 5 - Razão de dependência total, de jovens e de idosos e índice de idosos, segundo renda familiar per capita em salários mínimos. Brasil - 2000

\begin{tabular}{c|ccc|c}
\hline \multirow{2}{*}{$\begin{array}{c}\text { Renda familiar } \\
\text { per capita } \\
\text { (em salários mínimos) }\end{array}$} & \multicolumn{3}{|c|}{ Razão de dependência } & \multirow{2}{*}{$\begin{array}{c}\text { Índice de } \\
\text { idosos }\end{array}$} \\
\cline { 2 - 3 } & TOTAL & Jovens & Idosos & \\
\hline 0 a 0,5 & 82,2 & 76,2 & 5,9 & 7,8 \\
0,5 a 1 & 59,9 & 47,6 & 12,4 & 26,0 \\
1 a 2 & 43,1 & 34,3 & 8,8 & 25,8 \\
2 a 3 & 35,5 & 26,3 & 9,2 & 35,0 \\
3 a 5 & 34,1 & 24,5 & 9,7 & 39,5 \\
5 a 10 & 32,3 & 21,8 & 10,5 & 48,0 \\
$10+$ & 30,9 & 16,9 & 14,0 & 83,3 \\
BRASIL & 54,37 & 45,97 & 8,41 & 18,28 \\
\hline
\end{tabular}

Fonte: IBGE. Censos Demográficos de 2000

In: Brito, F. A Transição Demográfica no Brasil: as possibilidades e os desafios para a economia e a sociedade. Belo Horizonte: Cedeplar/UFMG, 2007.

\section{Crescimento Econômico e Distribuição de Renda}

As quatro décadas entre 1960 e 2000 também foram marcadas por importantes transformações econômicas. Segundo o Ipeadata, o PIB per capita passou de 2.060 dólares, em 1960, para 5.250, em 2000, e 5.720 em 2006 (em valores constantes do dólar de 2006), com forte crescimento entre 60 e 80 , cerca de $7,45 \%$ ao ano, e um crescimento menos intenso de cerca de $2,58 \%$ ao ano entre 80 e 2000. A agropecuária, responsável por $25 \%$ do PIB em 1960, teve sua participação reduzida para 8,9 \% em 2004, enquanto que a indústria, que correspondia a $18 \%$ do PIB em 1960, passou a responder por 42\% em 2004. Nesse período, a agropecuária teve um crescimento de $209 \%$ e a indústria cresceu $1.727 \%$.

Entretanto, esse extraordinário aumento da riqueza produzida e a modernização da economia não significaram melhoria na distribuição de renda. Segundo dados do censo, no ano 2000, cerca de $30 \%$ da população tinha uma renda familiar per capita menor que meio salário mínimo e 75\% uma renda familiar per capita menor que dois salários mínimos, situando-se no outro extremo 3\% da população com uma renda familiar per capita superior a 10 salários mínimos.

O Índice de Gini mostra uma piora da distribuição de renda, entre 1960 e 1991, com pequena melhoria em 2000 (Tabela 6). 
Tabela 6 - Índice de Gini, por ano, para renda familiar per capita das pessoas com 10 anos e mais. Brasil - 1960 - 2000

\begin{tabular}{c|c}
\hline Anos & Índice de Gini \\
\hline 1960 & 0,50 \\
1970 & 0,56 \\
1980 & 0,59 \\
1991 & 0,64 \\
2000 & 0,61 \\
\hline
\end{tabular}

Fonte: Ribeiro e Scalon, 2007

A Tabela 7 apresenta dados atualizados que mostram as grandes disparidades ainda existentes em indicadores de emprego e distribuição de renda por região e por cor da pele. Vale notar que, em 2006, cerca de $23 \%$ das famílias na Região Nordeste tinham uma renda per capita inferior a até um quarto do salário mínimo, enquanto esse percentual era de 5,5\% na Região Sul. Da mesma forma, a proporção de pobres na população nordestina, em 2005 , era cerca de três vezes maior que a do Sul.

A Tabela 8, também com dados atualizados de 2006, mostra a proporção de famílias nas diferentes classes de rendimento mensal familiar domiciliar total, segundo situação do domicílio (urbano, rural) e região. Observam-se, em todas as regiões, as grandes diferenças na proporção de famílias por classes de rendimento, de acordo com a situação urbano/rural, em prejuízo destas últimas. Há também grandes diferenças entre as regiões, situando-se o Sul e o Nordeste nos dois extremos. Cerca de 55\% das famílias urbanas no Sul residem em domicílios com renda total acima de três salários mínimos, ao passo que, no Nordeste, esta proporção é praticamente a metade $(26,3 \%)$. 
Tabela 7 - Indicadores econômicos, segundo região. Brasil

\begin{tabular}{|c|c|c|c|c|c|c|}
\hline \multirow{2}{*}{ Indicadores * } & \multicolumn{5}{|c|}{ Região } & \multirow{2}{*}{ BRASIL } \\
\hline & Norte & Nordeste & $\begin{array}{l}\text { Centro- } \\
\text { Oeste }\end{array}$ & Sudeste & Sul & \\
\hline $\begin{array}{l}\text { 1. População total e \% em } \\
\text { relação à população total do } \\
\text { país, } 2007\end{array}$ & $\begin{array}{c}15.342 .522 \\
(8,1 \%)\end{array}$ & $\begin{array}{c}52.193 .889 \\
(27,6 \%)\end{array}$ & $\begin{array}{c}13.516 .198 \\
(7,1 \%)\end{array}$ & $\begin{array}{c}80.641 .160 \\
(42,6 \%)\end{array}$ & $\begin{array}{c}27.641 .418 \\
(14,6 \%)\end{array}$ & $\begin{array}{c}189.335 .187 \\
(100,0 \%)\end{array}$ \\
\hline $\begin{array}{l}\text { 2. PIB per capita (em reais), } \\
2004\end{array}$ & $6.499,35$ & $4.926,86$ & $10.392,95$ & $12.539,04$ & $12.080,40$ & $9.728,83$ \\
\hline $\begin{array}{l}\text { 3. Índice de Gini da } \\
\text { distribuição do rendimento } \\
\text { mensal das pessoas de } 10 \\
\text { anos ou mais de idade com } \\
\text { rendimento, } 2006\end{array}$ & 0,508 & 0,556 & 0,558 & 0,529 & 0,510 & 0,547 \\
\hline 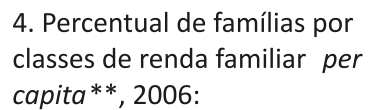 & & & & & & \\
\hline Sem rendimento $* * *$ & 4,1 & 3,2 & 2,4 & 2,2 & 1,6 & 2,5 \\
\hline Até $1 / 4$ salário mínimo & 12,0 & 19,6 & 5,1 & 3,8 & 3,9 & 8,6 \\
\hline Mais de 5 salários mínimos & 2,6 & 2,5 & 6,9 & 7,5 & 6,6 & 5,7 \\
\hline $\begin{array}{l}\text { 5. Proporção (\%) de pobres, } \\
2005\end{array}$ & 46,2 & 56,5 & 27,9 & 21,4 & 19,9 & 33,4 \\
\hline \multicolumn{7}{|l|}{$\begin{array}{l}\text { 6. Proporção (\%) de pobres, } \\
\text { por cor da pele, } 2005 \text { : }\end{array}$} \\
\hline Branca & 35,9 & 47,5 & 20,5 & 15,3 & 17,0 & 22,1 \\
\hline Preta & 44,8 & 56,2 & 32,0 & 27,7 & 28,0 & 37,8 \\
\hline Parda & 49,8 & 60,8 & 33,6 & 31,0 & 33,7 & 46,0 \\
\hline $\begin{array}{l}\text { 7. Taxa de desemprego ( } 10 \\
\text { anos ou mais de idade), } 2005\end{array}$ & 7,9 & 9,0 & 9,6 & 10,9 & 6,1 & 9,3 \\
\hline \multicolumn{7}{|l|}{$\begin{array}{l}\text { 8. Taxa de desemprego ( } 10 \\
\text { anos ou mais de idade), por } \\
\text { cor da pele, 2005: }\end{array}$} \\
\hline Branca & 7,7 & 8,0 & 8,1 & 9,7 & 5,6 & 8,2 \\
\hline Preta & 8,8 & 13,4 & 12,0 & 12,3 & 10,1 & 12,3 \\
\hline Parda & 7,9 & 8,9 & 10,7 & 12,7 & 8,2 & 10,2 \\
\hline
\end{tabular}

* A fonte do indicador número 1 é a Estimativa Populacional do IBGE para o ano de 2007; o indicador 3 é oriundo da PNAD, 2006 - IBGE. Os demais indicadores têm como fonte o IDB 2006 (Indicadores e Dados Básicos), produto da ação integrada do Ministério da Saúde e da Organização Pan-Americana da Saúde (Opas), no âmbito da Rede Interagencial de Informações para a Saúde (Ripsa).

** Exclusive o rendimento das pessoas cuja condição na família era pensionista, empregado doméstico ou parente do empregado doméstico.

*** A categoria "Sem rendimento" inclui as famílias cujos componentes receberam somente benefícios. 
Tabela 8 - Proporção (\%) de famílias residentes em domicílios particulares, por classes de rendimento mensal familiar domiciliar, segundo situação do domicílio e região. Brasil - 2006

\begin{tabular}{|c|c|c|c|c|c|}
\hline \multirow{2}{*}{$\begin{array}{c}\text { Situação do domicílio e classe } \\
\text { de rendimento }{ }^{(1)}\end{array}$} & \multicolumn{5}{|c|}{ Região } \\
\hline & Norte & Nordeste & $\begin{array}{l}\text { Centro- } \\
\text { Oeste }\end{array}$ & Sudeste & Sul \\
\hline \multicolumn{6}{|l|}{ Sem rendimento ${ }^{(2)}$} \\
\hline Urbana & 4,1 & 3,2 & 2,4 & 2,1 & 1,5 \\
\hline Rural & 3,9 & 3,1 & 2,4 & 2,4 & 1,9 \\
\hline \multicolumn{6}{|l|}{ Até 1 salário mínimo } \\
\hline Urbana & 15,9 & 23,9 & 10,9 & 8,3 & 7,7 \\
\hline Rural & 24,1 & 40,7 & 18,3 & 16,8 & 13,5 \\
\hline \multicolumn{6}{|l|}{ Mais de 1 a 3 salários mínimos } \\
\hline Urbana & 45,8 & 45,6 & 40,0 & 35,4 & 35,6 \\
\hline Rural & 52,6 & 46,3 & 54,4 & 52,5 & 47,4 \\
\hline \multicolumn{6}{|l|}{ Mais de 3 a 5 salários mínimos } \\
\hline Urbana & 16,3 & 12,5 & 18,2 & 20,7 & 22,2 \\
\hline Rural & 11,4 & 6,5 & 14,0 & 17,1 & 19,7 \\
\hline \multicolumn{6}{|l|}{ Mais de 5 salários mínimos } \\
\hline Urbana & 17,3 & 13,8 & 27,4 & 30,3 & 32,1 \\
\hline Rural & 6,7 & 2,2 & 9,6 & 9,0 & 16,4 \\
\hline
\end{tabular}

(1) Exclusive os rendimentos dos moradores de 10 anos de idade e dos moradores cuja condição no domicílio era pensionista, empregado doméstico ou parente do empregado.

(2) Inclusive as pessoas que receberam somente em benefícios.

Fonte: elaboração própria, a partir da Pesquisa Nacional por Amostra de Domicílios (Pnad) 2006. Instituto Brasileiro de Geografia e Estatística (IBGE).

Também no caso de idosos existem enormes diferenciais de renda. O Gráfico 9 mostra a distribuição percentual de pessoas com 65 anos ou mais de idade por classes de rendimento médio mensal domiciliar per capita, observando-se, por exemplo, que no Nordeste $68 \%$ dos idosos residem em domicílios com renda familiar per capita menor que um salário mínimo, enquanto no Sul e no Sudeste este percentual está abaixo dos 35\%.

Mesmo com as melhorias recentes na distribuição de renda - relacionadas ao controle da inflação e estabilidade macroeconômica proporcionadas pelo Plano Real, à valorização do salário mínimo e aos programas de transferência de renda intensificados nos últimos anos -, a distribuição de renda no Brasil continua entre as piores do mundo. Com base em um Índice de Gini de 0,57 em 2003, o relatório do Pnud de 2007 situa o Brasil em $11^{\circ}$ lugar entre os países com mais alta concentração de renda (em 2006, o Índice de Gini caiu para 0,54). Conforme pode ser observado no Gráfico 10, há uma melhoria na razão de renda, ou seja, no número de vezes que a renda dos $20 \%$ mais ricos supera a dos $20 \%$ mais pobres, embora em 2005 a renda dos $20 \%$ mais ricos seja ainda cerca de 22 vezes maior do que a renda dos $20 \%$ mais pobres. 
Gráfico 9 - Distribuição percentual de pessoas com 65 anos ou mais de idade, residentes em domicílios particulares, por classes de rendimento médio mensal domiciliar per capita, segundo as grandes regiões. Brasil - 2006

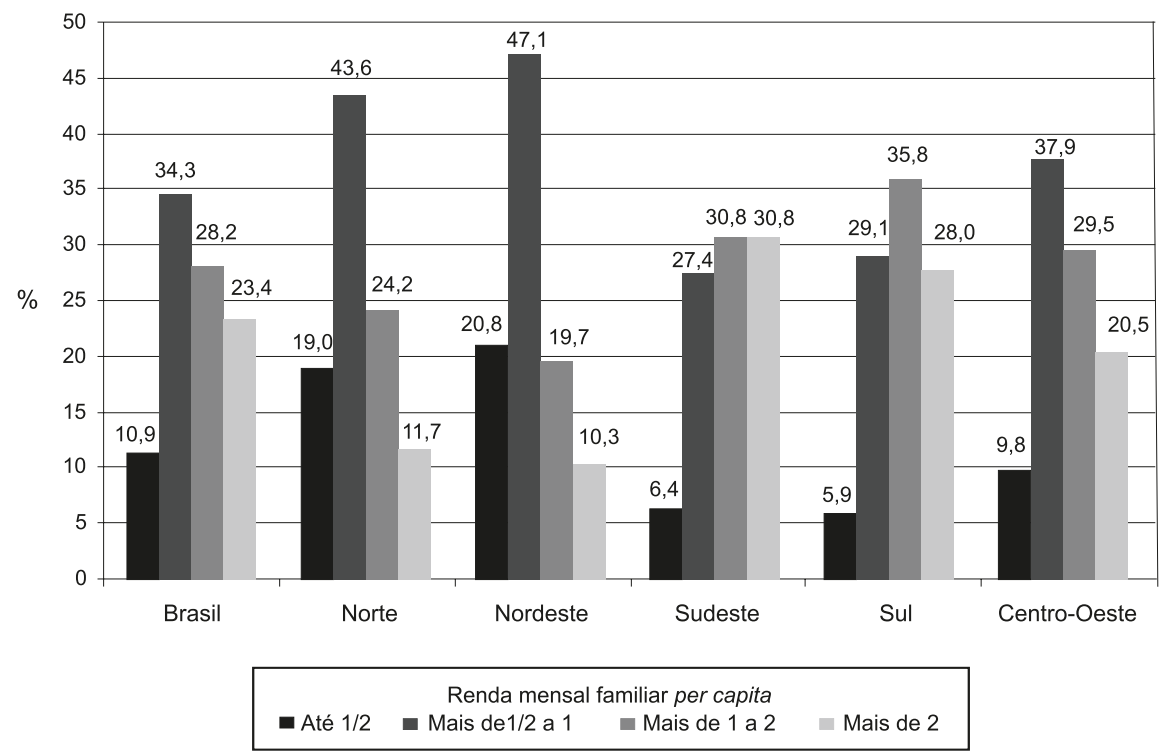

Fonte: Pesquisa Nacional por Amostra de Domicílios 2006. Instituto Brasileiro de Geografia e Estatística (IBGE).

Gráfico 10 - Razão de renda (n. de vezes que a renda dos $20 \%$ mais ricos supera a dos $20 \%$ mais pobres) por ano e região. Brasil - 1993, 1999, 2005

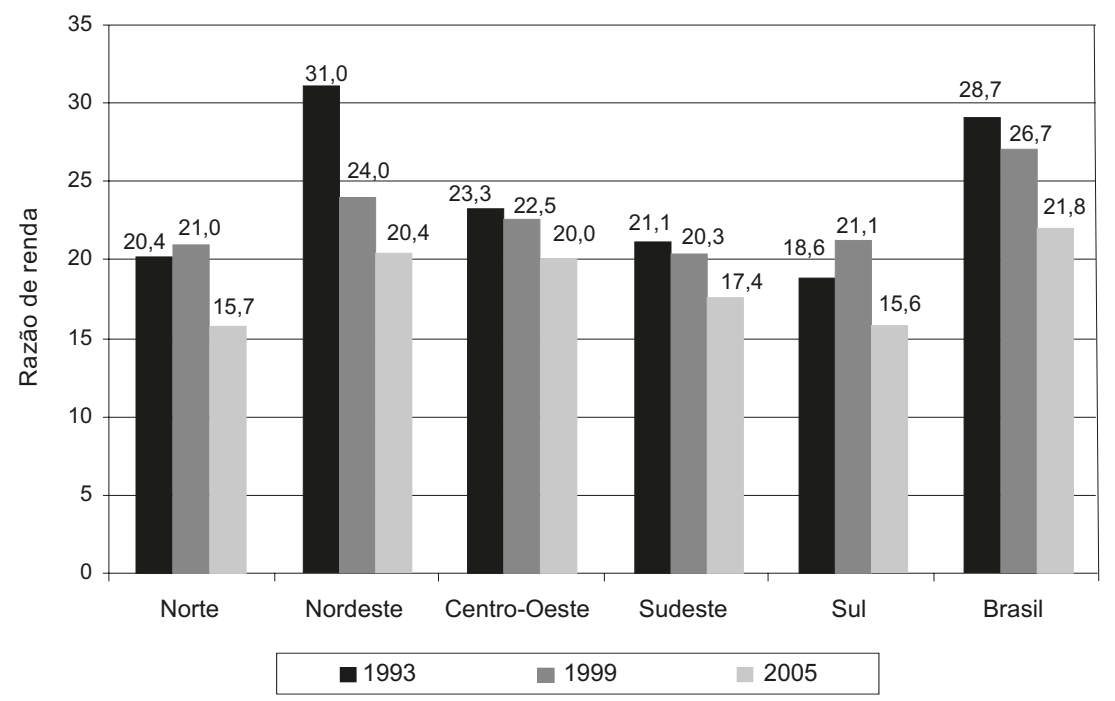

Obs.: Até o ano de 2003, informações não disponíveis para a área rural de RO, AC, AM, RR, PA e AP.

Fonte: IDB 2006 (Indicadores e Dados Básicos), produto da ação integrada do Ministério da Saúde e da Organização Pan-Americana da Saúde (Opas), no âmbito da Rede Interagencial de Informações para a Saúde (Ripsa). 


\section{Desenvolvimento Social: educação e saúde}

$\mathrm{Na}$ esfera do desenvolvimento social, ocorreram também grandes mudanças nas últimas décadas, destacando-se, entre elas, as ocorridas na educação. Conforme observado no Gráfico 11, em 1940, 56\% da população brasileira era analfabeta, percentual que cai para $40 \%$ em 1960 e $13,6 \%$ no ano 2000.

Gráfico 11 - Evolução temporal da taxa de analfabetismo por década. Brasil - 1940 - 2000

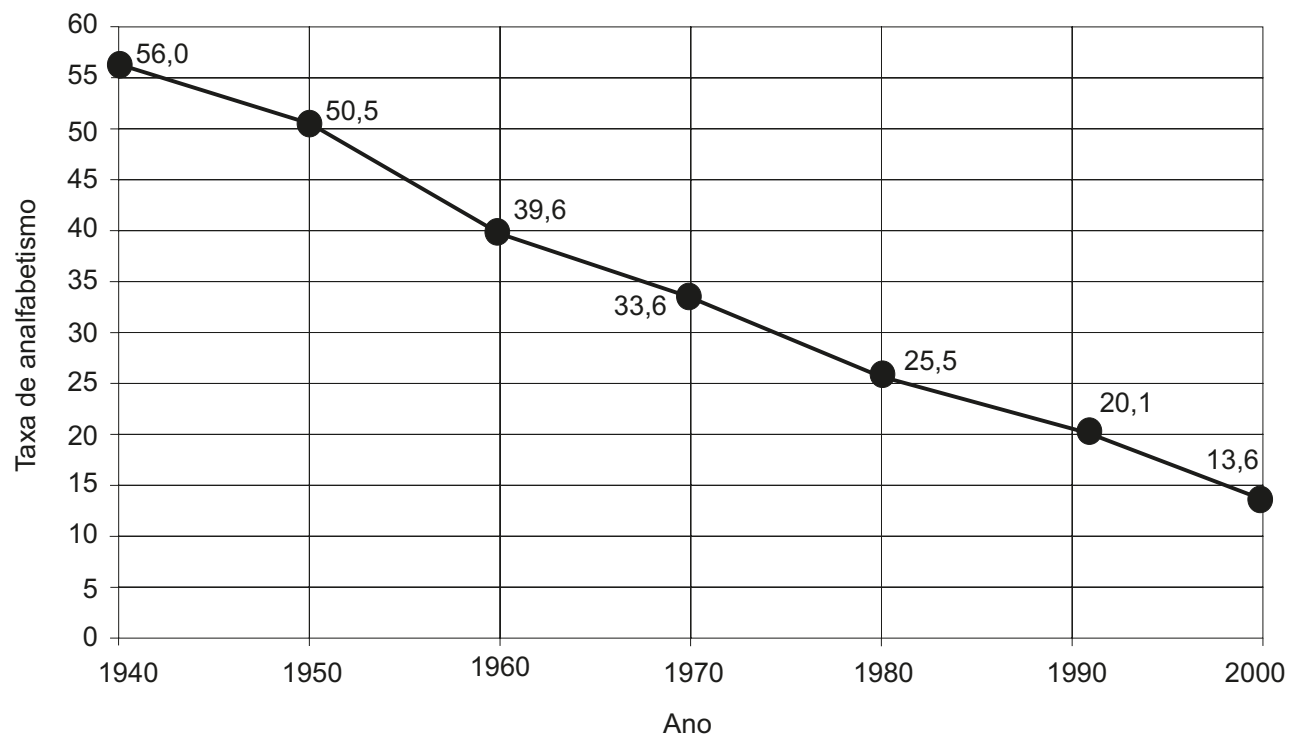

Fonte: IETS - Instituto de Estudos do Trabalho e Sociedade, a partir dos Censos Demográficos.

Segundo a Pnad, em 2006, havia 12,3\% de analfabetos entre as pessoas com 5 ou mais anos de idade, observando-se, entretanto, importantes diferenças regionais, já que este percentual na Região Sul era de $7,6 \%$, enquanto no Nordeste era de $22,10 \%$. Há, também, importantes diferenças de acordo com a renda familiar. Ainda segundo a Pnad 2006, a média de 10,4\% de analfabetos entre as pessoas com 15 ou mais anos de idade variava de $17,9 \%$ para as pessoas com rendimento mensal familiar per capita menor que meio salário mínimo até 1,3\% para as pessoas com mais de dois salários mínimos. Estas diferenças segundo renda estão também presentes no interior das regiões, sendo que, na Região Nordeste, a média de 20,8\% de analfabetos variava de $24,9 \%$ para as pessoas com menos de $1 / 2$ salário mínimo de renda mensal familiar per capita, até 1,9\% para as com mais de dois salários mínimos, enquanto na Região Sul a média de 5,7\% de analfabetos variava de 10,4\% para menos de meio salário até $1,1 \%$ para mais de dois salários. Estes e outros dados se encontram na Tabela 9. 
Tabela 9 - Pessoas de 15 anos ou mais de idade, analfabetas, total e taxa de analfabetismo, por classes de rendimento mensal familiar per capita, segundo as grandes regiões. Brasil -2006

\begin{tabular}{|c|c|c|c|c|c|c|}
\hline \multirow{3}{*}{ Grandes regiões } & \multicolumn{6}{|c|}{ Pessoas de 15 anos ou mais de idade, analfabetas } \\
\hline & \multirow{2}{*}{$\begin{array}{c}\text { TOTAL } \\
\text { (1000 pessoas) }\end{array}$} & \multicolumn{5}{|c|}{$\begin{array}{l}\text { Taxa de analfabetismo, por classes de rendimento familiar } \\
\text { per capita (salários mínimos) (\%) }\end{array}$} \\
\hline & & TOTAL & Até $1 / 2$ & $\begin{array}{l}\text { Mais de } \\
1 / 2 \text { a } 1\end{array}$ & $\begin{array}{l}\text { Mais de } \\
1 \text { a } 2\end{array}$ & Mais de 2 \\
\hline Brasil & 14.391 & 10,4 & 17,9 & 13,7 & 6,5 & 1,3 \\
\hline Norte & 1.142 & 11,3 & 15,1 & 13,1 & 6,8 & 2,4 \\
\hline Nordeste & 7.595 & 20,8 & 24,9 & 23,7 & 13,5 & 1,9 \\
\hline Sudeste & 3.667 & 6,0 & 10,1 & 9,5 & 5,1 & 1,2 \\
\hline Sul & 1.179 & 5,7 & 10,4 & 8,8 & 4,6 & 1,1 \\
\hline Centro-Oeste & 808 & 8,3 & 12,7 & 11,7 & 6,6 & 1,4 \\
\hline
\end{tabular}

Fonte: Pesquisa Nacional por Amostra de Domicílios 2006. Instituto Brasileiro de Geografia e Estatística (IBGE).

A taxa de analfabetismo, que no Nordeste é cerca de quatro vezes maior do que na Região Sul, também varia no interior das regiões de acordo com sexo, cor da pele e local de moradia, como pode ser observado na Tabela 10.

Estas diferenças tendem a se reproduzir, pois de acordo com o relatório do Unicef de 2006 sobre a situação da infância brasileira, os filhos de mulheres brasileiras com até um ano de escolaridade têm uma probabilidade 23 vezes maior de chegarem analfabetos à adolescência se comparados com os filhos de mulheres com 11 anos ou mais de estudo.

De acordo com o Instituto Nacional de Estudos e Pesquisas do Ministério da Educação (Inep/ MEC), a taxa de escolarização líquida, ou seja, o percentual da população de determinada faixa etária matriculada no nível de ensino adequado, cresceu no caso do ensino fundamental para todo o Brasil de 80\% em 1980 para 94,3\% em 2000. Há uma tendência à diminuição das diferenças regionais, já que a Região Nordeste, que apresenta o menor percentual, cresceu de 69,1\% em 1980 para 92,8 em 2000, e a Região Sudeste, com o maior percentual, cresceu de $89,2 \%$ para $96,1 \%$. No caso do ensino médio, embora a taxa de escolarização líquida permaneça bem mais baixa, observa-se também uma tendência de crescimento dessa taxa acompanhada de diminuição das ainda grandes diferenças regionais. Para o Brasil como um todo, o percentual cresceu de 14,3 \% em 1980 para 33,3\% em 2000, sendo que para a Região Nordeste cresceu de 6,5\% a 16,7\% no mesmo período e na Região Sudeste de 20,3\% para 45,6\%. 
Tabela 10 - Taxas de analfabetismo segundo sexo, cor da pele e local de moradia, por região. Brasil - 2005

\begin{tabular}{|c|c|c|c|c|c|c|}
\hline \multirow[b]{2}{*}{ Indicadores * } & \multicolumn{5}{|c|}{ Região } & \multirow[b]{2}{*}{ BRASIL } \\
\hline & Norte & Nordeste & $\begin{array}{l}\text { Centro- } \\
\text { Oeste }\end{array}$ & Sudeste & Sul & \\
\hline $\begin{array}{l}\text { 1. Taxa de analfabetismo } \\
\text { (15 anos ou mais de idade), } 2005\end{array}$ & 11,6 & 21,9 & 8,9 & 6,6 & 5,9 & 11,1 \\
\hline \multicolumn{7}{|l|}{$\begin{array}{l}\text { 2. Taxa de analfabetismo } \\
\text { ( } 15 \text { anos ou mais de idade), } \\
\text { por sexo, 2005: }\end{array}$} \\
\hline Feminino & 10,4 & 20,0 & 9,1 & 7,2 & 6,5 & 10,8 \\
\hline Masculino & 12,8 & 24,0 & 8,7 & 5,8 & 5,2 & 11,3 \\
\hline \multicolumn{7}{|l|}{$\begin{array}{l}\text { 3. Taxa de analfabetismo } \\
\text { ( } 15 \text { anos ou mais de idade), por } \\
\text { cor da pele, 2005: }\end{array}$} \\
\hline Branca & 7,4 & 17,6 & 6,6 & 4,9 & 4,7 & 7,0 \\
\hline Preta & 14,9 & 23,2 & 12,8 & 10,3 & 11,0 & 14,6 \\
\hline Parda & 12,8 & 23,8 & 10,5 & 8,8 & 11,5 & 15,6 \\
\hline \multicolumn{7}{|l|}{$\begin{array}{l}\text { 4. Taxa de analfabetismo } \\
\text { ( } 15 \text { anos ou mais de idade), por } \\
\text { situação, 2005: }\end{array}$} \\
\hline Urbana & 8,9 & 16,4 & 7,9 & 5,7 & 5,1 & 8,4 \\
\hline Rural & 20,0 & 36,4 & 15,4 & 17,2 & 9,8 & 25,0 \\
\hline
\end{tabular}

* Os indicadores têm como fonte o IDB 2006 (Indicadores e Dados Básicos), produto da ação integrada do Ministério da Saúde e da Organização Pan-Americana da Saúde (Opas), no âmbito da Rede Interagencial de Informações para a Saúde (Ripsa).

A Pnad 2006 mostra o extraordinário avanço da escolaridade no nível fundamental com cobertura quase universal entre 7 a 14 anos em todas as regiões, tanto na área urbana como rural. No caso do ensino médio, a taxa de freqüência líquida entre 15 a 17 anos ainda é bastante baixa para o Brasil como um todo, com grandes variações segundo região e segundo situação do domicílio, conforme mostra a Tabela 11.

Há importantes diferenças na média de anos de estudo das pessoas com 25 ou mais anos de idade de acordo com o rendimento mensal familiar per capita. Conforme se observa na Tabela 12 e no Gráfico 12, com dados da Pnad 2006, há um claro gradiente de anos de estudo conforme rendimento familiar no Brasil e nas diversas regiões. Tanto nas regiões com menor como naquelas com maior escolaridade, há uma diferença de cerca de seis anos na média de anos de estudo entre as pessoas situadas nos dois quintis extremos. 
Tabela 11 - Taxa de freqüência líquida a estabelecimento de ensino das pessoas de 7 a 17 anos de idade, por nível de ensino, grupos de idade e situação do domicílio (\%). Brasil - 2006

\begin{tabular}{l|ccc|ccc}
\hline \multirow{2}{*}{$\begin{array}{l}\text { Grandes } \\
\text { regiões }\end{array}$} & \multicolumn{3}{|c|}{ Fundamental } & \multicolumn{3}{c}{ Médio } \\
\cline { 2 - 7 } & \multicolumn{3}{|c}{ 7 a 14 anos } & \multicolumn{3}{c}{ 15 a 17 anos } \\
\cline { 2 - 7 } & TOTAL & Urbana & Rural & TOTAL & Urbana & Rural \\
\hline \multirow{2}{*}{ Brasil } & 94,8 & 95,3 & 93,0 & 47,1 & 51,9 & 26,9 \\
Norte & 93,7 & 94,2 & 92,4 & 34,7 & 40,8 & 17,4 \\
Sudeste & 93,4 & 93,9 & 92,3 & 33,1 & 40,6 & 17,6 \\
Sul & 95,7 & 95,9 & 93,6 & 57,9 & 59,6 & 40,6 \\
Centro-Oeste & 96,1 & 96,4 & 94,7 & 54,9 & 55,8 & 50,4 \\
\hline
\end{tabular}

Fonte: Pesquisa Nacional por Amostra de Domicílios 2006. Instituto Brasileiro de Geografia e Estatística (IBGE).

Tabela 12 - Média de anos de estudo das pessoas de 25 anos ou mais de idade, por quintis de rendimento mensal familiar per capita, segundo as grandes regiões. Brasil - 2006

\begin{tabular}{|c|c|c|c|c|c|c|}
\hline \multirow{2}{*}{$\begin{array}{l}\text { Grandes } \\
\text { Regiões }\end{array}$} & \multirow{2}{*}{ TOTAL } & \multicolumn{5}{|c|}{ Quintis de rendimento mensal familiar per capita } \\
\hline & & 10 & 20 & 3으 & $4 \stackrel{0}{2}$ & 5은 \\
\hline BRASIL & 6,7 & 3,9 & 5,0 & 5,5 & 6,7 & 10,2 \\
\hline Norte & 6,2 & 3,9 & 5,0 & 5,2 & 6,0 & 9,0 \\
\hline Nordeste & 5,2 & 2,9 & 3,8 & 4,4 & 4,9 & 8,1 \\
\hline Sudeste & 7,4 & 5,0 & 5,7 & 6,0 & 7,6 & 10,8 \\
\hline Sul & 7,1 & 4,7 & 5,7 & 5,9 & 7,3 & 10,4 \\
\hline Centro-Oeste & 6,9 & 4,7 & 5,1 & 5,3 & 7,1 & 10,6 \\
\hline
\end{tabular}


Gráfico 12 - Média de anos de estudo das pessoas de 25 anos ou mais de idade, por quintis de rendimento mensal familiar per capita. Brasil - 2006

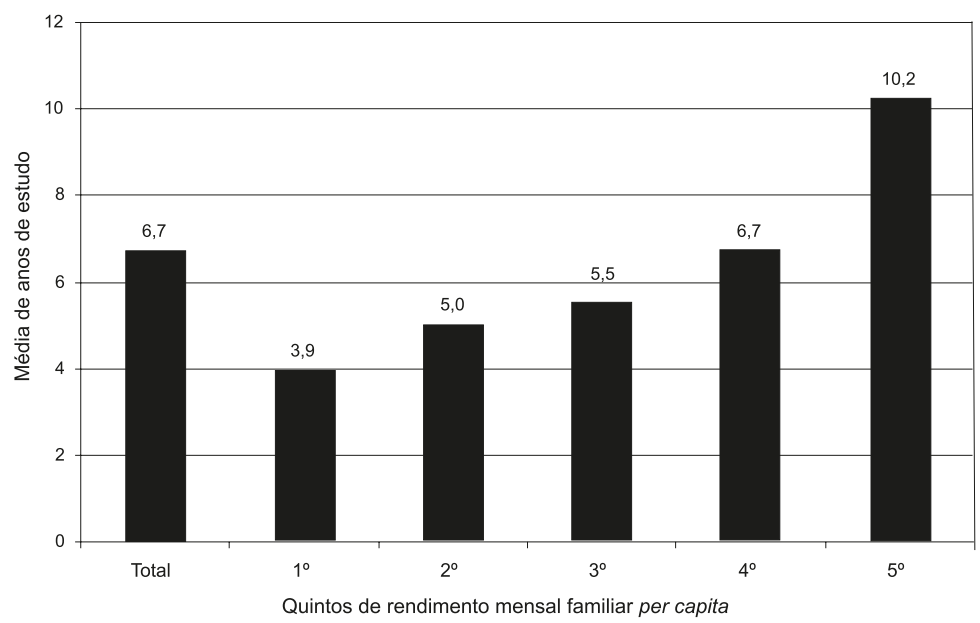

Fonte: Pesquisa Nacional por Amostra de Domicílios 2006. Instituto Brasileiro de Geografia e Estatística (IBGE).

As diferenças em escolaridade também são marcantes de acordo com a cor da pele. Segundo dados da Pnad 2006, a taxa de analfabetismo e analfabetismo funcional de pretos e pardos é cerca do dobro da observada nos brancos. Por sua vez, a proporção de pessoas de cor branca com 25 anos ou mais de idade com 15 ou mais anos de estudo é três vezes maior do que a encontrada entre pretos e pardos, como mostra a Tabela 13.

Tabela 13 - Escolaridade segundo cor da pele. Brasil - 2006

\begin{tabular}{l|c|ccc}
\hline \multicolumn{1}{c|}{ BRASIL } & TotAL & Branca & Preta & Parda \\
\hline Analfabetos (\%) & 10,4 & 6,5 & 14,1 & 14,7 \\
Analfabetos funcionais (\%) & 22,2 & 16,4 & 27,5 & 28,6 \\
$\begin{array}{l}\text { Média de anos de estudo } \\
\text { \% pessoas com 25 ou + anos } \\
\begin{array}{l}\text { de idade com 15 ou + anos } \\
\text { de estudo }\end{array}\end{array}$ & 7,2 & 8,1 & 6,4 & 6,2 \\
\hline
\end{tabular}

Fonte: Pesquisa Nacional por Amostra de Domicílios 2006. Instituto Brasileiro de Geografia e Estatística (IBGE).

A Pnad 2006 também mostra a distribuição dos estudantes da rede pública e privada no ensino médio e superior. Conforme pode ser observado na Tabela 14, no caso do ensino médio público, tanto para o Brasil como um todo como para as diversas regiões predominam os estudantes pertencentes ao $2^{\circ}, 3^{\circ}$, e $4^{\circ}$ quintis de renda, com baixa participação dos quintis extremos de menor e maior renda. O mesmo não ocorre no caso do ensino superior público, onde há um gradiente ascendente segundo o nível de renda, com forte predominância dos estudantes pertencentes ao quintil de renda mais alta. Estes dados indicam que embora o ensino público cumpra um papel compensatório no ensino médio, privilegiando as classes 
menos favorecidas, o mesmo não ocorre no ensino superior, onde as desigualdades sociais são reproduzidas e fortalecidas, pois quanto maior a renda maior o acesso ao ensino superior público em todas as regiões. No caso da rede particular, tanto para o ensino médio como para o ensino superior há um gradiente que acompanha o perfil de renda, com forte predominância do quintil de maior renda.

Tabela 14 - Estudantes da rede pública e da rede particular, por nível de ensino freqüentado, total e respectiva distribuição percentual, por quintis de rendimento mensal familiar per capita, segundo as grandes regiões. Brasil - 2006

\begin{tabular}{|c|c|c|c|c|c|c|c|c|c|c|c|c|}
\hline \multirow{4}{*}{$\begin{array}{l}\text { Grandes } \\
\text { regiões }\end{array}$} & \multicolumn{12}{|c|}{ Estudantes da Rede Pública } \\
\hline & \multicolumn{6}{|c|}{ Ensino médio } & \multicolumn{6}{|c|}{ Ensino superior } \\
\hline & \multirow[t]{2}{*}{$\begin{array}{c}\text { TOTAL } \\
(1000)\end{array}$} & \multicolumn{5}{|c|}{$\begin{array}{l}\text { Distribuição percentual, } \\
\text { por quintis de } \\
\text { rendimento mensal } \\
\text { familiar per capita }(\%)\end{array}$} & \multirow[t]{2}{*}{$\begin{array}{c}\text { TOTAL } \\
\text { (1000) }\end{array}$} & \multicolumn{5}{|c|}{$\begin{array}{l}\text { Distribuição percentual, } \\
\text { por quintis de } \\
\text { rendimento mensal } \\
\text { familiar per capita (\%) }\end{array}$} \\
\hline & & 10 & 2 은 & 3응 & 40 & 50 & & 10 & 20 & 3 은 & 40 & 50 \\
\hline BRASIL & 7043 & 18,3 & 25,5 & 25,8 & 20,7 & 9,7 & 1366 & 1,8 & 6,2 & 11,6 & 26,1 & 54,3 \\
\hline Norte & 641 & 13,2 & 20,1 & 26,1 & 23,6 & 17,0 & 151 & 1,8 & 5,7 & 8,8 & 21,8 & 61,9 \\
\hline Nordeste & 2058 & 14,2 & 21,4 & 27,0 & 24,7 & 12,7 & 388 & 0,6 & 3,0 & 8,8 & 19,1 & 68,5 \\
\hline Sudeste & 2882 & 22,8 & 27,5 & 23,2 & 19,4 & 7,1 & 476 & 2,1 & 5,4 & 10,1 & 24,1 & 58,3 \\
\hline Sul & 954 & 17,6 & 26,7 & 24,8 & 20,6 & 10,2 & 219 & 2,7 & 5,4 & 14,2 & 22,8 & 54,8 \\
\hline $\begin{array}{l}\text { Centro- } \\
\text { Oeste }\end{array}$ & 508 & 17,1 & 23,7 & 24,6 & 23,7 & 10,8 & 131 & 2,6 & 7,8 & 13,5 & 28,3 & 47,8 \\
\hline \multirow{4}{*}{$\begin{array}{l}\text { Grandes } \\
\text { regiões }\end{array}$} & \multicolumn{12}{|c|}{ Estudantes da Rede Particular } \\
\hline & \multicolumn{6}{|c|}{ Ensino médio } & \multicolumn{6}{|c|}{ Ensino superior } \\
\hline & $\begin{array}{l}\text { TOTAL } \\
(1000)\end{array}$ & \multicolumn{5}{|c|}{$\begin{array}{c}\text { Distribuição percentual, } \\
\text { por quintis de } \\
\text { rendimento mensal } \\
\text { familiar per capita (\%) }\end{array}$} & $\begin{array}{l}\text { TOTAL } \\
\text { (1000) }\end{array}$ & \multicolumn{5}{|c|}{$\begin{array}{l}\text { Distribuição percentual, } \\
\text { por quintis de } \\
\text { rendimento mensal } \\
\text { familiar per capita }(\%)\end{array}$} \\
\hline & & 10 & 20 & 3음 & $4 ㅇ$ & 5 은 & & 10 & 2o & 3응 & 4 은 & 5음 \\
\hline BRASIL & 1191 & 2,1 & 6,2 & 11,1 & 20,3 & 60,2 & 4198 & 1,0 & 3,2 & 8,8 & 22,8 & 64,2 \\
\hline Norte & 66 & 1,6 & 6,5 & 11,7 & 14,3 & 65,9 & 209 & 0,7 & 2,3 & 6,1 & 17,3 & 73,6 \\
\hline Nordeste & 287 & 1,6 & 3,7 & 9,9 & 22,1 & 62,6 & 657 & 0,5 & 2,0 & 5,7 & 14,8 & 77,1 \\
\hline Sudeste & 559 & 2,5 & 7,0 & 10,3 & 22,0 & 58,2 & 2190 & 1,5 & 4,6 & 11,1 & 27,3 & 55,5 \\
\hline Sul & 175 & 1,4 & 6,1 & 8,7 & 26,2 & 57,6 & 775 & 1,6 & 5,4 & 10,4 & 25,8 & 57,0 \\
\hline $\begin{array}{l}\text { Centro- } \\
\text { Oeste }\end{array}$ & 104 & 2,8 & 4,1 & 7,6 & 18,8 & 66,7 & 366 & 2,3 & 4,1 & 9,6 & 23,2 & 60,7 \\
\hline
\end{tabular}

(*) Os indicadores têm como fonte o IDB 2006 (Indicadores e Dados Básicos), produto da ação integrada do Ministério da Saúde e da Organização Pan-Americana da Saúde (Opas), no âmbito da Rede Interagencial de Informações para a Saúde (Ripsa). 
Nos últimos anos, houve um extraordinário avanço no número de instituições, assim como de egressos no ensino superior. Segundo o MEC/Inep, em 1980, havia um total de 882 instituições de ensino superior (IES), sendo 77,3\% delas privadas, e em 2004 havia 2.013 IES, com aumento da participação privada para 89\%. Em 1980, concluíram o curso superior 226.423 alunos (64,2\% em instituições privadas), cerca de $0,2 \%$ da população total do país, e em 2005 esse número aumentou para 717.858 alunos (72,8\% em instituições privadas), correspondendo a cerca de $0,4 \%$ da população do país.

Quanto à pós-graduação, também houve um crescimento significativo: segundo a Coordenação de Aperfeiçoamento de Pessoal de Nível Superior, do Ministério da Educação (Capes/MEC), em 1987 houve 4.750 titulados em mestrado e doutorado, 932 dos quais em doutorado (19,6\%), número que cresceu para 40.406 titulados em 2006, 9.192 dos quais em doutorado (22,7\%), um aumento do número anual de titulados doutores de praticamente dez vezes no período. Em 2004, foram titulados 8.856 doutores, cerca de $80 \%$ deles na Região Sudeste. Deste total de 8.856 doutores, 8.000 foram titulados em instituições de ensino públicas, federais e estaduais e 856 em instituições privadas. Vale notar que as instituições estaduais foram responsáveis pela titulação de 4.076 doutores entre os 8.000 titulados por instituições públicas, sendo quase sua totalidade titulada por instituições estaduais de São Paulo, responsáveis por 3.841 dos 4.076 titulados. O desenvolvimento do ensino superior e da pós-graduação, principalmente em nível de doutorado, se reflete na produção científica. O número de artigos científicos produzidos por autores brasileiros, na base do Institute for Scientific Information (ISI), que registra a literatura científica de maior impacto a nível internacional, pouco mais que duplicou entre 1981 e 1994, enquanto no período seguinte (1994 a 2006) cresceu quase quatro vezes, conforme se observa no Gráfico 13. Entre 1981 e 2006, o número de artigos de autores brasileiros cresceu 795,5\%, bem acima dos Estados Unidos, Reino Unido e Alemanha, por exemplo, que cresceram, respectivamente, $66,2 \%, 95,1 \%$ e $112,7 \%$.

Esse importante crescimento do número de artigos publicados por autores brasileiros, com impacto internacional, permitiu um significativo aumento do peso relativo da produção científica do país no contexto mundial. Entre 1981 e 1994, a produção científica brasileira oscilava entre 0,5 e 0,9\% da produção mundial e, graças a um crescimento relativo constante a partir de então, atingiu cerca de $2 \%$ da produção mundial em 2006 . No contexto latinoamericano a produção científica de autores brasileiros corresponde hoje a cerca de $50 \%$ de toda a produção da região, conforme se observa no Gráfico 14. 
Gráfico 13 - Brasil: artigos publicados em periódicos científicos indexados no ISI - 1981 - 2006

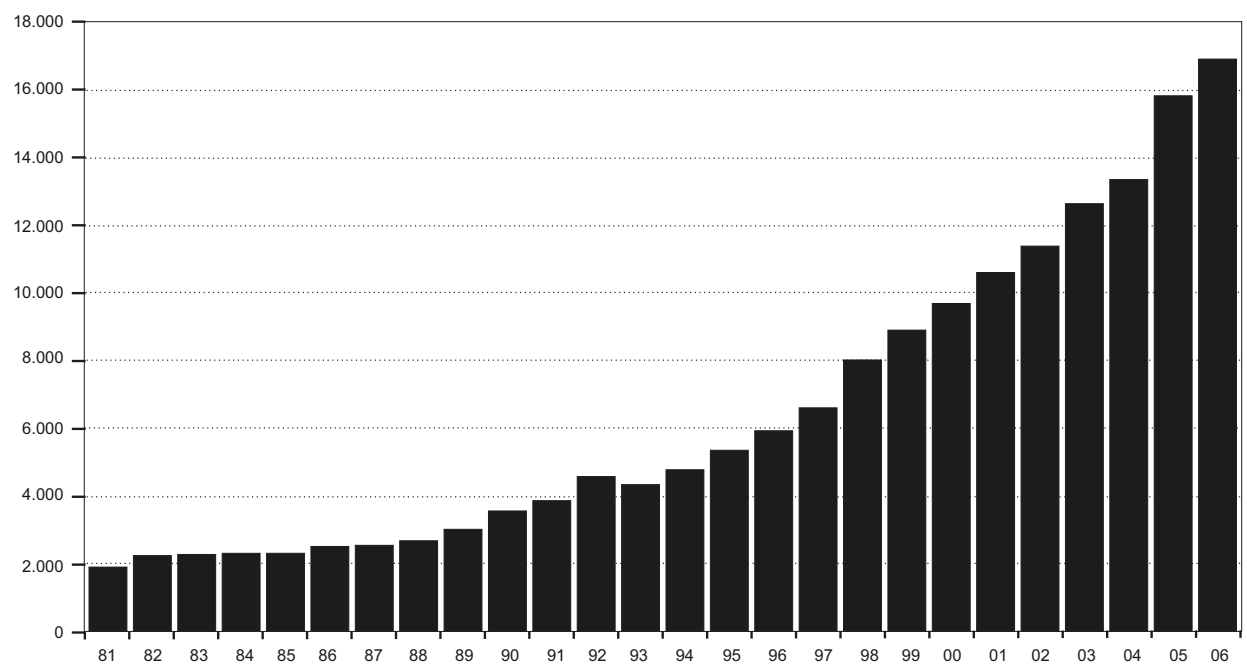

Fonte(s): Institute for Scientific Information (ISI). National Science Indicators. Elaboração: Coordenação-Geral de Indicadores - ASCAV/SEXEC Ministério da Ciência e Tecnologia.

Gráfico 14 - Brasil: percentual de artigos publicados em periódicos científicos indexados no ISI, em relação à América Latina e ao mundo, 1981 - 2006

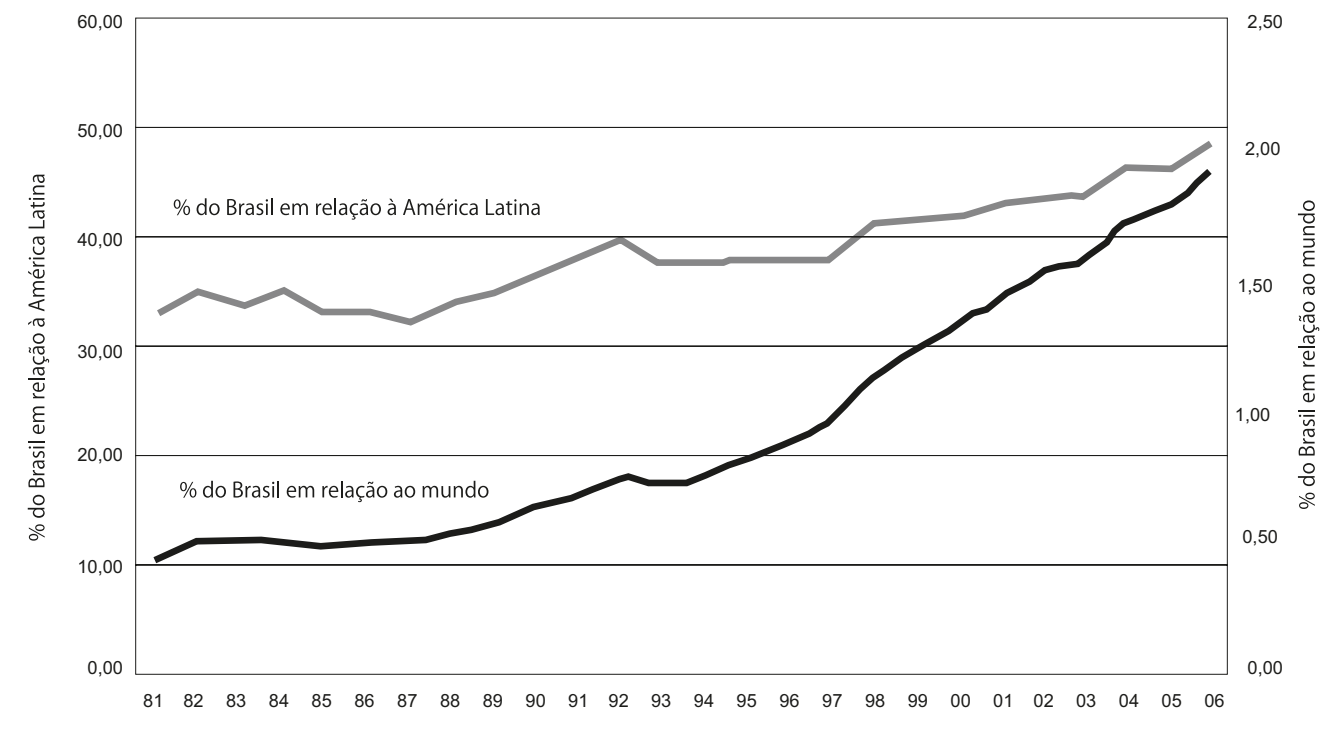

Fonte(s): Institute for Scientific Information (ISI). National Science Indicators. Elaboração: Coordenação-Geral de Indicadores - ASCAV/SEXEC Ministério da Ciência e Tecnologia. 
A exemplo do que ocorre com o ensino de pós-graduação, as atividades científico-tecnológicas estão altamente concentradas. Segundo o Diretório de Grupos de Pesquisa do Conselho Nacional de Desenvolvimento Científico e Tecnológico (CNPq), cerca de 70 a $80 \%$ desses grupos se situam nas regiões Sudeste e Sul, o mesmo ocorrendo para a distribuição de pesquisadores e doutores. Como conseqüência, a produção científica está também bastante concentrada. Os autores das regiões Sudeste e Sul foram responsáveis por cerca de 80\% dos artigos publicados em revistas de circulação nacional e internacional no ano de 2002 . No caso da produção científica em saúde, esta concentração é particularmente prejudicial, já que características epidemiológicas e da organização de serviços específicas de cada região obrigam a existência de uma capacidade instalada de pesquisa local para o estudo destas especificidades.

Além da alta concentração das atividades científico-tecnológicas há uma grande desproporção entre a produção científica expressa pela publicação de artigos e a produção tecnológica expressa pela concessão de patentes, com grande prejuízo desta última, indicando a crônica dificuldade do país para transformar os conhecimentos que produz em inovações e produtos. Além de escassas, as patentes concedidas se limitam praticamente às regióes Sudeste e Sul. Segundo o Instituto Nacional de Propriedade Industrial (Inpi), o número de pedidos de patentes tipo privilégio de invenção feitos por residentes no país foi de apenas 679 no ano 2000, caindo para 389 em 2001, 351 em 2002, 413 em 2003 e 546 em 2004.

Esta debilidade na cadeia pesquisa/inovação/produção, representada pela relativamente baixa concessão de patentes em relação à produção científica, pode ser em parte explicada pela escassa presença de pesquisadores dedicados à pesquisa e desenvolvimento (P\&D) nas empresas. De fato, segundo dados do Ministério da Ciência e Tecnologia (MCT), para 2004, 65,9\% dos pesquisadores envolvidos em P\&D (equivalência de tempo integral) estão vinculados a instituições do ensino superior e apenas $26,3 \%$ a empresas, proporção praticamente inversa à observada em países desenvolvidos.

Quanto ao financiamento das atividades de P\&D, o Brasil mantém uma proporção de gastos em relação ao PIB de pouco mais de $1 \%$. Segundo o IBGE, esta proporção foi de $1,22 \%$ em 2000 e 1,17\% em 2004, bem abaixo dos 3,15\% do Japão, 2,64\% da Coréia, 2,6\% dos Estados Unidos ou 2,5\% da Alemanha, segundo dados da Unesco. Houve um grande avanço nos anos recentes quanto à proporção do gasto total em P\&D proveniente de recursos privados, passando de 23,9\% em 1990 (segundo a Red de Indicadores de Ciencia y Tecnología - RICYT) para 39,71\% em 2000 e 44,55\% em 2004 (MCT). Os gastos públicos correspondentes a 60,29\% em 2000 e 55,45\% em 2004 são em sua maioria (cerca de 70\%) provenientes de recursos federais. Os gastos estaduais correspondem a cerca de $30 \%$ dos gastos públicos, sendo que $70 \%$ dos gastos estaduais correspondem a três estados: São Paulo $(48,9 \%)$, Paraná $(12,4 \%)$ e Rio de Janeiro (8,8\%).

Os importantes avanços e contradições no desenvolvimento econômico-social das últimas décadas são também observados na situação de saúde. Segundo o IBGE, a taxa de mortalidade infantil (TMI) que era de 124 óbitos no primeiro ano de vida para cada mil nascidos vivos em 
1960, caiu para 48,3 em 1990, 35,26 em 2000 e 25,1 em 2006. O declínio médio anual da TMI, que se mantinha em $1 \%$ ao ano (aa) desde 1940 , cresce para 1,5\% aa entre 1965/1975, para $4,5 \%$ aa entre $1975 / 85$ e se mantém em cerca de $2,6 \%$ aa, desde então, com ligeira queda nos últimos anos.

O Gráfico 15 mostra a evolução da TMI de 1960 a 2006 para o Brasil e regiões, mantendo-se a Região Nordeste como a que apresenta as mais altas taxas em todo o período e a Região Sul com as menores taxas.

Gráfico 15 - Evolução da mortalidade infantil. Brasil e regiões - 1960 - 2006

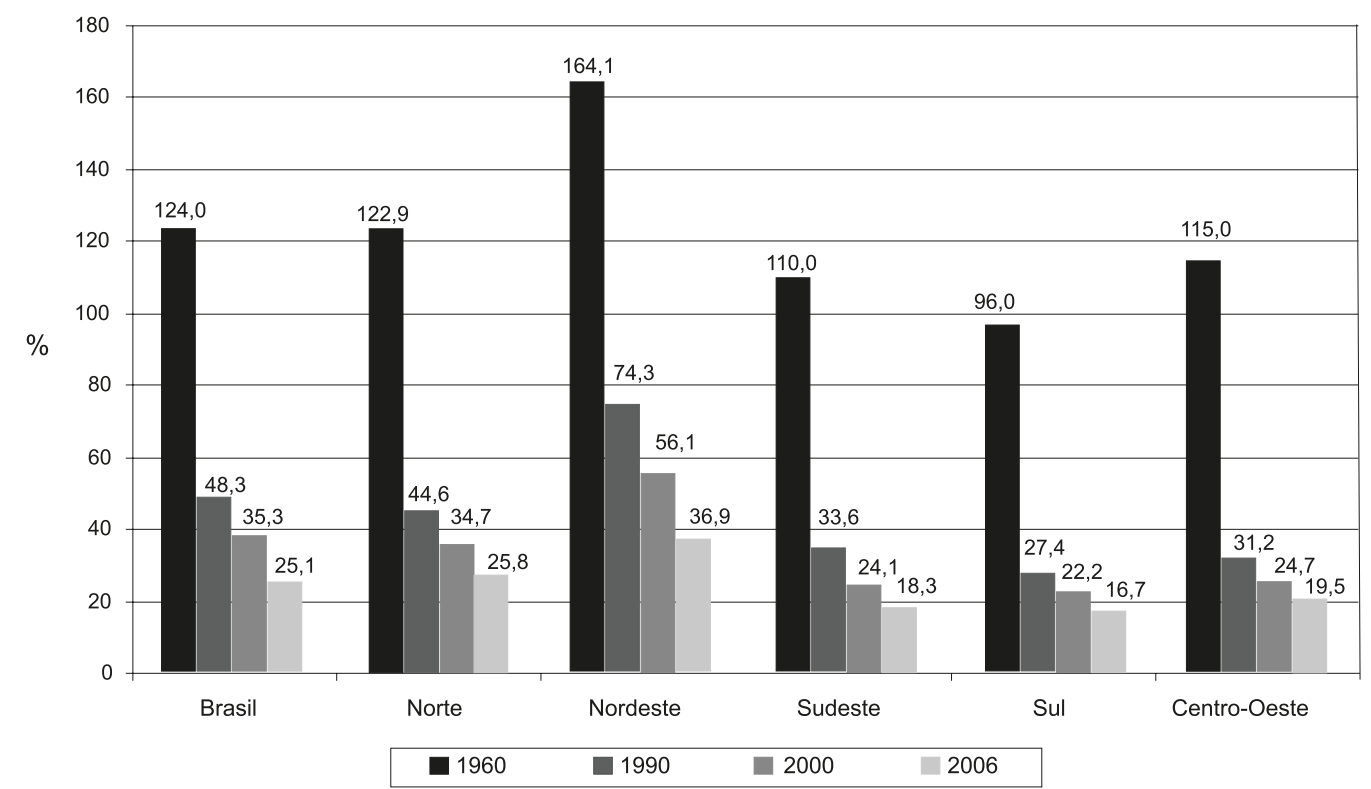

Fonte: IBGE (1999). Evolução e Perspectivas da Mortalidade Infantil no Brasil. Rio de Janeiro e Projeção da População do Brasil por Sexo e Idade para o Período 1980 2050 - Revisão 2004

A proporção de mortes de menores de um ano de idade, sobre o total de óbitos, reduziu-se de 24\%, em 1980, para 5\%, em 2005, variando de 11,3\% na Região Norte a 3,4\% na Região Sul (Gráfico 16). Em 2003, 58\% dos óbitos informados ocorreram na faixa de 60 ou mais anos de idade, com variações de 43\%, na Região Norte, a 62\%, na Região Sul.

Quanto à esperança de vida ao nascer, o Gráfico 17 mostra um ganho de mais de 20 anos, entre 1960 e 2006, para o Brasil como um todo. O valor de 72,4 anos em 2006 é 9 anos inferior ao do Japão, país com a maior expectativa de vida ao nascer em todo o mundo. Embora persistam importantes diferenças regionais, como, por exemplo, a expectativa de vida no Nordeste em 2006 ainda é dois anos menor do que era a do Sul em 1990, há uma tendência à diminuição dessas diferenças. Em 1960, um brasileiro que nascesse no Nordeste tinha uma expectativa de vida 20 anos menor que a de outro brasileiro nascido na Região Sul, diferença que cai para cinco anos em 2006. 
Gráfico 16 - Percentual de óbitos infantis no total de óbitos, * por região. Brasil - 2005

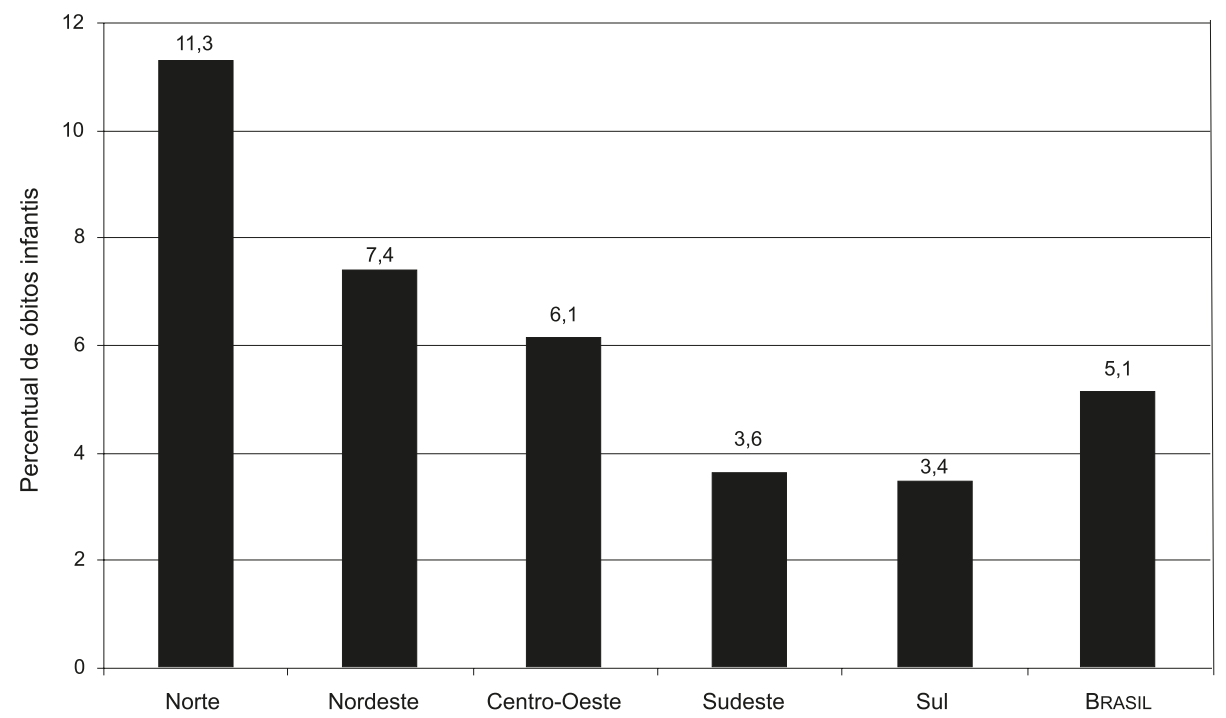

* Coeficiente de mortalidade infantil proporcional.

Fonte: Caderno de Informações em Saúde, Datasus/MS, julho/2007.

Gráfico 17 - Evolução da esperança de vida ao nascer. Brasil e regiões - 1960 - 2006

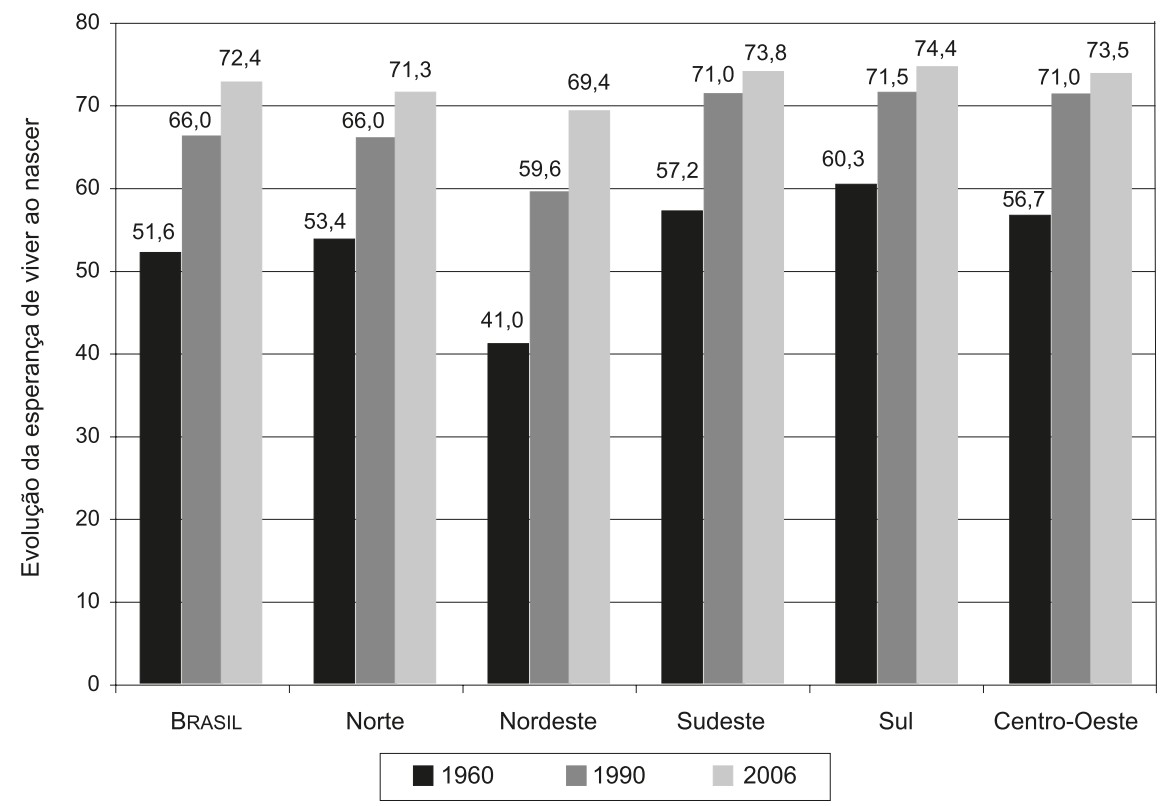

Fonte: 1940/80 - IBGE. DPE/DEPIS e Simões (1996); 1990 - IBGE Estimativas preliminares grandes regiões 1991/2030; 2006- IBGE Projeção pop. Período 1980-2050-revisão 2004. 
Com relação às diferenças entre a mortalidade masculina e a feminina, entre 1960 e 2006, a sobremortalidade masculina cresceu acentuadamente, principalmente na faixa dos 20 aos 24 anos de idade: em 1960, a chance de um homem com 20 anos de idade morrer antes de passar para o grupo etário seguinte (25 a 29 anos) era 1,1 vez maior que a de uma mulher do mesmo grupo etário. Já em 2006, a chance masculina, na mesma comparação com a chance feminina, no mesmo grupo etário (20 a 24 anos), aumentou para 4,1 vezes.

A principal causa do aumento da sobremortalidade masculina são os óbitos por causas externas (ou violentos). Dados do Ministério da Saúde mostram que, no Brasil, em 2005, houve 1.003 .005 óbitos e $12,5 \%$ deles (125.816) foram por causas externas. Entre estes, $83,5 \%$ (105.062) ocorreram na população masculina. Os homicídios são a primeira causa de morte entre as causas externas, sendo responsáveis por 38\% dos óbitos neste grupo de causas, 89\% deles na faixa etária entre 15 a 49 anos. A taxa de mortalidade específica por homicídios encontrada no sexo masculino é cerca de 12 vezes maior do que no feminino, chegando a quinze vezes na faixa etária de 20 a 29 anos. A taxa de homicídios no sexo masculino para pretos e pardos é superior a dos brancos em todas as regiões do país, como mostra o Gráfico 18.

Gráfico 18 - Taxa padronizada de homicídios no sexo masculino, segundo cor da pele e região. Brasil - 2004

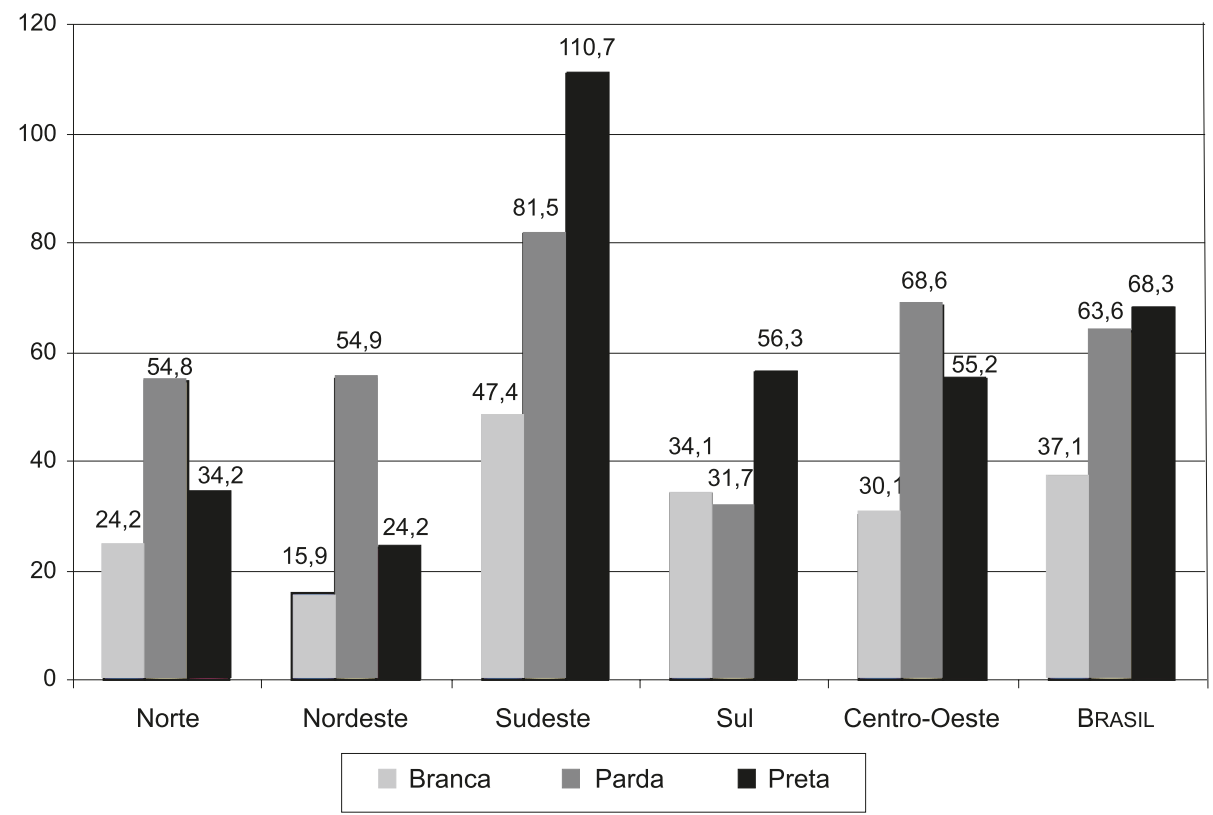

Fonte: Secretaria de Vigilância em Saúde - MS

A Tabela 15 mostra as diferenças na expectativa de vida ao nascer entre sexos para o Brasil e regiões. A diferença de cerca de 7 a 8 anos favorável às mulheres tende a aumentar, pois no período de 1991 a 2000 houve um ganho de 2,59 anos em média para o Brasil como um todo, sendo que para os homens esse ganho foi de 2,26 anos e para as mulheres de 2,84 anos. 
Tabela 15 - Esperança de vida ao nascer, por sexo, segundo as grandes regiões. Brasil - 2006

\begin{tabular}{l|c|c|c}
\hline \multirow{2}{*}{$\begin{array}{l}\text { Grandes } \\
\text { regiões }\end{array}$} & \multicolumn{3}{|c}{ Esperança de vida ao nascer } \\
\cline { 2 - 4 } & TOTAL & Homens & Mulheres \\
\hline BRASIL & 72,4 & 68,7 & 76,2 \\
Norte & 71,3 & 68,5 & 74,3 \\
Nordeste & 69,4 & 65,8 & 73,1 \\
Sudeste & 73,8 & 69,8 & 77,9 \\
Sul & 74,4 & 71,1 & 78,0 \\
Centro-Oeste & 73,5 & 70,1 & 77,0 \\
\hline
\end{tabular}

Fontes: Projeto IBGE/Fundo de População das Nações Unidas - UNFPA/BRASIL (BRA/02/P02), População e Desenvolvimento: Sistematização das Medidas e Indicadores Sociodemográficos, oriundos da Projeção da População por Sexo e Idade, por Método Demográfico, das Grandes Regiões e Unidades da Federação para o Período 1991/2030; IBGE, Diretoria de Pesquisas, Coordenação de População e Indicadores Sociais, Projeção da População do Brasil por Sexo e Idade para o Período 1980-2050 - Revisão 2004.

Os anos 60 também marcam uma inflexão importante nas causas de mortalidade, o que se convencionou chamar de transição epidemiológica. Nas regiões Sudeste e Sul, pela primeira vez, a mortalidade por doenças cardiovasculares superou a mortalidade por doenças infecciosas, o que viria a ocorrer nas regiões Norte, Nordeste e Centro-Oeste duas décadas depois, durante os anos 80. Como pode ser observado na Tabela 16, em 1985, embora em todas as regiões já houvesse uma predominância das doenças cardiovasculares como primeira causa de morte, a mortalidade na Região Norte por doenças infecciosas ainda era cerca de 2,5 vezes maior do que a observada na Região Sudeste.

Segundo Cesse (2007), as capitais brasileiras que experimentam mais precocemente mudanças na estrutura etária, urbanização e desenvolvimento são as que propiciam também, de forma mais precoce, as condições para o crescimento das doenças crônicas não-transmissíveis. De acordo com a autora, as transições epidemiológica e demográfica observadas no Brasil, em lugar de significar uma verdadeira mudança, correspondem, na realidade, a uma sobreposição de padrões, tratando-se, portanto, de processos inconclusos, marcados pelas desigualdades existentes na sociedade.

Tabela 16 - Standard Mortality Ratio (SMR) por grupos de causas para as regiões brasileiras no ano de 1985

\begin{tabular}{l|ccccc}
\hline \multirow{2}{*}{ Grupo de causas } & \multicolumn{5}{|c}{ SMR } \\
\cline { 2 - 6 } & Norte & Nordeste & $\begin{array}{c}\text { Centro- } \\
\text { Oeste }\end{array}$ & Sul & Sudeste* \\
\hline Infecciosas & 253 & 168 & 159 & 88 & 100 \\
Cardiovasculares & 25 & 56 & 89 & 101 & 100 \\
Neoplasias & 75 & 51 & 87 & 118 & 100 \\
Externas & 103 & 93 & 136 & 96 & 100 \\
\hline
\end{tabular}


A Tabela 17, com dados de 2005, mostra que os diferenciais de mortalidade por grupos de causas entre as regiões foram reduzidos, embora persistam importantes diferenças na mortalidade por causas mal definidas, chegando este grupo a ser três vezes maior nas regiões Norte e Nordeste em comparação com o Sul e o Centro-Oeste, o que deve estar relacionado ao acesso e à qualidade da atenção à saúde.

Tabela 17 - Mortalidade proporcional (\%), por grupos de causas (CID-10), segundo região. Brasil - 2005

\begin{tabular}{|c|c|c|c|c|c|c|}
\hline \multirow{2}{*}{ Grupos de causas } & \multicolumn{5}{|c|}{ Região } & \multirow[b]{2}{*}{ BRASIL } \\
\hline & Norte & Nordeste & $\begin{array}{l}\text { Centro- } \\
\text { Oeste }\end{array}$ & Sudeste & Sul & \\
\hline $\begin{array}{l}\text { I- Algumas doenças } \\
\text { infecciosas e parasitárias }\end{array}$ & 7,6 & 5,8 & 5,4 & 5,0 & 4,0 & 5,2 \\
\hline II - Neoplasias (tumores) & 13,0 & 13,4 & 14,6 & 17,1 & 20,0 & 16,3 \\
\hline $\begin{array}{l}\text { IX - Doenças do aparelho } \\
\text { circulatório }\end{array}$ & 24,4 & 31,1 & 30,2 & 32,3 & 32,2 & 31,5 \\
\hline $\begin{array}{l}X \text { - Doenças do aparelho } \\
\text { respiratório }\end{array}$ & 10,7 & 9,2 & 10,2 & 11,4 & 11,5 & 10,8 \\
\hline $\begin{array}{l}\mathrm{XVI} \text { - Algumas afecções } \\
\text { originadas no período } \\
\text { perinatal }\end{array}$ & 7,4 & 5,2 & 3,6 & 2,3 & 2,1 & 3,3 \\
\hline $\begin{array}{l}\text { XX - Causas externas de } \\
\text { morbidade e mortalidade }\end{array}$ & 19,3 & 15,0 & 17,9 & 13,2 & 12,8 & 14,1 \\
\hline Causas mal definidas & 17,7 & 17,2 & 5,2 & 8,1 & 5,8 & 10,4 \\
\hline
\end{tabular}

Fonte: Caderno de Informações em Saúde, Datasus/MS, julho/2007.

Com relação às causas de mortes infantis em menores de um ano, conforme pode ser observado nas Tabelas 18 e 18.1, elaboradas por Cesar Victora para a CNDSS, em todas as regiões há uma significativa diminuição de mortes devidas a infeccções respiratórias e diarréia, principalmente esta última, que, em 1985-1987, era responsável por 17,3\% dos óbitos, caindo para 4,2\% em 2003-2005. Ao mesmo tempo, houve um aumento das causas perinatais e malformações em todas as regiões, embora persistam grandes disparidades. Por exemplo, a proporção de mortes por diarréia na Região Nordeste é cerca de quatro vezes superior a da Região Sudeste. É importante também observar a expressiva queda da mortalidade por causas mal definidas, particularmente na Região Nordeste, caindo de 45,5\% em 1985-1987 para 9,7\% em 2003-2005, o que deve estar relacionado à melhoria do acesso e da qualidade da atenção. 
Tabela 18 - Distribuição percentual das mortes infantis por causa ${ }^{1}$

\begin{tabular}{|c|c|c|c|c|c|c|c|}
\hline Causa & Ano & $\mathrm{N}$ & $\mathrm{NE}$ & SE & $S$ & $\mathrm{CO}$ & BRASIL \\
\hline \multirow{3}{*}{$\begin{array}{l}\text { Causas } \\
\text { perinatais }\end{array}$} & $1985-87$ & $42.1 \%$ & $42.9 \%$ & $48.9 \%$ & $46.4 \%$ & $48.7 \%$ & $46.5 \%$ \\
\hline & 1995-97 & $61.4 \%$ & $53.9 \%$ & $58.8 \%$ & $53.0 \%$ & $56.7 \%$ & $56.8 \%$ \\
\hline & 200305 & $61.2 \%$ & $62.2 \%$ & $61.0 \%$ & $58.7 \%$ & $57.2 \%$ & $60.9 \%$ \\
\hline \multirow{3}{*}{ Malformações } & $1985-87$ & $4.9 \%$ & $3.6 \%$ & $8.1 \%$ & $11.4 \%$ & $8.6 \%$ & $7.1 \%$ \\
\hline & 1995-97 & $8.5 \%$ & $7.3 \%$ & $12.2 \%$ & $16.2 \%$ & $13.4 \%$ & $11.2 \%$ \\
\hline & 2003-05 & $12.7 \%$ & $11.4 \%$ & $18.3 \%$ & $21.5 \%$ & $20.0 \%$ & $15.7 \%$ \\
\hline \multirow{3}{*}{$\begin{array}{l}\text { Infecções } \\
\text { respiratórias }\end{array}$} & $1985-87$ & $11.5 \%$ & $11.4 \%$ & $15.7 \%$ & $14.2 \%$ & $12.9 \%$ & $13.9 \%$ \\
\hline & 1995-97 & $8.9 \%$ & $9.7 \%$ & $10.7 \%$ & $11.1 \%$ & $8.7 \%$ & $10.2 \%$ \\
\hline & 2003-05 & $8.2 \%$ & $6.9 \%$ & $6.6 \%$ & $5.9 \%$ & $6.8 \%$ & $6.9 \%$ \\
\hline \multirow{3}{*}{ Diarréia } & $1985-87$ & $30.1 \%$ & $27.0 \%$ & $11.8 \%$ & $12.5 \%$ & $12.9 \%$ & $17.3 \%$ \\
\hline & $1995-97$ & $9.3 \%$ & $15.4 \%$ & $4.7 \%$ & $5.0 \%$ & $6.4 \%$ & $8.1 \%$ \\
\hline & 2003-05 & $5.1 \%$ & $7.1 \%$ & $1.8 \%$ & $1.9 \%$ & $3.1 \%$ & $4.2 \%$ \\
\hline \multirow{3}{*}{$\begin{array}{l}\text { Outras } \\
\text { infecções }\end{array}$} & $1985-87$ & $5.3 \%$ & $6.1 \%$ & $5.3 \%$ & $6.0 \%$ & $7.1 \%$ & $5.7 \%$ \\
\hline & $1995-97$ & $5.6 \%$ & $6.0 \%$ & $5.6 \%$ & $5.0 \%$ & $6.1 \%$ & $5.6 \%$ \\
\hline & 2003-05 & $5.2 \%$ & $4.2 \%$ & $4.2 \%$ & $3.1 \%$ & $3.8 \%$ & $4.2 \%$ \\
\hline \multirow{3}{*}{ Outras causas } & 1985-87 & $6.1 \%$ & $9.0 \%$ & $10.2 \%$ & $9.5 \%$ & $9.8 \%$ & $9.5 \%$ \\
\hline & 1995-97 & $6.3 \%$ & $7.7 \%$ & $8.0 \%$ & $9.7 \%$ & $8.7 \%$ & $8.1 \%$ \\
\hline & 2003-05 & $7.6 \%$ & $8.2 \%$ & $8.1 \%$ & $8.9 \%$ & $9.1 \%$ & $8.1 \%$ \\
\hline \multirow{3}{*}{$\begin{array}{l}\text { Causas mal } \\
\text { definidas }^{2}\end{array}$} & $1985-87$ & $23.9 \%$ & $45.5 \%$ & $6.0 \%$ & $11.0 \%$ & $11.6 \%$ & $23.0 \%$ \\
\hline & $1995-97$ & $16.0 \%$ & $25.5 \%$ & $5.0 \%$ & $6.3 \%$ & $6.0 \%$ & $12.6 \%$ \\
\hline & 2003-05 & $11.0 \%$ & $9.7 \%$ & $3.9 \%$ & $4.3 \%$ & $2.7 \%$ & $6.9 \%$ \\
\hline
\end{tabular}

${ }^{1}$ Expressos como percentuais de todas as mortes com causas definidas.

${ }^{2}$ Expresso como percentual de todas as mortes infantis.

Fonte: Cesar Victora, CNDSS.

Quanto ao Coeficiente de Mortalidade Infantil (CMI) específico por causas (Tabela 18.1), vale notar que a mortalidade por diarréia - que era responsável por cerca de 10 mortes para cada mil nascidos vivos no Brasil em 1985-1987 - é responsável por menos de uma morte em 2003-2005, queda que no Nordeste é de 24,4 para 2,4 no mesmo período. Da mesma forma, é dramática a queda do CMI por causas mal definidas, caindo no país como um todo de 14,3 mortes para cada mil nascidos-vivos em 1985-1987 para 1,5 em 2003-2005, sendo que no Nordeste esta queda foi de 41,2 para 3,3. 
Tabela 18.1 - Coeficiente de mortalidade infantil específico por causas (estimados a partir da combinação dos dados do Sistema de Informação sobre Mortalidade - SIM - com as estimativas de mortalidade)

\begin{tabular}{|c|c|c|c|c|c|c|c|}
\hline Causa $^{1}$ & Ano & $\mathrm{N}$ & NE & SE & $S$ & $\mathrm{CO}$ & BRASIL \\
\hline \multirow{3}{*}{ Causas perinatais } & $1985-87$ & 24.8 & 38.9 & 21.8 & 17.5 & 19.9 & 29.0 \\
\hline & $1995-97$ & 22.8 & 32.6 & 15.2 & 12.1 & 14.6 & 21.3 \\
\hline & 200305 & 15.8 & 20.9 & 9.1 & 8.7 & 10.5 & 13.7 \\
\hline \multirow{3}{*}{ Malformações } & $1985-87$ & 2.9 & 3.3 & 3.6 & 4.3 & 3.5 & 4.4 \\
\hline & $1995-97$ & 3.1 & 4.4 & 3.2 & 3.7 & 3.4 & 4.2 \\
\hline & 2003-05 & 3.3 & 3.8 & 2.7 & 3.2 & 3.7 & 3.5 \\
\hline \multirow{3}{*}{$\begin{array}{l}\text { Infecções } \\
\text { respiratórias }\end{array}$} & $1985-87$ & 6.7 & 10.3 & 7.0 & 5.4 & 5.3 & 8.7 \\
\hline & 1995-97 & 3.2 & 5.9 & 2.8 & 2.5 & 2.3 & 3.8 \\
\hline & 200305 & 2.1 & 2.3 & 1.0 & 0.9 & 1.3 & 1.5 \\
\hline \multirow{3}{*}{ Diarréia } & $1985-87$ & 17.7 & 24.4 & 5.3 & 4.7 & 5.3 & 10.8 \\
\hline & $1995-97$ & 3.3 & 9.3 & 1.2 & 1.1 & 1.7 & 3.0 \\
\hline & $2003-05$ & 1.3 & 2.4 & 0.3 & 0.3 & 0.6 & 0.9 \\
\hline \multirow{3}{*}{ Outras infecções } & $1985-87$ & 3.1 & 5.5 & 2.4 & 2.3 & 2.9 & 3.5 \\
\hline & $1995-97$ & 2.0 & 3.6 & 1.4 & 1.1 & 1.6 & 2.1 \\
\hline & 2003-05 & 1.3 & 1.4 & 0.6 & 0.5 & 0.7 & 0.9 \\
\hline \multirow{3}{*}{ Outras causas } & $1985-87$ & 3.6 & 8.1 & 4.6 & 3.5 & 4.0 & 5.9 \\
\hline & $1995-97$ & 2.3 & 4.7 & 2.1 & 2.2 & 2.2 & 3.0 \\
\hline & 2003-05 & 1.9 & 2.8 & 1.2 & 1.3 & 1.7 & 1.8 \\
\hline \multirow{3}{*}{$\begin{array}{l}\text { Causas mal } \\
\text { definidas }\end{array}$} & $1985-87$ & 14.1 & 41.2 & 2.7 & 4.1 & 4.7 & 14.3 \\
\hline & $1995-97$ & 5.8 & 15.4 & 1.3 & 1.4 & 1.5 & 4.7 \\
\hline & 2003-05 & 2.8 & 3.3 & 0.6 & 0.6 & 0.5 & 1.5 \\
\hline
\end{tabular}

${ }^{1}$ Distribuindo as mortes por causas mal definidas proporcionalmente em cada grupo de causas conhecidas. Fonte: Cesar Victora, CNDSS.

As tendências positivas observadas nas últimas décadas com relação à renda, escolaridade e saúde se expressam na evolução do índice de desenvolvimento humano (IDH), do Programa das Nações Unidas para o Desenvolvimento (PNUD), que passou de 0,649 em 1975 para 0,800 em 2005. 


\subsection{A Estratificação Socioeconômica e a Saúde}

As condições socioeconômicas, culturais e ambientais de uma dada sociedade, ou seja os determinates mais gerais e distais do modelo de Dahlgren e Whitehead, geram uma estratificação econômico-social dos indivíduos e grupos da população, conferindo-lhes posições sociais distintas, as quais por sua vez provocam diferenciais de saúde. Em outras palavras, a distribuição da saúde e da doença em uma sociedade não é aleatória, estando associada à posição social, que por sua vez define as condições de vida e de trabalho dos indivíduos e grupos.

O modelo de Diderichsen e Hallqvist (1998), adaptado por Diderichsen, Evans e Whitehead (2001), procura mostrar as relações entre a posição social e diversos tipos de diferenciais de saúde, conforme pode ser observado na Figura 2. Neste modelo, (I) representa o processo segundo o qual cada indivíduo ou grupo ocupa uma dada posição social como resultado de diversos mecanismos sociais como o sistema educacional e o mercado de trabalho. De acordo com a posição social ocupada pelos diferentes indivíduos aparecem diferenciais, como o diferencial de exposição a riscos que causam danos à saúde (II), o diferencial de vulnerabilidade à ocorrência de doença frente à exposição a estes riscos (III) e o diferencial de conseqüências sociais ou físicas uma vez contraída a doença (IV). Este modelo também permite identificar alguns pontos de incidência de políticas que atuem seja sobre os mecanismos de estratificação social, seja sobre os diferenciais de exposição, de vulnerabilidade e de conseqüências.

Figura 2 - Diferenciais de saúde segundo a posição social

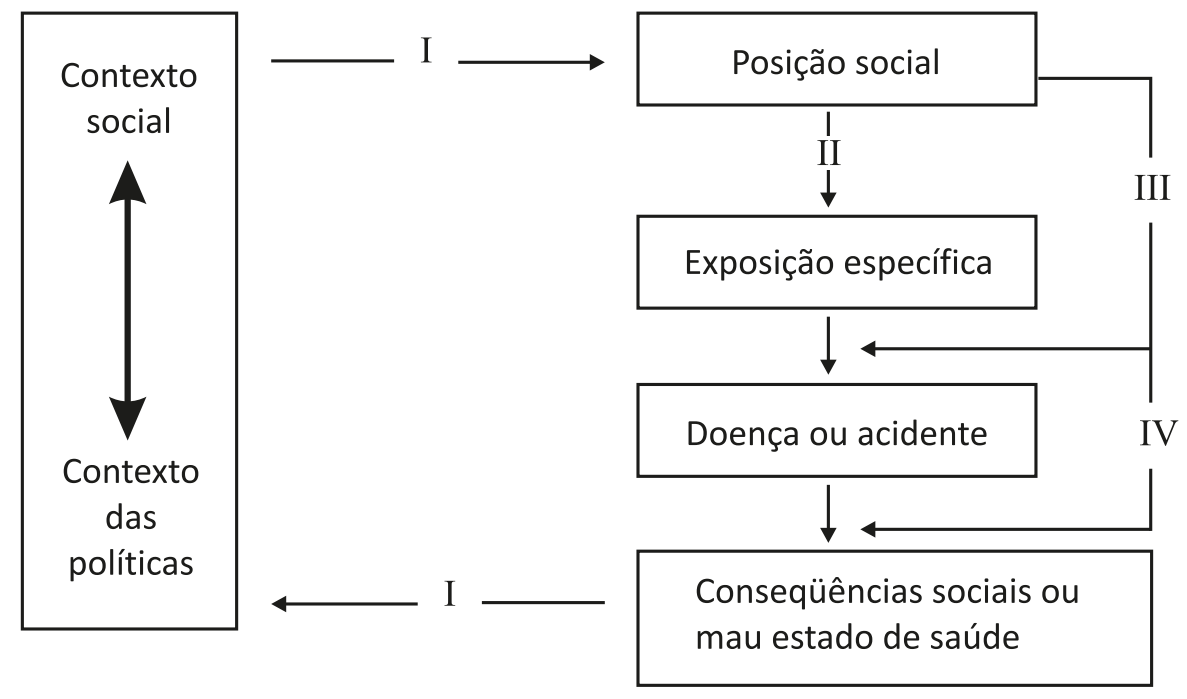

Fonte: Diderichsen e Hallqvist, 1998. 
Por exemplo, a intervenção sobre os mecanismos de estratificação social é das mais cruciais para combater as iniqüidades em saúde, incluindo-se aqui políticas que diminuam as diferenças sociais como as relacionadas ao mercado de trabalho, à educação e à seguridade social. Um segundo conjunto de políticas busca diminuir os diferenciais de exposição a riscos, tendo, por exemplo, como alvo, os grupos que vivem em condições de habitação insalubres, trabalham em ambientes pouco seguros ou estão expostos a deficiências nutricionais. O combate aos diferenciais de vulnerabilidade inclui intervenções que buscam fortalecer a resistência a diversas exposições, como por exemplo, a educação das mulheres para diminuir sua própria vulnerabilidade e a de seus filhos. A intervenção no sistema de saúde busca reduzir os diferenciais de exposição e de vulnerablidade, por meio de ações preventivas (vacinas, educação sobre fatores de risco etc.), bem como os diferenciais de conseqüências ocasionadas pela doença, aqui incluindo melhoria da qualidade dos serviços a toda a população, apoio a deficientes, acesso a cuidados de reabilitação e mecanismos de financiamento eqüitativos que impeçam adicional empobrecimento causado pela doença.

Nesta seção, são apresentadas algumas associações entre estratificação socioeconômica (segundo renda, escolaridade, gênero, cor da pele e local de moradia) e resultados de saúde, destacando as iniqüidades em saúde derivadas dos diferenciais de exposição, vulnerabilidade e conseqüências de acordo com a posição social ocupada por indivíduos e grupos da população.

Renda e escolaridade estão fortemente associados a resultados de saúde. Messias (2003), analisando dados do censo de 2000, mostrou que o PIB per capita, a distribuição de renda e a taxa de analfabetismo estão associados à expectativa de vida.

Os efeitos do nível de instrução se manifestam das mais diferentes formas: na percepção dos problemas de saúde; na capacidade de entendimento das informações sobre saúde; na adoção de estilos de vida saudáveis; no consumo e utilização dos serviços de saúde; e na adesão aos procedimentos terapêuticos.

A realização de exames preventivos para câncer de mama e de colo de útero, assim como de consultas pré-natal são bons exemplos das desigualdades de acesso e utilização de serviços de saúde de acordo com escolaridade, observando-se um nítido gradiente segundo esta variável, como mostram os Gráficos 19, 20 e 21. 
Gráfico 19 - Proporção (\%) de mulheres de 25 anos ou mais de idade que já realizaram alguma vez exame de mamografia, por anos de estudo. Brasil - 2003

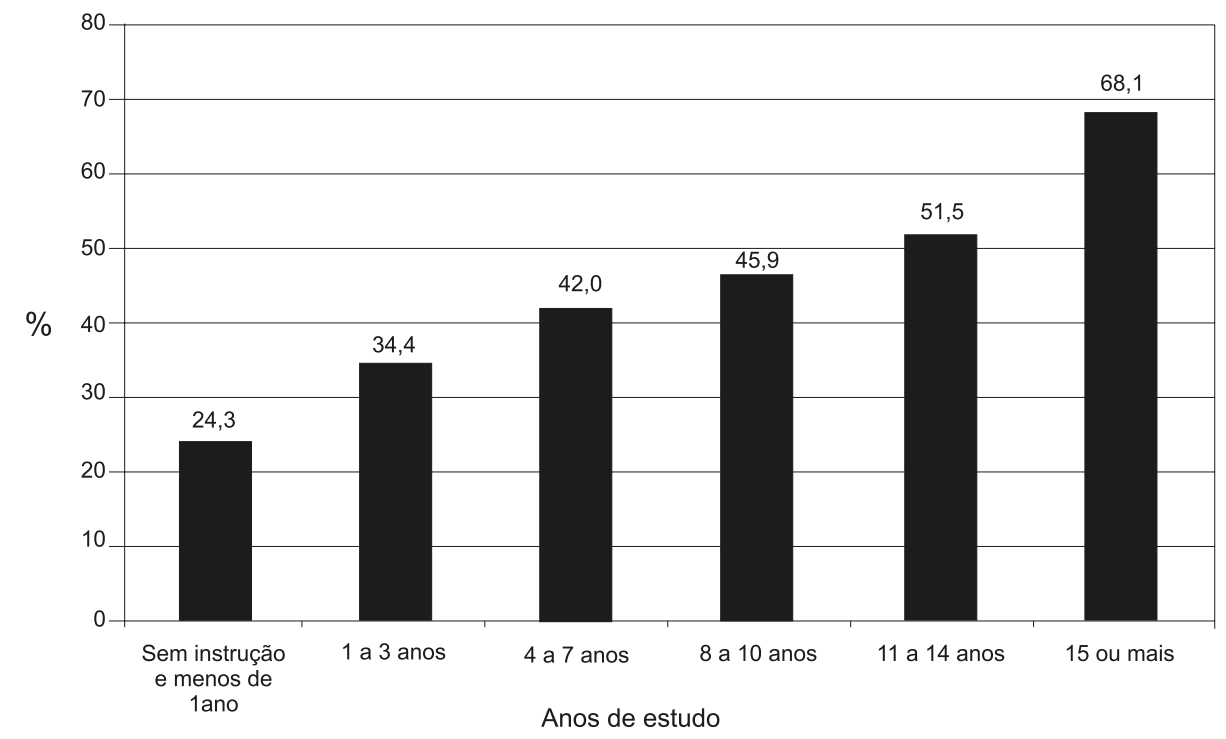

Fonte: Elaboração própria, a partir da Pesquisa Nacional por Amostra de Domicílios (PNAD) 2003 Acesso e Utilização de Serviços de Saúde, IBGE.

Gráfico 20 - Proporção (\%) de mulheres de 25 anos ou mais de idade que realizaram alguma vez exame preventivo para câncer de colo uterino, por anos de estudo. Brasil - 2003

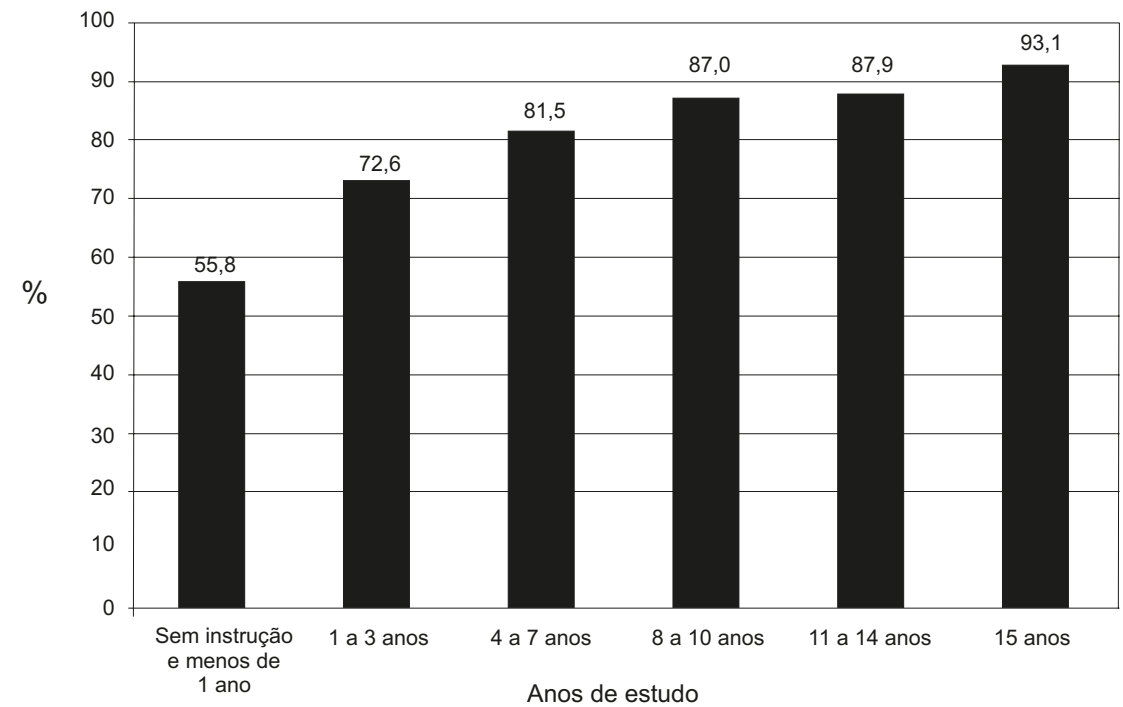

Fonte: Elaboração própria, a partir da Pesquisa Nacional por Amostra de Domicílios (PNAD) 2003 Acesso e Utilização de Serviços de Saúde, IBGE. 
Gráfico 21 - Proporção (\%) de nascidos vivos, por número de consultas de pré-natal e escolaridade da mãe. Brasil-2005

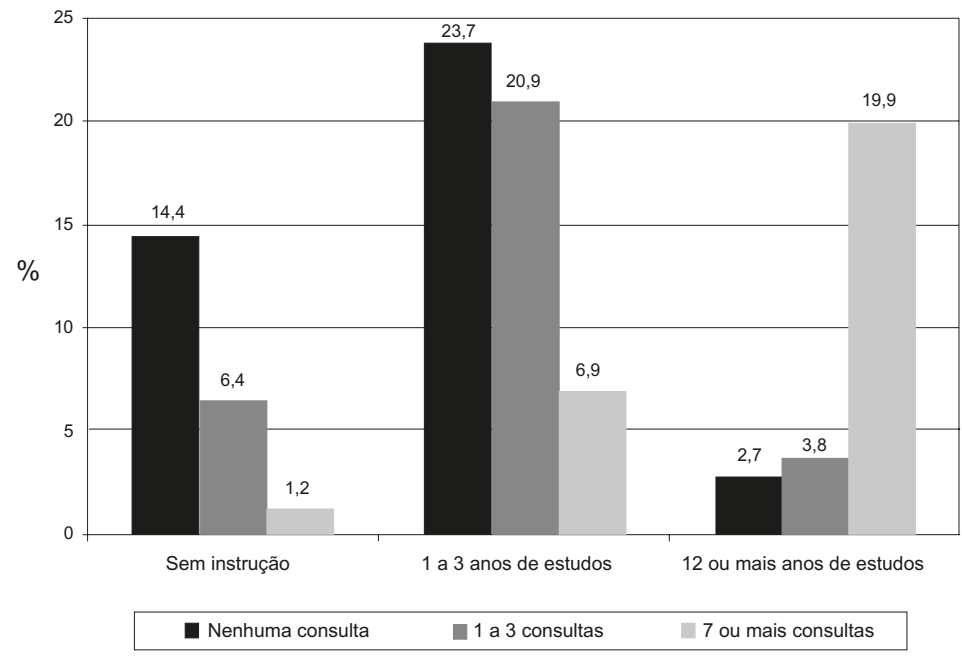

Fonte: Sistema de Informação sobre Nascidos Vivos (Sinasc).

Os Gráficos 22, 22.1 e 22.2 exemplificam os grandes contrastes observados entre municípios no que se refere a indicadores econômicos, sociais e de condições de vida e sua associação com diferenciais de saúde. Os gráficos comparam os diversos indicadores sociais e de saúde dos municípios com maior e menor renda per capita dentro de uma mesma faixa populacional. Os dados são do censo de 2000, já que as demais fontes para estes indicadores, como Pnud2006, não possuem representatividade amostral em nível de município.

Gráfico 22 - Indicadores socioeconômicos de municípios entre 50 e 100 mil habitantes, com menor e maior renda per capita -2000

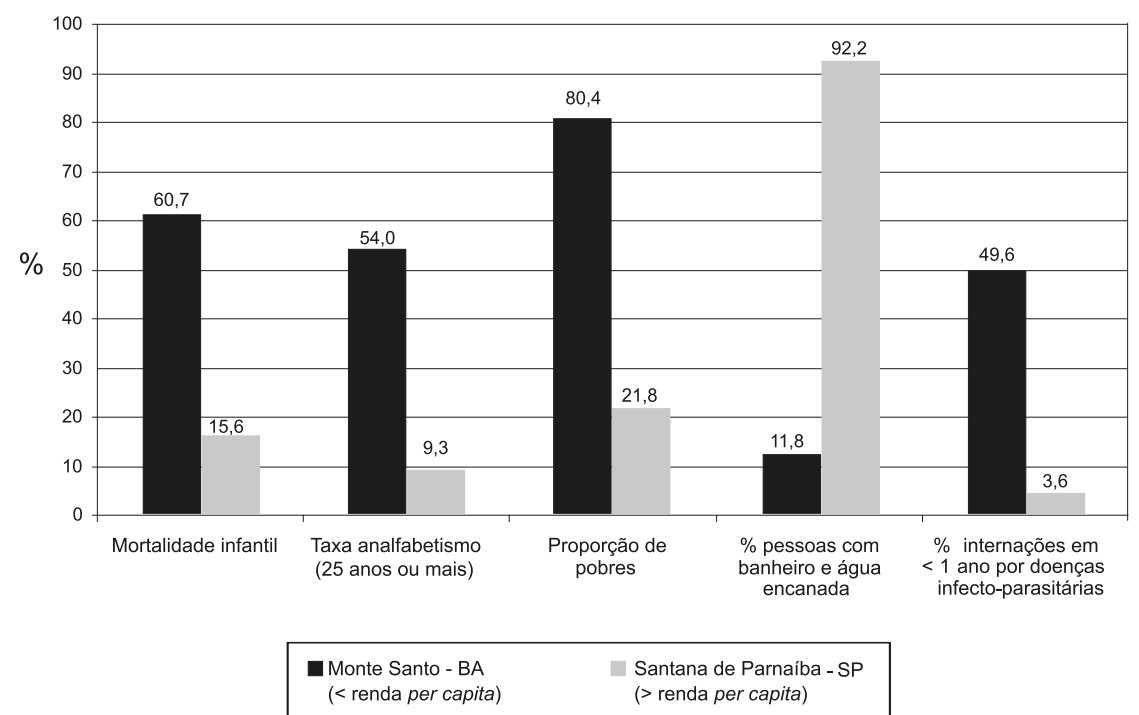

Fonte: Atlas do Desenvolvimento Humano - PNUD; Sistema de Informações Hospitalares do SUS (SIH-SUS) - Datasus. 
Gráfico 22.1 - Indicadores socioeconômicos de municípios entre 100 e 500 mil habitantes com menor e maior renda per capita -2000

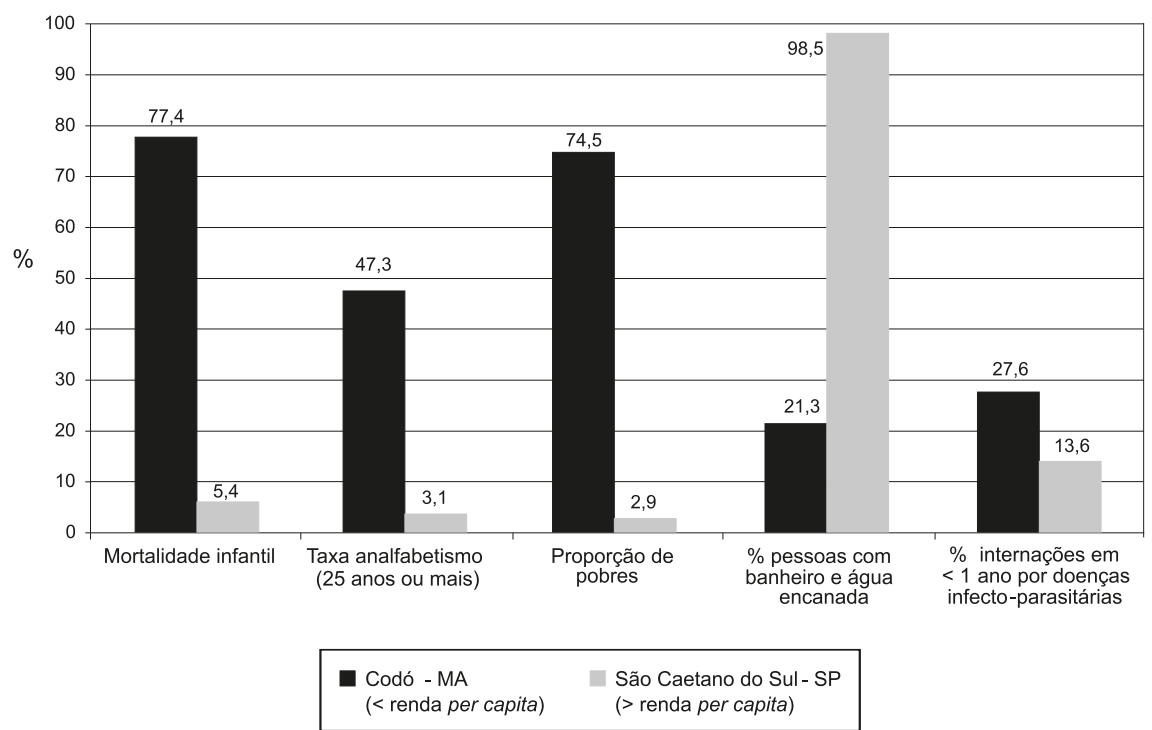

Fonte: Atlas do Desenvolvimento Humano - PNUD; Sistema de Informações Hospitalares do SUS (SIH-SUS) - Datasus.

Gráfico 22.2 - Indicadores socioeconômicos de municípios com mais de 500 mil habitantes com menor e maior renda per capita - 2000

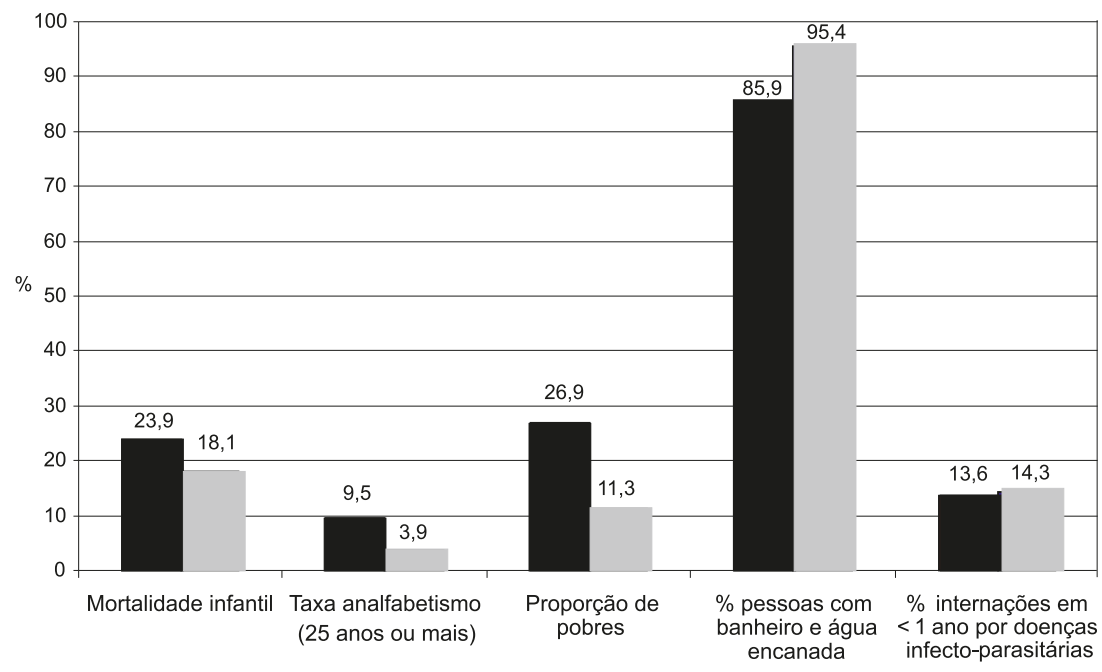

Duque de Caxias - RJ Porto Alegre - RS

(< renda per capita) (> renda per capita)

Fonte: Atlas do Desenvolvimento Humano - PNUD; Sistema de Informações Hospitalares do SUS (SIH-SUS) - Datasus. 
A revisão da literatura publicada nos últimos cinco anos permite identificar uma série de estudos que tratam das relações entre escolaridade, renda e saúde. A seguir são apresentados alguns resultados destes estudos.

Dachs (2002), a partir dos dados da Pesquisa Nacional por Amostra de Domicílios (Pnad), de 1998, avaliou a autopercepção de saúde nas categorias "muito bom”, "bom”, "regular", "ruim" e "muito ruim". Quanto à renda, observou desigualdade importante nos indivíduos dos decis extremos: enquanto $70 \%$ do decil mais baixo tiveram avaliação boa/muito boa, este valor atingiu $87 \%$ no decil mais alto. Já para a avaliação ruim/muito ruim, os valores foram 3,8\% e 1,6\%, respectivamente. Para a escolaridade, estas desigualdades foram mais evidentes: entre os que tinham menos de um ano de estudo, pouco mais da metade (51\%) referiu estado de saúde bom/muito bom, comparados a $90 \%$ daqueles com ensino superior. Quanto à avaliação ruim/muito ruim, os de menor tempo de estudo relataram $13,5 \%$ contra apenas 4,7\% dos indivíduos com nível superior.

Barata et al. (2007) analisaram desigualdades na percepção do estado de saúde de jovens e adultos segundo cor, a partir destes mesmos dados. Considerando apenas gênero/etnia, os homens pretos apresentaram prevalência $23 \%$ maior de saúde regular ou ruim, comparados aos homens brancos. Esta diferença aumentou para 45\%, após ajuste para idade, e diminuiu para $16 \%$ após ajuste para escolaridade e $11 \%$ após ajuste para renda. Isto sugere que uma parte considerável das desigualdades se explica pelo status socioeconômico. Para as mulheres brancas, comparadas aos homens brancos, a prevalência de saúde regular ou ruim foi 49\% maior, após ajuste para todas as variáveis, enfatizando a importância do gênero na autopercepção de saúde.

Lima-Costa, Matos e Camarano (2006) avaliaram condições gerais de saúde, usando como indicadores as seguintes situações: "interrupção das atividades habituais nas duas últimas semanas", "ter estado acamado nas duas últimas semanas" e "dificuldade para realizar alguma atividade da vida diária”. A pesquisa foi baseada nos dados da Pnad de 1998 e 2003, encontrando que os indivíduos com renda menor que 0,67 salários mínimos apresentavam maior freqüência dessas situações quando comparados aos de renda superior. Os valores foram semelhantes nos dois períodos avaliados.

Ishitani et al. (2006), utilizando dados de municípios com melhor qualidade de informação, observaram associação negativa da escolaridade e mortalidade por doenças cardiovasculares. A cada aumento de um ponto percentual na proporção de indivíduos com alta escolaridade, diminui em 3,25 por 100.000 habitantes a taxa de mortalidade. No caso das doenças hipertensivas e cerebrovasculares, manteve-se associação negativa com escolaridade e positiva com taxa de pobreza. Por outro lado, em relação às doenças isquêmicas, a associação com escolaridade também foi negativa, mas com a taxa de pobreza também foi negativa. Portanto, as desigualdades se caracterizam por maior acometimento das populações com menor renda, com exceção das doenças isquêmicas. A escolaridade foi o maior determinante, com forte efeito protetor. 
Os dados da Pnad 2003 foram estudados por Barros et al. (2006), no que se refere à prevalência de doenças crônicas. A escolaridade, ajustada para sexo, idade, cor da pele e macrorregião, mostrou que as pessoas com 0-3 anos de estudo tiveram quase duas vezes mais doenças que aquelas com mais de oito anos de estudo.

Lessa et al. (2006) estudaram os determinantes de hipertensão em Salvador (BA) e mostraram comportamento diferente da escolaridade para homens e mulheres. No sexo feminino, quanto menor o tempo de estudo, maior prevalência de hipertensão, comparada à faixa de alta escolaridade. No sexo masculino, os dois extremos (alta e baixa escolaridade) mostraram prevalências aumentadas, em relação à escolaridade média.

Da Costa et al. (2007) avaliaram fatores socioeconômicos, comportamentais e nutricionais para hipertensão na cidade de Pelotas, em um estudo transversal realizado em 2000. Comparadas com uma renda maior que 10 salários mínimos, todas as outras faixas salariais mostraram prevalência duas vezes maior de hipertensão, não tendo sido encontrada associação com escolaridade.

Marins et al. (2007) investigaram a associação entre fatores socioeconômicos e um índice composto de risco cardiovascular (hipertensão + obesidade + tabagismo + razão cinturaquadril + sedentarismo + alcoolismo). A presença de dois a seis itens constituía risco. As variáveis renda ("baixa" - menor que a mediana do estudo) e escolaridade ("baixa" - menor ou igual a 8 anos de estudo) foram analisadas em uma regressão logística, separadamente para homens e mulheres. Em ambos os sexos, foi encontrada maior importância da escolaridade, com uma freqüência de risco cerca de duas vezes maior em indivíduos com escolaridade baixa.

Kilsztajn et al. (2005), estudando homicídios na Região Metropolitana de São Paulo (38 municípios e 96 distritos do município de São Paulo), encontraram escolaridade baixa (menos de 7 anos de estudo) fortemente associada à taxa de homicídios, ajustada para idade, sexo e cor da pele. Gawrysewski e Costa (2005) também estudaram homicídios nos 96 distritos do município de São Paulo em 2000, observando forte correlação negativa com a renda média, ou seja, maiores coeficientes foram encontrados nos distritos com menor renda e menores coeficientes naqueles com maior renda.

\subsection{Condiçóes de Vida, Ambiente e Trabalho}

As condições materiais de vida e trabalho dos indivíduos e grupos, assim como sua vulnerabilidade aos impactos ambientais estão fortemente influenciadas pela posição social que ocupam e que pode ser definida por meio de uma série de váriavéis como renda, escolaridade, gênero e outras (ver Figura 2). Estas condições de vida e trabalho e seus efeitos psicossociais constituem um dos principais mediadores através dos quais a estratificação socioeconômica influencia a situação de saúde de indíviduos ou grupos, bem como os diferenciais observados entre eles. Analisando as condições materiais de vida e trabalho dos 
diversos grupos sociais, pode-se, em grande parte, responder a questões fundamentais como: onde se originam as iniqüidades em saúde entre grupos sociais? Quais são os caminhos pelos quais os determinantes sociais produzem as iniqüidades em saúde?

Neste item, são apresentados alguns aspectos fundamentais das condições de vida e trabalho, com ênfase nas desigualdades existentes entre estas condições e sua associação com a situação de saúde. Destacam-se as condições de alimentação e nutrição, saneamento básico e habitação, ambientais, de emprego e trabalho, assim como o acesso a serviços de saúde e à informação.

\section{Alimentação e Nutrição}

A alimentação, cujo acesso e qualidade estão claramente influenciados por fatores socioeconômicos, comportamentais e culturais, constitui-se num dos mais importantes determinantes sociais da saúde. Nas últimas décadas, o Brasil vem passando por um processo de transição nutricional, que consiste na substituição de um padrão alimentar baseado no consumo de cereais, feijões, raízes e tubérculos por uma alimentação mais rica em gorduras (especialmente hidrogenadas) e açúcares, além da crescente ingestão de ingredientes químicos. Conforme já mencionado na seção em que foram tratados os processos de transição demográfica e epidemiológica, o processo de transição nutricional é também marcado pela sobreposição de padrões, pela temporalidade indefinida e, sobretudo, pelas desigualdades de acordo com a estratificação socioeconômica.

Essa mudança nos padrões alimentares vem aumentando o risco de sobrepeso e obesidade, condições que contribuem de forma importante para o aparecimento de doenças crônicas e incapacidades, incluindo desde condições debilitantes que afetam a qualidade de vida, tais como a osteoartrite, dificuldades respiratórias, problemas músculo-esqueléticos, problemas de pele e infertilidade, até condições graves como doença coronariana, diabetes tipo 2 e certos tipos de câncer. Segundo o Instituto Nacional de Câncer (Inca, 2006), o sobrepeso e a obesidade são a segunda causa evitável de câncer, atrás apenas do tabagismo.

A Pesquisa de Orçamento Familiar (POF), de 2003, mostrou que o número de brasileiros adultos com excesso de peso tinha praticamente dobrado em relação a 1974, quando foi feito o Estudo Nacional de Despesas Familiares. O percentual de meninos com excesso de peso mais do que triplicou, passando de 3,9\% em 1974-1975 para 17,9\% em 2002-2003. Para as meninas, esse aumento foi de $100 \%$, passando de $7,5 \%$ para $15,4 \%$ no mesmo período. Em 2003, o excesso de peso atingia, em média, quatro em cada dez brasileiros adultos, superando em cerca de oito vezes o déficit de peso entre as mulheres e em quinze vezes entre os homens. Considerando o universo de brasileiros com 20 anos ou mais de idade, o IBGE estima que haja 3,8 milhões de pessoas (ou 4,0\%) com déficit de peso e 38,8 milhões (40,6\%) com excesso de peso, das quais 10,5 milhões são consideradas obesas.

Alguns dos estudos mais recentes que analisam a problemática da alimentação e nutrição no Brasil e o processo de transição nutricional são mencionados a seguir. 
O estudo de Batista-Filho e Rissin (2003) mostra diferenças importantes na prevalência de desnutrição por região e por estrato urbano e rural, sendo o Nordeste rural a região mais afetada com 8,8\%, em oposição ao Centro-Sul urbano, com 5,8\%.

Por outro lado, Veiga, Cunha e Sichieri (2004) observaram que o índice de massa corpórea (IMC) vem aumentando em meninos e meninas, tanto nas regiões Nordeste como Sudeste, embora para as meninas do Sudeste já tenha começado a ocorrer uma reversão da tendência. Magalhães e Mendonça (2003) confirmam esses achados, mostrando que a prevalência de sobrepeso/obesidade (S/O) foi de $8,45 \%$ no Nordeste e $11,53 \%$ no Sudeste, sendo que no Nordeste há maior risco de S/O para meninas tanto na área urbana como na rural e no Sudeste a situação é inversa, com menor risco de S/O para meninas na área urbana, mas não na rural. O estudo de Veiga, Cunha e Sichieri (2004) também confirma o mesmo padrão, mostrando que o IMC aumentou mais entre os meninos; nas meninas, houve aumento na Região Nordeste, ao passo que no Sudeste, ao contrário, começou a haver decréscimo. No estudo de Dutra, Araújo e Bertoldi (2006), não houve diferença para sobrepeso entre meninos e meninas de Pelotas.

Quanto aos idosos, Cunha e Sichieri (2007) encontraram um aumento na prevalência de obesidade no período de 1975 a 1997, atingindo 37,4\% nos homens e 50,6\% nas mulheres, persistindo o baixo peso, embora com prevalência menor, alcançando $13 \%$ na Região Nordeste, em ambos os sexos. O maior incremento de índice de massa corporal (IMC) ocorreu nos homens da zona rural na Região Sudeste. Em idosos de São Paulo (SP), Barbosa et al. (2007) relataram prevalência maior de obesidade nas mulheres (40,5\%), comparadas aos homens (21,6\%). Em idosos de Bambuí (MG), Barreto, Passos e Lima-Costa (2003) apontaram prevalência de obesidade de $12,5 \%$, positivamente associada com sexo feminino e inversamente associada à prática de atividade física. O baixo peso afetou 15\% dos indivíduos estudados e foi mais elevado nos homens de renda mais baixa, sendo a escolaridade protetora para o baixo peso, mas associada positivamente à obesidade. Campos et al. (2006), também estudando idosos, observaram que o aumento da renda domiciliar aumentou a prevalência de sobrepeso e obesidade. A alta escolaridade foi protetora para baixo peso, mas não foi encontrada associação entre escolaridade e obesidade.

Monteiro, Conde e Castro (2003) discutem a importância da escolaridade para o risco de obesidade, a partir de três grandes inquéritos populacionais nas regiões Sudeste e Nordeste do Brasil (1975, 1989 e 1997). Os autores concluem que houve aumento contínuo da obesidade em todos os estratos de escolaridade da população masculina, enquanto nas mulheres este aumento ocorreu de 1975 a 1989, tendendo a se concentrar nas mulheres com baixa escolaridade (menor ou igual a 4 anos) e a se estabilizar ou diminuir nas demais faixas, no período de 1989 a 1997. No estrato de máxima escolaridade, o declínio foi de 25\%.

A complexidade da transição nutricional no Brasil e sua relação com determinantes socioeconômicos foi mostrada por Monteiro, Conde e Popkin (2007), a partir de uma revisão de vários estudos seccionais realizados no país. A análise por sexo e já ajustada para idade 
mostra que, entre os homens, tem havido aumento de obesidade em todas as faixas de renda, com um gradiente: quanto maior a renda, maior a prevalência. Já no caso das mulheres, o incremento da obesidade foi mais acentuado nos dois quintis mais baixos de renda, com uma tendência à queda na maior faixa de renda. O padrão nos adolescentes é semelhante: no estudo de Magalhães e Mendonça (2003), a renda per capita domiciliar mensal elevada só se mostrou associada a sobrepeso e obesidade entre meninos. As meninas de maior renda mostram uma tendência à queda de sobrepeso/obesidade.

Alguns resultados dos estudos apresentados são bastante consistentes. Os estudos de Monteiro, Conde e Popkin (2001, 2007) e Monteiro, Conde e Castro (2003) mostram que a transição nutricional no Brasil se apresenta com uma dupla carga, desnutrição e obesidade. Segundo Doaket al. (2005), essa dupla carga freqüentemente ocorre no mesmo grupo familiar, principalmente no meio urbano, em famílias de baixa renda. Também segundo Monteiro, Conde e Popkin (2001), há uma diferença entre homens e mulheres quanto à associação de renda/escolaridade com a situação nutricional: entre adultos, a obesidade em mulheres associa-se negativamente com educação e renda e entre os homens associa-se positivamente com renda e negativamente com educação. A tendência à obesidade nas camadas mais pobres ocorre mais precocemente entre as mulheres, comparadas aos homens (Monteiro et al., 2004a, 2004b). Dada a complexidade da transição nutricional no país, é importante seguir investigando os principais mecanismos envolvidos na progressão acelerada da obesidade nos estratos menos favorecidos da população brasileira, com vistas a aumentar a efetividade das políticas e programas que buscam incidir sobre este problema.

\section{Saneamento Básico e Habitação}

A Pesquisa Nacional por Amostra de Domicílios (Pnad) registrou melhoria nos índices de cobertura dos serviços de água e esgoto no período de 1999 a 2004. Segundo a Pnad 2004, o percentual de domicílios particulares permanentes atendidos por rede geral de abastecimento de água aumentou de $80 \%$ para $83 \%$ e o percentual de domicílios servidos por esgotamento sanitário adequado (rede coletora ou fossa séptica) aumentou de $65 \%$ para $70 \%$, no referido período. Entretanto, há que se destacar as desigualdades regionais e entre municípios. Em 2005, enquanto nas regiões Sul e Sudeste, respectivamente, 83\% e 91\% da população estavam cobertos pela rede geral de abastecimento de água, na Região Norte a cobertura desses serviços alcançava apenas $54,8 \%$ da população e no Nordeste $72 \%$. Mas não há unanimidade a respeito dos dados: o mais recente levantamento sobre o tema, realizado pelo Centro de Políticas Sociais da Fundação Getulio Vargas (FGV) e pelo Instituto Trata Brasil (Neri, 2007), aponta para o fato de que 53\% da população brasileira ainda não teriam acesso a um saneamento adequado, e, no atual ritmo de ampliação do acesso, a universalização só se daria em 115 anos.

O Gráfico 23 mostra a associação entre a cobertura por saneamento básico e a mortalidade por doença diarréica em menores de 5 anos. 
Gráfico 23 - Indicadores de saneamento básico, segundo região. Brasil

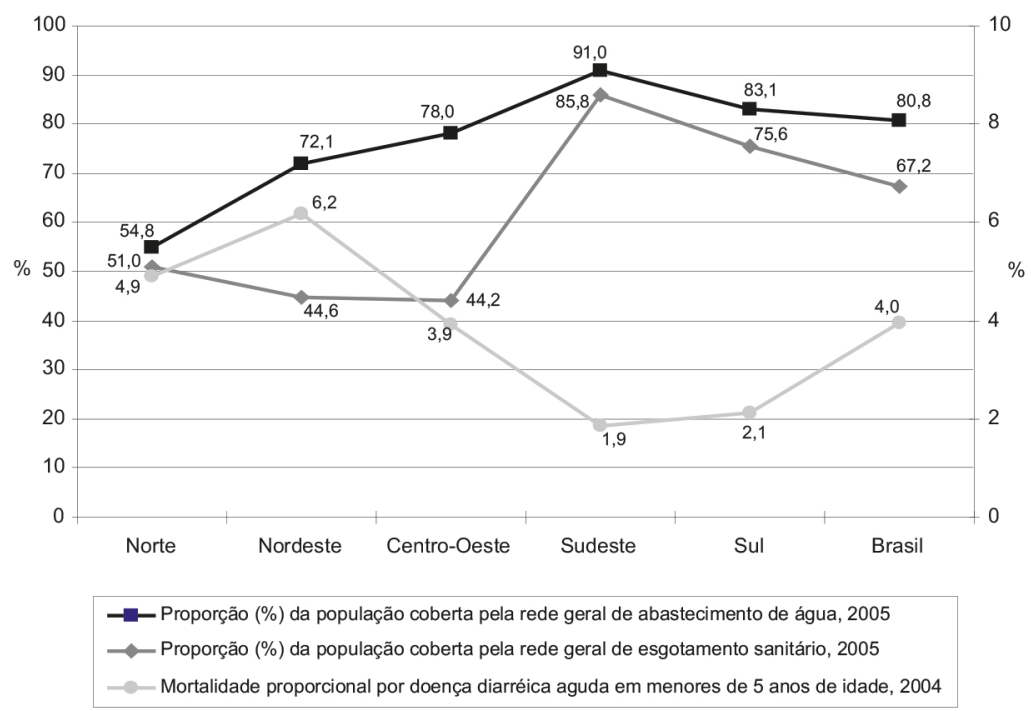

Fonte: IDB 2006 (Indicadores e Dados Básicos), produto da ação integrada do Ministério da Saúde e da Organização Pan-Americana da Saúde (Opas), no âmbito da Rede Interagencial de Informações para a Saúde (Ripsa).

No que se refere às regiões metropolitanas das capitais, as diferenças também são bastante significativas. Por exemplo, a proporção da população coberta pela rede de esgotamento sanitário, em 2005, variava de 44,26\% em Recife e 66,33\% em Fortaleza até 92,21\% em Curitiba e 91,97\% em Porto Alegre (Gráfico 24).

Gráfico 24 - Indicadores de saneamento básico, regiões metropolitanas. Brasil

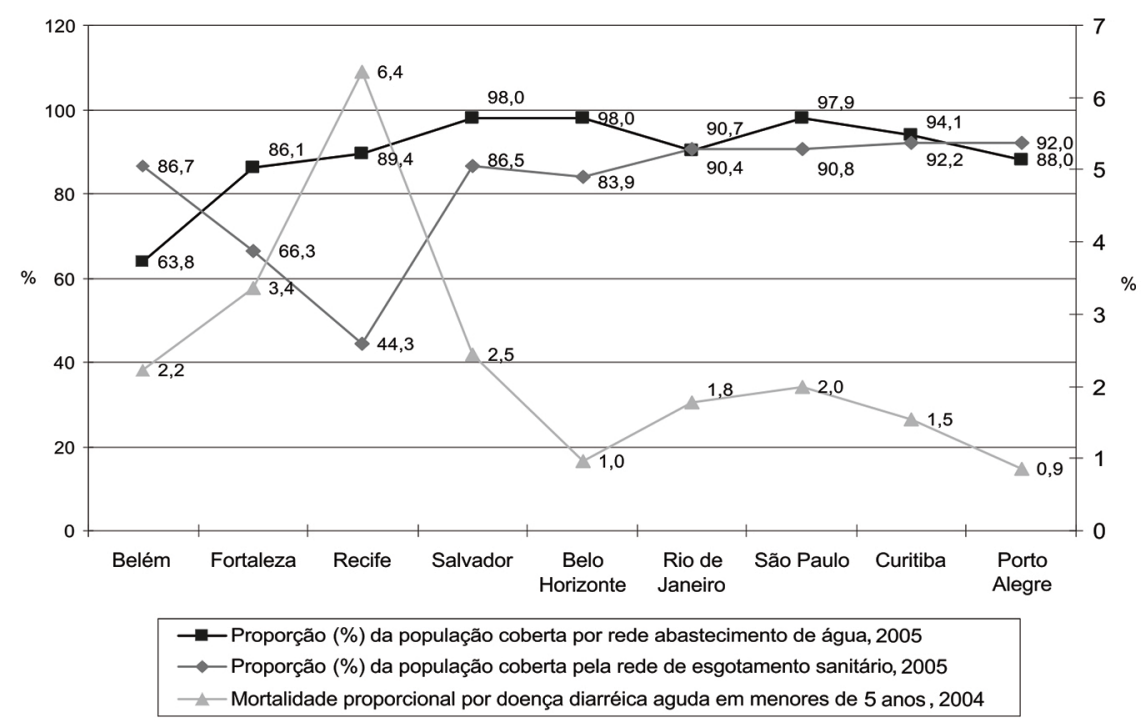

Fonte: IDB 2006 (Indicadores e Dados Básicos), produto da ação integrada do Ministério da Saúde e da Organização Pan-Americana da Saúde (Opas), no âmbito da Rede Interagencial de Informações para a Saúde (Ripsa). 
Entre os estudos que buscam avaliar o impacto do saneamento básico na doença diarréica aguda infantil, merece destaque um estudo realizado em Salvador por Barreto et al. (2007). Este estudo avaliou o efeito, sobre a morbidade por diarréia em menores de 3 anos, de uma intervenção iniciada em 1997, que ampliou a cobertura de serviços de esgoto na cidade de $26 \%$ para $80 \%$ dos domicílios. Foram feitos dois estudos longitudinais: em 1997-1998, antes da intervenção, e em 2003-2004, depois que ela foi completada. Cada estudo acompanhou uma coorte de crianças de 0-36 meses (841 no primeiro e 1.007 no segundo estudo), por um máximo de oito meses. Após os necessários ajustes para outras variáveis potencialmente confusoras, os autores concluíram que a prevalência de diarréia caiu em $22 \%$ entre a primeira e segunda coorte (9,2 dias por criança/ano antes da intervenção para 7,3 dias por criança/ano após a mesma).

\section{Condições de Emprego e Trabalho}

Os problemas de saúde dos trabalhadores estão intimamente relacionados com o grau de desenvolvimento alcançado por um país ou uma região. Os avanços tecnológicos e as mudanças industriais redefiniram o cenário do trabalho no Brasil, com a passagem de uma economia primariamente agrária e de mineração para uma economia industrial, com ênfase nas atividades de comércio e serviço. As características desse processo de transição tiveram por conseqüência importantes problemas sociais e econômicos que se expressam, por exemplo, por um crescimento constante do setor informal, salários baixos, maior insegurança no emprego e grandes diferenças sociais e regionais no que se refere a desemprego e trabalho infantil, como mostra a Tabela 19.

Tabela 19 - Indicadores de condições de emprego e trabalho, segundo região. Brasil

\begin{tabular}{|c|c|c|c|c|c|c|}
\hline \multirow{2}{*}{ Indicadores } & \multicolumn{5}{|c|}{ Região } & \multirow[b]{2}{*}{ BRASIL } \\
\hline & Norte & Nordeste & $\begin{array}{l}\text { Centro- } \\
\text { Oeste }\end{array}$ & Sudeste & Sul & \\
\hline $\begin{array}{l}\text { Taxa de desemprego ( } 10 \\
\text { anos ou mais de idade), } 2005\end{array}$ & 7,9 & 9,0 & 9,6 & 10,9 & 6,1 & 9,3 \\
\hline \multicolumn{7}{|l|}{$\begin{array}{l}\text { Taxa de desemprego ( } 10 \\
\text { anos ou mais de idade), por } \\
\text { cor da pele, 2005: }\end{array}$} \\
\hline Branca & 7,7 & 8,0 & 8,1 & 9,7 & 5,6 & 8,2 \\
\hline Preta & 8,8 & 13,4 & 12,0 & 12,3 & 10,1 & 12,3 \\
\hline Parda & 7,9 & 8,9 & 10,7 & 12,7 & 8,2 & 10,2 \\
\hline $\begin{array}{l}\text { Taxa de trabalho infantil ( } 10 \\
\text { a } 14 \text { anos de idade), } 2005\end{array}$ & 14,6 & 17,9 & 8,9 & 7,1 & 12,5 & 12,0 \\
\hline \multicolumn{7}{|l|}{$\begin{array}{l}\text { Taxa de trabalho infantil ( } 10 \\
\text { a } 14 \text { anos de idade), por cor } \\
\text { da pele, 2005: }\end{array}$} \\
\hline Branca & 12,6 & 15,0 & 7,6 & 5,9 & 12,5 & 9,6 \\
\hline Preta & 10,2 & 15,3 & 9,3 & 8,1 & 9,4 & 10,8 \\
\hline Parda & 15,3 & 19,2 & 9,6 & 8,7 & 12,7 & 14,4 \\
\hline
\end{tabular}

Fonte: IDB 2006 (Indicadores e Dados Básicos), produto da ação integrada do Ministério da Saúde e da Organização Pan-Americana da Saúde (Opas), no âmbito da Rede Interagencial de Informações para a Saúde (Ripsa).

${ }^{2}$ Esta seção é uma tradução livre de parte do estudo de caso do Brasil coordenado por Vilma Souza Santana (Ufba) para a "Knowledge Network on Employment Conditions and Health - Emconet" da Comissão sobre Determinantes Sociais da Saúde da OMS, tendo como autores Elizabeth Costa Dias, Roberval Passos de Oliveira, Jorge Mesquita Huet Machado, Carlos Mynaio Gómez, Marco António Gomes Pérez, Maria da Graça Luderitz Hoefel e Vilma Sousa Santana. 
Estudos mostram que o desemprego, o trabalho informal e a exclusão do mercado de trabalho estão associados a uma pior condição de saúde entre adultos brasileiros, independentemente de características sociodemográficas como escolaridade, renda e região de residência (Giatti \& Barreto, 2006).

A estes problemas se associam o deterioramento das condições de trabalho e crescentes danos ambientais. Os acidentes de trabalho são um dos subprodutos destas tendências, juntamente com uma grande carga de doenças profissionais e doenças relacionadas ao trabalho, cujas conseqüências contribuem para o agravamento dos problemas sociais que o país enfrenta. Acompanhando as grandes diferenças no desenvolvimento social e econômico das diversas regiões do Brasil, as características da saúde dos trabalhadores e das lesões e doenças relacionadas ao trabalho mostram um padrão misto, caracterizando uma carga dupla de doenças. Verifica-se a presença de algumas doenças já controladas em países desenvolvidos, como a silicose e outras pneumoconioses, envenenamento por chumbo, asbestose, mesotelioma relacionado com o asbesto, ao lado de outras "novas" doenças relacionadas ao trabalho como afecções musculoesqueléticas (como a síndrome do túnel do carpo e outras), doenças dermatológicas causadas por compostos químicos, além dos sintomas e desordens mentais relacionadas ao estresse, como a síndrome do burn-out. A combinação de formas tradicionais e novas de organização do trabalho acaba por determinar altos níveis de exposição aos perigos químicos e físicos, tarefas repetitivas, excessivo uso de força, posturas inadequadas, exposição ao estresse e fatores psicossociais, causando sofrimento e incapacidades temporárias e de longo prazo (Gómez \& Lacaz, 2005).

Contrariamente às doenças "profissionais" tradicionais, a identificação do grau de relação com o trabalho destas novas doenças associadas a condições modernas de trabalho, cuja importância é crescente, depende de estudos epidemiológicos que comparem diferentes grupos de trabalhadores, classificados de acordo com o tipo de trabalho, o tipo de ocupação e/ou o tipo de empresa (Schilling, 1984).

Apesar da importância da carga de doenças e das lesões relacionadas ao trabalho, as estatísticas nacionais e os dados epidemiológicos ainda são dispersos e de baixa qualidade. 0 Ministério da Previdência Social produz relatórios anuais, que se limitam aos trabalhadores formais, excluindo também os empregados públicos civis e militares. Os dados do Sistema Único de Saúde (SUS), a respeito de lesões e doenças relacionadas ao trabalho, são de baixa confiabilidade, apesar da recente obrigação legal de relatá-los às autoridades de saúde pública (Binder \& Cordeiro, 2003).

De acordo com os dados oficiais, referentes unicamente aos trabalhadores formais, 2.700 trabalhadores morreram em 2005 e 491.000 ficaram fora do trabalho, recebendo benefícios do seguro do trabalhador. Ao longo dos últimos 20 anos, vem ocorrendo uma diminuição constante dos acidentes de trabalho fatais, com uma queda de incidência de 26,2 por 100.000 (estimada em 1990) para 11,4 por 100.000 em 2003, correspondendo a uma redução de $56,5 \%$ (Santana, Nobre \& Waldvogel, 2005). Esta tendência foi interpretada como resultante do aumento da participação do setor terciário na economia (o setor de serviços), onde os riscos ocupacionais de acidentes são usualmente baixos, e também da migração dos trabalhadores 
formais para a economia informal (Wünsch Filho, 1999, 2004). Esta tendência de declínio foi também atribuída a mudanças no sistema de notificação (Fachini et al., 2005), já que não há nenhuma evidência de que foram adotadas no país ações eficazes para a prevenção.

Salerno (1998), estudando registros da mortalidade, em uma área altamente industrializada do estado de São Paulo, estimou para 1990 uma taxa de mortalidade por ferimentos decorrentes de acidentes do trabalho de 40,43 por 100.000 , entre trabalhadores subcontratados na indústria de transformação, quatro vezes mais alta que a taxa estimada para trabalhadores diretamente empregados, que foi de 9,39 por 100.000. Embora a mortalidade tenha declinado, em 1995, para 25,97 por 100.000 entre os subcontratados, a diferença aumentou de 6 para 1 quando comparados com os diretamente empregados. A incidência nacional de lesões não-fatais decorrentes de acidentes do trabalho estimada por estatísticas do Ministério da Previdência Social é de 1,6\% (Wünsch Filho, 1999), o que difere significativamente das estimativas obtidas em estudos baseados na comunidade. Por exemplo, no estado de São Paulo, Barata et al. (1998) referem uma incidência de 3,49\% de acidentes do trabalho, menor do que a de 5,8\% encontrada em Salvador, Bahia (Santana \& Loomis, 2004).

Os resultados de diversos estudos baseados na comunidade não mostraram nenhuma evidência de que os trabalhadores informais estão submetidos a um risco mais elevado de acidentes ocupacionais não fatais, quando comparados aos trabalhadores formais, o que sugere que as condições do trabalho são precárias tanto para trabalhadores informais como formais, em áreas urbanas e rurais (Barata, Ribeiro \& Moraes, 2000; Santana \& Loomis, 2004; Barbin Jr. \& Martini, 2006). Entretanto, diversos estudos mostraram, consistentemente, que os transtornos psicológicos menores ou sintomas mentais são mais comuns entre trabalhadores informais (Lurdermir \& Lewis, 2003; Santana et al., 1997).

Vários estudos mostram também a importância da violência, da agressão intencional e dos acidentes de tráfego, no perfil das mortes relacionadas ao trabalho no país (Machado \& Gomez, 1994; Waldvogel, 2002; Nobre, 2007). Grande número de acidentes fatais que ocorrem durante atividades do trabalho não são reconhecidos como mortes relacionadas ao trabalho. Tais ocorrências aparecem nas estatísticas como homicídios ou acidentes de trânsito, o que contribui para o sub-registro de acidentes do trabalho no Brasil (Hennington, Cordeiro \& Moreira Filho, 2004). Tem sido observado um grande número de mortes no trânsito de motoboys - entregadores de mercadorias que usam motocicletas, muito comuns nas grandes cidades e cada vez mais vistos também em áreas rurais, substituindo veículos de tração animal (Diniz, Assunção \& Lima, 2005).

As doenças profissionais e relacionadas ao trabalho podem ser comparadas a um iceberg: somente uma parcela pequena é visível e conhecida. Com o objetivo de melhorar a capacidade dos serviços de saúde para diagnosticar e registrar as doenças relacionadas ao trabalho, o Ministério da Saúde elaborou, em 1999, uma lista nacional de doenças relacionadas ao trabalho que foi endossada pelo Instituto Nacional de Seguridade Social (INSS). Ao redor de 200 eventos, classificados de acordo com a Classificação Internacional de Doenças (CID- 10a ed.), foram listados, utilizando um sistema de dupla entrada pelo risco/exposição e pelo dano de saúde/doença. 
No período de 2000 a 2002, o INSS reconheceu 58.978 casos de doenças relacionadas ao trabalho, o que corresponde somente aos trabalhadores que têm contratos formais e são elegíveis para benefícios, que representam apenas $23 \%$ do total de trabalhadores. Conseqüentemente, grande número de casos permanecem desconhecidos. Um bom exemplo são as doenças respiratórias relacionadas ao trabalho, que mostram uma sobreposição entre o passado, o presente e o futuro. Além dos casos já existentes de silicose, novos casos vêm ocorrendo, apesar dos esforços nacionais para a erradicação desta doença. A situação atual com relação à exposição à silica é bastante diferente do que ocorria no passado, embora ainda haja a necessidade de soluções inovadoras para a vigilância e para os programas de combate às pneumoconioses no país (Castro et al., 2004; Castro, Silva \& Vicentin, 2005; Bon, 2006). Um estudo transversal com trabalhadores de pedreiras estimou uma prevalência de $54 \%$ de silicose, encontrando também diversos casos de sílico-tuberculose (Antão, 2003). A maioria de pacientes de silicose (66\%), registrados em um programa de cuidado à saúde, estavam vinculados a formas arcaicas de processo de trabalho na economia informal (Carneiro et al., 2002).

O mesotelioma pleural maligno e outras doenças respiratórias relacionadas ao asbesto estão começando a aparecer, uma vez que a latência para seu aparecimento é relativamente grande e a história da exposição ocupacional e/ou ambiental ao asbesto no país é relativamente recente (Mendes, 2001; Castro et al., 2005). Estão também aparecendo casos de asma relacionados ao trabalho, que gradativamente está se transformando numa doença respiratória de alta freqüência, apesar de seu escasso reconhecimento por parte dos médicos, o que leva a dificuldades para obtenção de benefícios (Faria et al., 2006; Fernandes, Stelmachi \& Algranti, 2006).

As doenças dermatológicas relacionadas ao trabalho, dado o número elevado de casos, a incidência cumulativa, o impacto econômico e o mau prognóstico, vêm se constituindo num relevante problema de saúde pública. O setor manufatureiro, principalmente o que lida com metais e química, e a construção civil, são responsáveis pela maioria dos casos. Atualmente, um bom número de pacientes vem do comércio por atacado e varejo, serviços, atividades de limpeza e serviços de saúde. Em um estudo transversal realizado com trabalhadores de uma indústria farmacêutica, Melo (1999) estimou uma prevalência de $78 \%$ de doenças de pele, sendo que $23 \%$ daquelas relacionadas ao trabalho não tiveram nenhum registro de seu caráter ocupacional.

Com relação aos distúrbios músculo-esqueléticos relacionados ao trabalho, é amplamente reconhecido que este grupo de afecções está liderando, em nível mundial, a maior carga das conseqüências de condições inadequadas de trabalho (principalmente fatores organizacionais, esforços mecânicos e fadiga) na saúde dos trabalhadores. As áreas do corpo mais afetadas são a coluna, o pescoço e os membros superiores, sendo que a bacia e o joelho são também freqüentemente atingidos. Estima-se que os distúrbios músculoesqueléticos são responsáveis por um terço de todas as causas que requerem afastamento do trabalho. Os setores manufatureiros e de serviços são responsáveis por metade dos casos, enquanto caminhoneiros, profissionais de enfermagem e trabalhadores fora da construção 
civil são responsáveis por um quinto dos mesmos. Entre profissionais de enfermagem de 23 instituições de saúde do estado de Minas Gerais, Murofuse e Marziale (2005) encontraram registros de afecções osteomusculares em 12\% de seus prontuários médicos, sendo que 35\% cumpriam com os critérios para identificá-los como relacionados ao trabalho.

As causas orgânicas e não-orgânicas das desordens mentais também merecem ser mencionadas. Exposições a neurotoxinas, tais como mercúrio, chumbo, manganês ou solventes orgânicos são algumas das causas orgânicas mais comuns de distúrbios mentais relacionados ao trabalho. Os problemas mentais sem causa orgânica são reconhecidos como um dos principais problemas de saúde ocupacional, tanto no Brasil como no resto do mundo, com uma proporção elevada de trabalhadores que relatam níveis médios a elevados de estresse no trabalho, o que os leva a sofrer os conseqüentes efeitos psicológicos adversos. As causas não orgânicas de tensão psicológica resultam: do ambiente físico de trabalho; das tarefas e responsabilidades; da estrutura organizacional; dos relacionamentos interpessoais no trabalho; das mudanças de trabalho; de eventos traumáticos, tais como doença ocupacional ou ferimento por acidente do trabalho.

Os distúrbios mentais não-orgânicos incluem o estresse pós-traumático, doenças psicossomáticas, uso de drogas, ansiedade e depressão. Diversos estudos recentes realizados no Brasil tratam deste problema, como o estudo realizado por Porto et al. (2006) com professores no estado da Bahia, encontrando que a prevalência de distúrbios mentais entre professores submetidos a elevado grau de tensão era 1,5 vezes maior do que entre professores com menor grau de tensão. Os distúrbios mentais foram associados a mudanças ou deslocamentos de trabalho entre trabalhadores da indústria de mineração de ferro (Guimarães \& Teixeira, 2003) e à implantação de um processo de "reestruturação" de uma companhia estatal (Brant \& Dias, 2004), estudos realizados no estado de Minas Gerais.

A perda da audição induzida pelo ruído deve ser incluída como uma afecção relacionada ao trabalho de alta prevalência. De fato, um recente estudo, realizado no estado do Rio de Janeiro, estimou uma prevalência de 15,9\% entre trabalhadores da indústria de metal (Guerra et al., 2005). Em Goiânia, um outro estudo relatou $21 \%$ de prevalência entre trabalhadores da mesma indústria (Araújo, 2002). No estado de Santa Catarina, uma prevalência de 25,9\% foi encontrada por Sakae et al. (2006), nos resultados de exames audiométricos de trabalhadores que atendem ao Serviço Social da Indústria (Sesi). Em diversos ambientes, o ruído coexiste com outros fatores potencialmente perigosos para a audição, de modo que é importante adotar uma certa cautela antes de atribuir o achado de perda de audição a uma única causa (Azevedo, 2004; Mello \& Waismann, 2004).

Entre trabalhadores rurais, apenas $33,7 \%$ possuem contratos formais de trabalho. Além dos problemas relacionados aos pesticidas (Silva et al., 2005), a incidência de ferimentos decorrentes de acidentes do trabalho parece ser mais elevada do que as estimativas relatadas em áreas urbanas. Fehlberg, Santos e Tomasi (2001) encontraram uma incidência de 11\% de acidentes do trabalho entre trabalhadores rurais em um estado do sul do país. o crescimento do consumo dos pesticidas no Brasil levou o país a ser, atualmente, o quarto maior usuário do mundo. Estimativas do Ministério do Meio Ambiente revelam que, nas últimas duas décadas, 
o consumo de pesticidas no país aumentou quatro vezes (Brasil, 2000). Segundo dados do Sistema Nacional de Informações Toxicológicas (Sinitox), a taxa total de envenenamentos humanos agudos por pesticidas foi de 8,0 por 100.000 em 2003, estimando-se que destes 1,25 por 100.000 estavam relacionados ao trabalho. Faria, Fassa \& Fachinni (2007) estimaram uma incidência de envenenamentos agudos entre trabalhadores rurais de 2,2 por 100.000, durante o período de 2001-2002. A prevalência de trabalhadores expostos variou de $3 \%$ a $23 \%$, o que corresponde a cerca de 540.000 trabalhadores envenenados, com um número potencial de mortes de aproximadamente 4.000 trabalhadores por ano (Moreira et al., 2002).

\section{Ambiente e Saúde ${ }^{3}$}

A urbanização, o crescimento do transporte e das indústrias, assim como a expansão da fronteira agrícola, criaram as condições propícias para uma permanente exposição de contingentes populacionais, progressivamente maiores, à poluição atmosférica e dos corpos hídricos. Esta poluição é gerada por fontes fixas e móveis de emissão de poluentes, por acidentes com produtos químicos voláteis e pelas mudanças no uso do solo geradas por atividades agropastoris, provocando, como conseqüência, efeitos adversos sobre a saúde das populações expostas. Segundo a Organização Mundial da Saúde (WHO, 2000), o número estimado de mortes causadas por problemas decorrentes da poluição atmosférica no mundo é de cerca de 3 milhões por ano, o que representa $5 \%$ do total de 55 milhões de mortes que ocorrem anualmente. Em algumas populações, cerca de 30\% a 40\% dos casos de asma e $20 \%$ a 30\% de todas as doenças respiratórias podem ser relacionadas à poluição atmosférica.

O impacto da poluição do ar na saúde, no Brasil, tem sido amplamente documentado na literatura. Vários estudos enfocam os efeitos de curto prazo provocados pela poluição do ar, embora esse fenômeno possa também provocar danos à saúde a médio e a longo prazos. Os estudos epidemiológicos utilizados na maioria das pesquisas sobre a relação "exposiçãoefeito da poluição do ar" fazem uso de dados secundários, tais como o número de óbitos, internações hospitalares, atendimentos realizados na rede básica de saúde, admissões em serviços de urgência por diversas causas, uso de medicamentos, procedimentos específicos, como a nebulização, dentre outros indicadores de saúde escolhidos, que podem ser apresentados de forma diária, semanal ou mensal. Os estudos têm mostrado que aumentos nos níveis de poluentes do ar se associam a aumentos na mortalidade e na morbidade, tanto por problemas respiratórios como cardiovasculares, em especial entre idosos e crianças. Outros efeitos referem-se a perdas econômicas, aumento no absenteísmo escolar, dias de trabalho perdidos, asma e nebulizações.

Crianças e idosos têm sido identificados como os dois grupos etários mais vulneráveis aos efeitos da poluição atmosférica. Esses efeitos atingem, principalmente, o sistema respiratório, por contato direto com o poluente, e o cardiovascular, por ação direta nas células dos vasos e

${ }^{3}$ Esta seção baseia-se no capítulo sobre Ambiente e Saúde da publicação "Brasil 2006: uma análise da situação de saúde no Brasil", do Ministério da Saúde, Secretaria de Vigilância em Saúde. Brasília: Ministério da Saúde, 2006. 620 p.: il. ISBN 85-334-1223-1. Contou também com a contribuição de Roberto Smeraldi. 
do coração ou por resposta inflamatória sistêmica (Godleski et al., 2000). Portanto, apesar de todos estarem sujeitos aos efeitos adversos dos poluentes do ar, são os indivíduos portadores de doenças do pulmão e/ou do coração os mais afetados. Na década de 1990, as primeiras estimativas de efeito da poluição do ar mostraram que a mortalidade total de idosos está diretamente associada com a variação do material particulado inalável (PM10), pois variações de $10 \mu \mathrm{g} / \mathrm{m} 3$ nas suas concentrações aumentam as mortes de idosos em 1,3\% (Saldiva et al., 1995). Entre essas mortes, a maior parte se deve às doenças respiratórias e cardiovasculares (Miraglia et al., 1997). Além do PM10, outros poluentes como o dióxido de enxofre (SO2) e o monóxido de carbono (CO) também estão diretamente ligados a efeitos adversos à saúde.

Os poluentes causam, também, um importante impacto na morbidade. Aumentos no número de atendimentos em pronto-socorro por doenças respiratórias em idosos (Martins et al., 2002a, 2002b) e doenças isquêmicas do coração (Lin et al., 2003) também estão ligados a aumentos de concentrações de $\mathrm{PM} 10, \mathrm{SO}_{2}, \mathrm{CO}, \mathrm{NO}_{2}$, poluentes primários, e $\mathrm{O}_{3}$, um poluente secundário. Todos esses são poluentes comuns em grandes centros urbanos, como a Região Metropolitana de São Paulo. Mais recentemente, foi demonstrado que os efeitos dos poluentes nas doenças cardiovasculares se manifestam também em adultos e que as mulheres podem ser mais acometidas que os homens (Martins et al., 2004; Martins et al., 2006). Entre as crianças e os adolescentes, os efeitos adversos dos poluentes estão amplamente distribuídos por diferentes grupos etários. Ainda no período fetal, aumentos agudos de $\mathrm{NO}_{2}$ e $\mathrm{SO}_{2}$ podem precipitar mortes fetais tardias (Pereira et al., 1998), enquanto a exposição crônica ao longo da gestação pode acarretar diminuição do peso de nascimento (Gouveia, Bremer \& Novaes, 2004). Após o nascimento, nos primeiros 28 dias de vida, a mortalidade neonatal é influenciada pelos poluentes (Lin et al., 2004), e esse efeito adverso pode ser notado, de modo mais intenso, até os 5 anos de idade (Saldiva et al., 1994; Conceição et al., 2001).

Os atendimentos de pronto-socorro e as internações hospitalares por doenças respiratórias são bons indicadores dos efeitos da poluição do ar na saúde de crianças e adolescentes e têm sido amplamente utilizados nos estudos realizados, principalmente na Região Metropolitana de São Paulo. Desses estudos, pode-se concluir que tanto as doenças infecciosas como as doenças inflamatórias são afetadas pelos poluentes (Lin et al., 1999; Braga et al., 1999; Martins et al., 2002a, b; Farhat et al., 2005). Entretanto, o impacto é maior entre as crianças com menos de 2 anos e entre os adolescentes com mais de treze anos de idade (Braga et al., 2001), mostrando, dentro desse grupo etário, diferentes suscetibilidades. Dentre as cidades da referida Região Metropolitana, os maiores efeitos dos poluentes sobre as doenças respiratórias são encontrados na cidade de São Paulo e nas cidades do ABC paulista (Freitas et al., 2002).

Além dos grupos suscetíveis, alguns estudos realizados na Região Metropolitana de São Paulo identificaram alguns aspectos muito importantes para os estudos de epidemiologia ambiental. Mesmo entre crianças, adolescentes e idosos, os efeitos dos poluentes podem ser modulados pela condição socioeconômica daqueles que estão expostos (Sobral, 1989; Martins 
et al., 2004; Martins et al., 2002a, 2002b; Martins et al., 2006). Os indivíduos apresentam respostas diferentes a estímulos semelhantes em função das suas condições de vida. Esse ponto é de fundamental importância na formulação de políticas públicas voltadas para o estabelecimento de metas de redução de emissão de poluentes. Outro ponto importante é a possibilidade de encontrar alterações clínicas e metabólicas, que são precursoras de doenças respiratórias e cardiovasculares, entre indivíduos sadios mas expostos aos poluentes do ar. Esse é o caso do estudo que mostra controladores de tráfego da Companhia de Engenharia de Tráfego da Prefeitura Municipal de São Paulo apresentando alterações da pressão arterial e de marcadores inflamatórios sangüíneos em dias mais poluídos (Santos et al., 2005). Essas alterações podem não ser suficientes para desencadear doenças em indivíduos normais, mas podem explicar o que leva as pessoas com doenças prévias a apresentarem descompensação clínica nos dias mais poluídos.

Os custos financeiros da poluição do ar também foram estimados, nos estudos anteriormente referidos, a partir dos valores estatísticos de referência do valor da morbidade humana para países em desenvolvimento, na faixa de US\$512.000,00. Dessa forma, os custos foram estimados na ordem de grandeza de US\$ 1,5 bilhão por ano, apenas em referida área metropolitana (Saldiva, depoimento pessoal a Roberto Smeraldi, 2008).

Outra questão de grande relevância é a conversão de ecossistemas para dar lugar ao avanço da fronteira de colonização. Ao longo da última década, este fenômeno atingiu, em média, mais de 3,5 milhões de hectares por ano, principalmente na floresta amazônica e no cerrado, mas também na caatinga, pantanal, mata atlântica e pampa (Inpe/Prodes, 2007; Fundação SOS Mata Atlântica, 2007). A conversão de ecossistemas naturais se dá em função de uma série de fatores, incluindo especulação fundiária, aprópriação de terras públicas, movimentos populacionais vinculados a grandes obras de infra-estrutura não planejadas, assentamento de colonos, pressão da pecuária ou de certas commodities agrícolas (como nos casos recentes da cana ou da soja) e atividade madeireira ilegal.

O processo de conversão contribui de inúmeras formas para o agravamento dos problemas de saúde, inclusive porque a fronteira carece de infra-estrutura para o atendimento das populações que a protagonizam. Uma atividade que contribui de forma significativa para o agravamento das doenças respiratórias é a das queimadas, que se dividem em queimadas de derrubadas (vinculadas ao desmatamento e que acontecem uma vez por todas) e queimadas de pastagem ou de renovação de determinadas culturas, como no caso da cana. Em todos os casos, crianças e idosos são especialmente vulneráveis. Em mais de 600 municípios do país, a situação atinge todo ano picos cronicamente emergenciais (Bussamra et al., 2004).

Outra conseqüência do desmatamento é a malária, que, após ter diminuído no começo da década, voltou nos últimos anos ao patamar do final dos anos 90, na faixa de aproximadamente 600 mil casos registrados por ano. A derrubada da floresta e o represamento de igarapés e rios favorecem a proliferação do mosquito transmissor (Anopheles darlingi), que utiliza água parada e limpa para se reproduzir. Dois estudos publicados recentemente reforçam 
essa tese. o primeiro, que utiliza dados de assentamentos rurais de Rondônia, afirma que as áreas de desmatamento recentes têm maiores incidências da doença ("malária de fronteira”) quando comparadas às áreas de desmatamento antigas (Castro et al., 2006). O segundo estudo, realizado na amazônia peruana, revela que nas áreas sob desmatamento, as taxas de picadas do inseto transmissor chegam a ser 278 vezes maiores do que nas áreas florestadas (Vittor et al., 2006). A incidência de malária nos municípios da Amazônia ocorre com maior freqüência nas regiões onde há desmatamento com alta intensidade nos últimos anos - como o centro-oeste do Pará, norte de Rondônia, noroeste do Mato Grosso e sul do Amazonas (Celentano \& Veríssimo, 2007). Assentados da reforma agrária, índios e ribeirinhos são os mais vulneráveis. Áreas não-florestais e fronteiras antigas de desmatamento apresentam menor intensidade da doença.

\section{Acesso a Serviços de Saúde}

Os serviços de saúde possuem a capacidade de diminuir a exposição aos fatores de risco para a saúde de indivíduos e grupos, assim como a vulnerabilidade e, principalmente, as conseqüências da exposição a esses fatores de risco. O acesso eqüitativo aos serviços de saúde é, portanto, de grande importância para diminuir os diferenciais observados em relação a estes aspectos.

A Constituição de 1988, além de reconhecer a saúde como direito de todo cidadão e dever do Estado, estabeleceu as bases do Sistema Único de Saúde (SUS). De acordo com o texto constitucional, o SUS tem três princípios constitucionais e três princípios organizativos. Os princípios constitucionais incluem a universalização da assistência, garantida a todo cidadão; a integralidade da atenção, incluindo todas as ações necessárias à promoção, prevenção, tratamento e reabilitação; e a eqüidade, ofertando serviços e bens segundo as necessidades. Os princípios organizativos são a descentralização da gestão, com participação das esferas federal, estadual e municipal; a regionalização e hierarquização das redes de serviços; e a participação da comunidade na gestão do sistema.

Os números do SUS impressionam pela magnitude. No ano de 2005, foram realizadas cerca de 450 milhões de consultas médicas, 11,8 milhões de internações, 2,6 milhões de partos, 250 milhões de exames laboratoriais, 40 milhões de vacinações, 80 mil cirurgias cardíacas e 20 mil transplantes de órgãos.

O Programa de Saúde da Família (PSF) é um programa de Atenção Básica em Saúde, onde equipes multiprofissionais são responsáveis pelo acompanhamento de um número definido de famílias, localizadas em uma área geográfica limitada. As equipes atuam em ações de promoção da saúde, prevenção, recuperação e reabilitação de doenças e agravos. São formadas por um médico de família, um enfermeiro, um auxiliar de enfermagem e seis agentes comunitários de saúde, podendo, ainda, contar com um dentista, um auxiliar de consultório dentário e um técnico em higiene bucal. Cada equipe é responsável por mil famílias, abrangendo uma população total de 3 mil a 4,5 mil pessoas. O trabalho da equipe se desenvolve nas residências, nas Unidades Básicas de Saúde e na comunidade. 
Iniciado em 1994, o Programa conta, em 2008, com cerca de 27,5 mil equipes (mais de 150 mil profissionais), atuando em 5.131 municípios (92\% do total de municípios brasileiros). Em 2006, o PSF atendia a mais de 80 milhões de pessoas (cobertura de 44\% da população), com um orçamento total de R 2 bilhões (US\$ 900 milhões) por ano (Tabela 20).

Tabela 20 - Indicadores do PSF, segundo região. Brasil - 2006

\begin{tabular}{|c|c|c|c|c|c|c|}
\hline \multirow[b]{2}{*}{ Indicadores } & \multicolumn{5}{|c|}{ Região } & \multirow[b]{2}{*}{ BRASIL } \\
\hline & Norte & Nordeste & $\begin{array}{l}\text { Centro- } \\
\text { Oeste }\end{array}$ & Sudeste & Sul & \\
\hline $\begin{array}{l}\text { População coberta } \\
\text { (1) }\end{array}$ & 5.569 .915 & 32.634 .393 & 5.830 .341 & 26.384 .939 & 11.675 .249 & 82.216 .837 \\
\hline $\begin{array}{l}\text { \% de população } \\
\text { coberta pelo } \\
\text { Programa }\end{array}$ & 37,9 & 63,2 & 43,9 & 33,2 & 42,8 & 44,0 \\
\hline $\begin{array}{l}\text { Média mensal de } \\
\text { visitas por família } \\
\text { (2) }\end{array}$ & 0,1 & 0,1 & 0,1 & 0,1 & 0,1 & 0,1 \\
\hline $\begin{array}{l}\text { \% de cobertura de } \\
\text { consultas de pré- } \\
\text { natal ( } 2 \text { ) }\end{array}$ & 85,4 & 88,7 & 95,0 & 94,1 & 95,8 & 91,2 \\
\hline
\end{tabular}

(1) Situação no final do ano.

(2) Como numerador e denominador, foi utilizada a média mensal.

Fonte: Caderno de Informações em Saúde, Datasus/MS, julho/2007.

Outro programa cujos avanços merecem ser destacados é o Programa Nacional de Imunização (PNI), que em 2008 completa 35 anos. O PNI logrou superar as grandes diferenças regionais na cobertura de vacinações de anos anteriores, alcançando uma cobertura praticamente universal em menores de um ano a partir de 1999, quando chegou a 94,7\%, enquanto que em 1978, atingia somente 40\% das crianças. O Gráfico 25 mostra os resultados obtidos para a vacinação contra a poliomielite. Este padrão se repete para o sarampo, DPT e outras vacinas incluídas no Programa, o que trouxe como resultado a erradicação da poliomielite (último caso em junho de 1989 e certificado de erradicação concedido pela OMS em 1994) e a diminuição da incidência e mortalidade das demais doenças.

Apesar destes inegáveis avanços na produção de serviços e dos princípios de universalidade e eqüidade que regem o SUS, ainda se observam importantes desigualdades na oferta de recursos e serviços, assim como uma forte influência da posição social dos indivíduos no acesso, utilização e qualidade dos serviços de saúde. 
Gráfico 25 - Cobertura vacinal contra poliomielite, por região. Brasil - 1994 - 2006

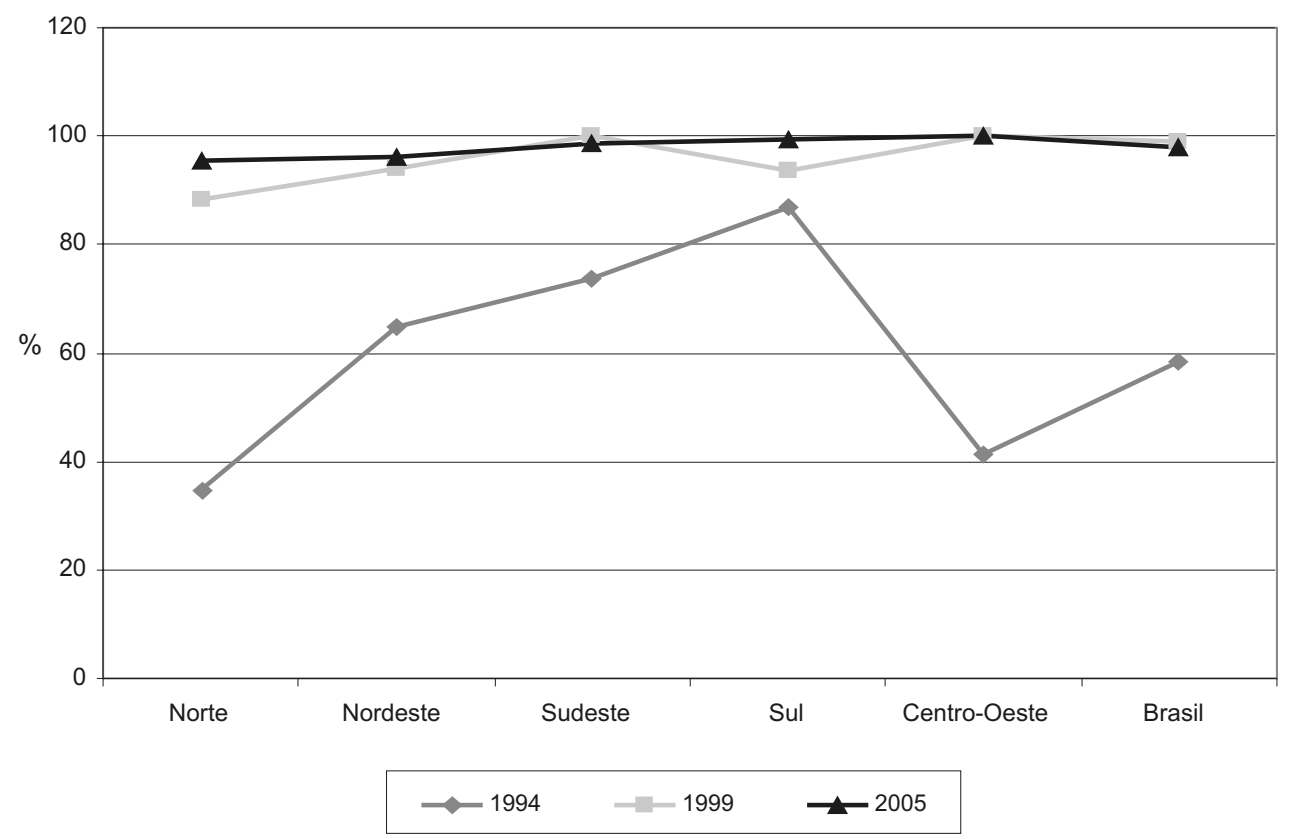

Fonte: Programa Nacional de Imunização (PNI).

O Brasil gasta 7\% do Produto Interno Bruto (PIB) em saúde, cerca de 530 dólares per capita, abaixo de Argentina (US\$1.045), Chile (US\$827) e Uruguai (US\$ 781), para citar alguns países do Cone Sul. A proporção de gasto público/privado, em termos percentuais, é de 49/51, proporção esta que nos países citados (Argentina, Chile e Uruguai) é de 55/45, 53/47 e 71/29, respectivamente (Opas, 2007). A Tabela 21 mostra que o gasto público per capita em saúde é relativamente baixo em todas as regiões e não cumpre uma função compensatória, tendendo a reforçar as desigualdades. A tabela também mostra que as famílias de menor renda gastam uma proporção muito maior de seu orçamento com saúde em comparação com as de maior renda, chegando essa diferença, no caso das regiões Norte, Centro-Oeste e Sul, a ser cerca de 2,5 vezes maior em pontos percentuais. Pode-se também observar que há uma grande disparidade entre as regiões na distribuição de leitos e médicos, particularmente destes últimos, altamente concentrados na Região Sudeste.

A organização dos serviços de saúde no Brasil é do tipo misto, com um sistema público de acesso universal (SUS) e um sistema privado de seguros e planos de saúde, sendo que a cobertura deste último está claramente relacionada ao nível de renda, como mostra o Gráfico 26. 
Tabela 21 - Indicadores de serviços de saúde, segundo região. Brasil

\begin{tabular}{|c|c|c|c|c|c|c|}
\hline \multirow[b]{2}{*}{ Indicadores } & \multicolumn{5}{|c|}{ Região } & \multirow[b]{2}{*}{ BRASIL } \\
\hline & Norte & Nordeste & $\begin{array}{l}\text { Centro- } \\
\text { Oeste }\end{array}$ & Sudeste & Sul & \\
\hline Médicos por mil habitantes, 2005 & 0,8 & 1,0 & 1,7 & 2,3 & 1,7 & 1,7 \\
\hline Leitos por mil habitantes, 2005 & 1,9 & 2,3 & 2,6 & 2,4 & 2,8 & 2,4 \\
\hline $\begin{array}{l}\text { Gasto público total com saúde per } \\
\text { capita (em reais), } 2004\end{array}$ & 308,3 & 252,0 & 325,6 & 360,6 & 306,7 & 358,5 \\
\hline $\begin{array}{l}\text { Despesa familiar com assistência à } \\
\text { saúde como proporção (\%) da } \\
\text { renda familiar, segundo classes de } \\
\text { rendimento, 2003: }\end{array}$ & & & & & & \\
\hline Até 400 reais & 6,6 & 5,3 & 10,4 & 9,7 & 7,6 & 7,1 \\
\hline Mais de 6.000 reais & 2,6 & 4,5 & 3,9 & 5,1 & 3,2 & 4,5 \\
\hline
\end{tabular}

Fonte: IDB 2006 (Indicadores e Dados Básicos), produto da ação integrada do Ministério da Saúde e da Organização Pan-Americana da Saúde (Opas), no âmbito da Rede Interagencial de Informações para a Saúde (Ripsa).

Gráfico 26 - Proporção (\%) da população residente coberta por plano de saúde, por classes de rendimento mensal familiar e região. Brasil - 2003

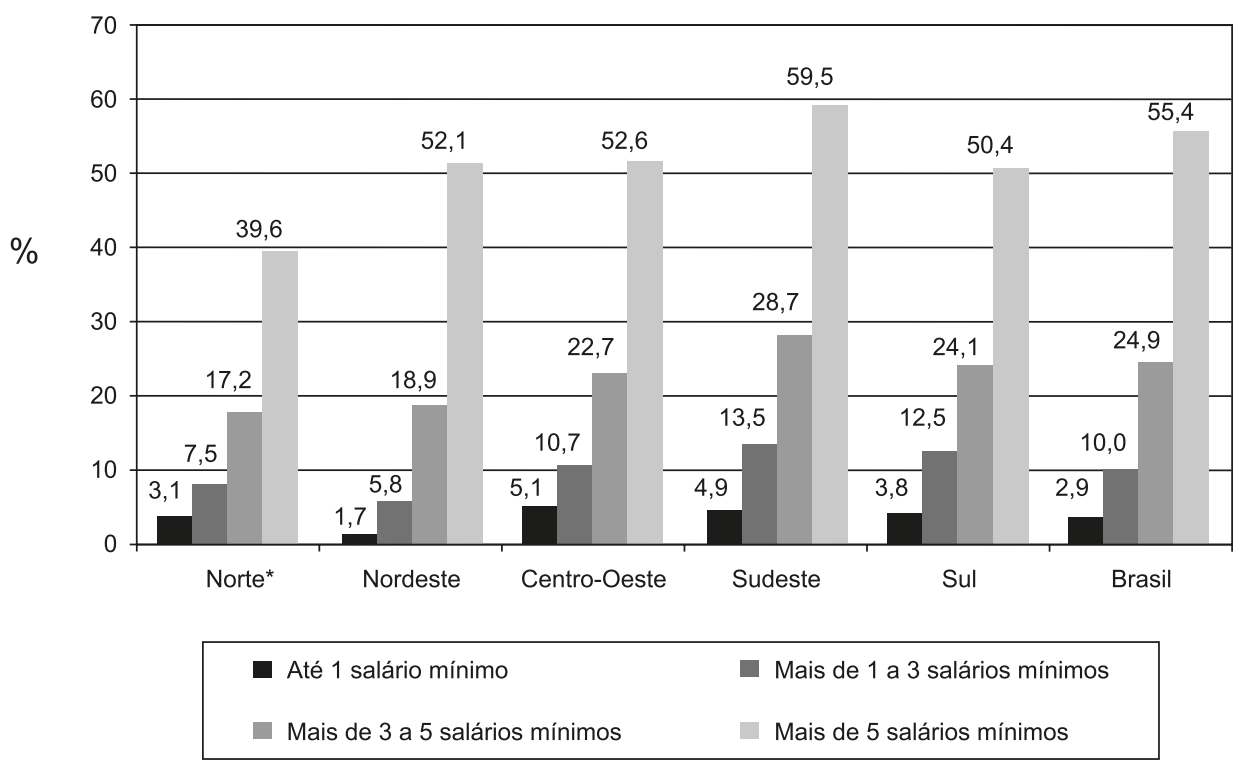

*Exclusive a população rural.

Fonte: Elaboração própria, a partir da Pesquisa Nacional por Amostra de Domicílios (Pnad) 2003 - Acesso e Utilização de Serviços de Saúde. Instituto Brasileiro de Geografia e Estatística (IBGE). 
No Gráfico 27, construído com dados da Pesquisa Nacional por Amostra de Domicílios (Pnad), de 2003, a partir da pergunta sobre onde a pessoa procurou atendimento para uma determinada queixa no período de referência, observa-se uma clara relação entre nível de renda e percentual de pessoas que procuram serviços do SUS ou dos planos de saúde.

Gráfico 27 - Porcentagem de pessoas ocupadas, de 10 anos e mais (na semana de referência), atendidas pelo SUS e/ou que têm plano de saúde, por nível de renda (em salários mínimos per capita). Brasil - 2003

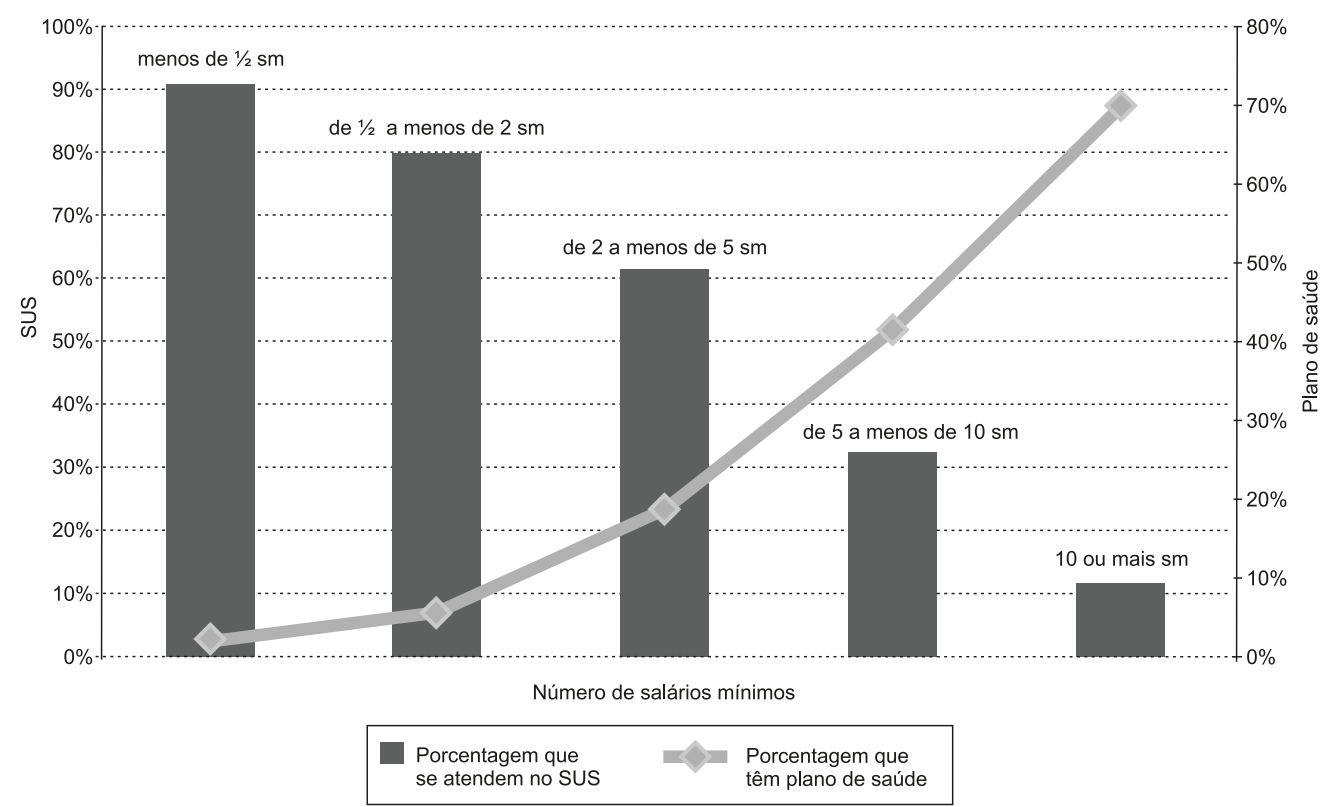

Fonte: Pesquisa Nacional por Amostra de Domicílios (Pnad), 2003.

Dados da Pesquisa Mundial de Saúde mostram uma associação entre melhor nível socioeconômico e maior uso de serviços de saúde, o que, para Viacava, Souza Jr. e Szwarcwald (2005), pode significar um maior uso de serviços pela população mais saudável (Gráfico 28).

As desigualdades sociais no acesso e na utilização de serviços de saúde estão, em grande medida, relacionadas com a estrutura e funcionamento dos sistemas de saúde, o que faz com que tais desigualdades sejam bastante permeáveis às políticas setoriais. Os determinantes da utilização de serviços de saúde estão relacionados às necessidades de saúde (morbidade, gravidade e urgência da doença), aos usuários (idade, sexo, renda, educação, região de moradia), aos prestadores de serviços (especialidade, experiência profissional, tipo de prática, formas de pagamento), à organização da oferta (disponibilidade de médicos, hospitais, ambulatório, acesso geográfico, modo de remuneração) e à política do sistema de saúde (tipo de sistema de saúde, proposta assistencial, distribuição de recursos, legislação, entre outros) (Travassos \& Martins, 2004). 
Gráfico 28 - Porcentagem de pessoas ocupadas de 10 anos e mais (na semana de referência), atendidas por médico e/ou dentista, por nível de renda (em salários mínimos per capita). Brasil - 2003

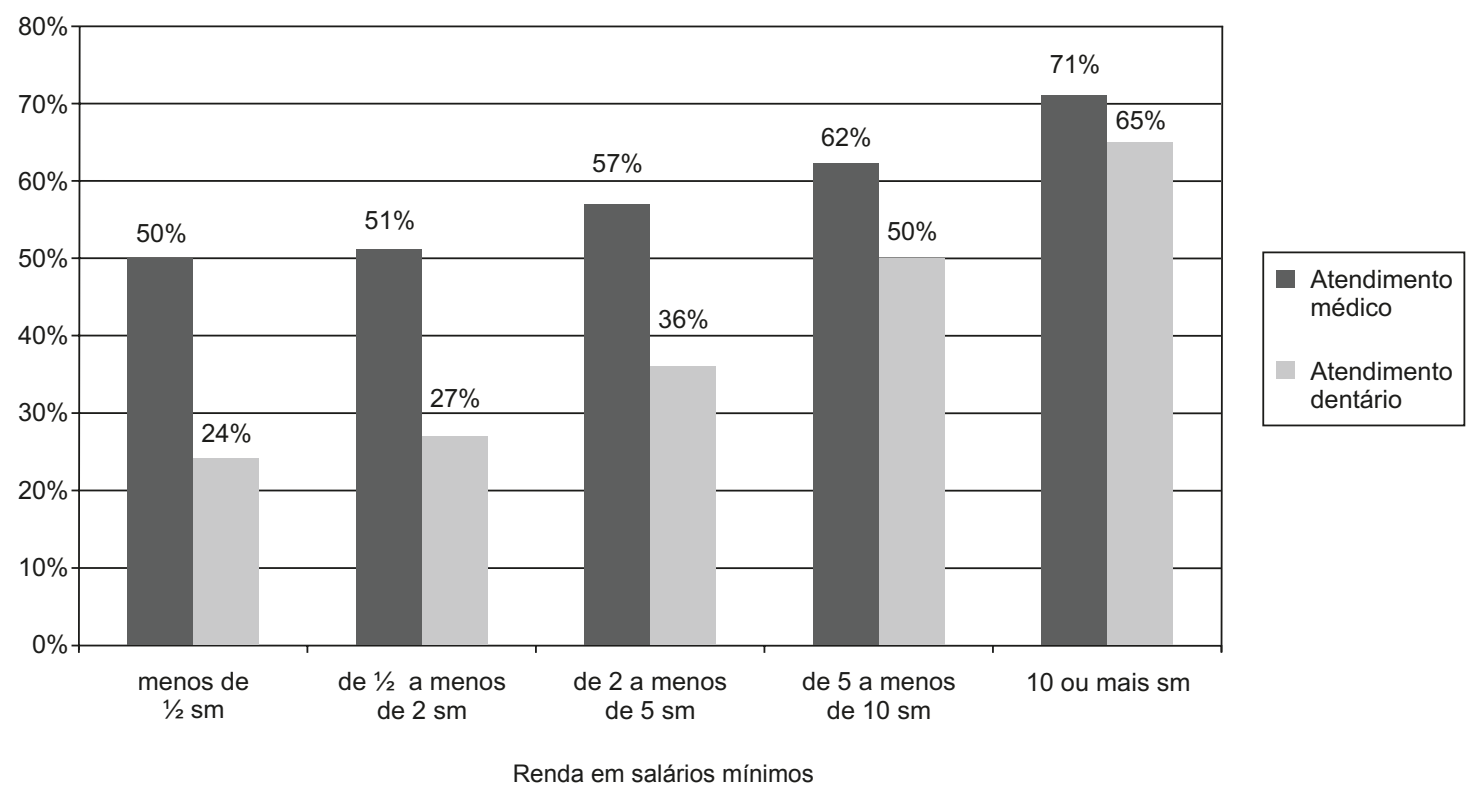

Fonte: Pesquisa Nacional por Amostra de Domicílios (Pnad), 2003.

Na literatura publicada nos últimos cinco anos, há um importante número de estudos dedicados a conhecer a influência destes diversos fatores no acesso e utilização dos serviços de saúde no Brasil.

Castro, Travassos e Carvalho (2005) procuraram identificar o efeito da oferta de serviços de saúde nas internações hospitalares para adultos e crianças, concluindo que a oferta não altera a associação entre a posição social e o uso de internações hospitalares no Brasil. Os autores encontraram que 97 a 99\% da variação na chance de internação são explicados por características do indivíduo, ou seja, apenas 1 a 3\% da variação do uso das internações pode ser atribuído a diferenças na oferta entre as unidades da federação.

Ao analisar o perfil dos indivíduos que procuraram os serviços de saúde nos últimos 15 dias, mas não conseguiram (acesso não realizado), Ribeiro et al. (2006) observaram maior dificuldade para aqueles com pior nível socioeconômico. As tentativas sem êxito de acesso aos serviços de saúde foram maiores entre os usuários do SUS, embora 11,2\% dos indivíduos com cobertura por planos de saúde também não tenham conseguido ser atendidos no mesmo período de referência, mostrando que a posse de planos de saúde não é suficiente para garantir o acesso. Segundo os autores, tal fato sugere que, pelo menos em parte, os problemas de acesso não se esgotam nas características socioeconômicas dos indivíduos, refletindo também problemas de oferta e organização dos serviços de saúde. 
Entretanto, os papéis das variáveis individuais e de necessidade têm se destacado nos estudos recentes. Análise dos dados da Pnad de 2003 revela que as pessoas da classe de maior renda com restrição de atividades rotineiras por motivo de saúde nos 15 dias que antecederam a entrevista têm 59,5\% mais chances de usar serviços de saúde do que aquelas da classe de menor renda. O mesmo efeito é observado em relação à escolaridade: entre os indivíduos com 9 ou mais anos de escolaridade a chance de uso é 20,9\% maior do que a das pessoas de menor escolaridade. Apesar da persistência de um padrão de marcadas desigualdades sociais no uso de serviços de saúde tanto para adultos quanto para as crianças, observa-se uma tendência de redução ao se comparar com as informações obtidas na Pnad de 1998 (Travassos, Oliveira \& Viacava, 2006).

A associação inversa entre renda e uso de serviços de saúde foi observada por Lima-Costa, Matos e Camarano (2006), ao comparar os grupos etários de 20-64 anos e 65 anos e mais, mostrando que as desigualdades sociais afetam igualmente adultos e idosos.

Estudo realizado na cidade de Pelotas mostra que o consumo de consultas médicas é fortemente influenciado pela renda. Indivíduos pertencentes às classes sociais A e B apresentam uma chance $13 \%$ maior de obter uma consulta nos três meses anteriores à entrevista quando comparados com aqueles das classes D e E (Capilheira \& Santos, 2006).

A clientela usuária do SUS é constituída, predominantemente, pela parcela da população de menor renda e baixa escolaridade. Ribeiro et al. (2006), analisando os dados da Região Metropolitana de São Paulo, mostra a presença de um gradiente inversamente proporcional entre as variáveis escolaridade e renda e o atendimento pelo SUS, que se mantém mesmo após o controle de outras variáveis. A chance de um indivíduo com até 3 anos de estudo usar o serviço público é quatro vezes maior do que aquele com 11 anos de estudo ou mais, enquanto naqueles pertencentes aos estratos mais baixos de renda a chance é dezenove vezes maior, quando comparados com os de maior renda.

Pessoto et al. (2007), analisando as desigualdades no uso de serviços de saúde entre o setor público e o setor privado na região metropolitana de São Paulo, mostram que os possuidores de planos de saúde, independentemente da renda, demandam mais serviços de saúde, quando comparados com aqueles sem plano de saúde. Além disso, o tempo médio de espera para consulta, indicador de qualidade no acesso aos serviços de saúde, é menor entre a população beneficiária dos planos de saúde.

Em relação ao tipo de serviço utilizado, os que possuem cobertura por planos de saúde procuram mais clínicas e consultórios, e somente 3,9\% usam as unidades de saúde do SUS, principalmente para vacinação e acesso a medicamentos cedidos pela rede pública. A parte da população usuária apenas do SUS procura mais prontos-socorros do que centros de saúde (duas vezes mais), sendo muito baixa a referência de uso de clínicas e consultórios. Estas desigualdades apontam para uma grande diferença entre a porta de entrada no sistema de saúde para a população usuária do SUS e os consumidores de planos de saúde. A maior 
procura por atendimento de urgência/emergência entre os usuários do SUS reflete menor oferta e/ou acesso à rede de unidades básicas (Ribeiro et al., 2006).

Com relação às diferenças regionais, o artigo de Travassos, Oliveira e Viacava (2006), já citado, comparando os dados dos dois últimos suplementos de saúde da Pnad (1998 e 2003), pode ser considerado o estudo-síntese da questão. Nele foi observado que as desigualdades geográficas no acesso aos serviços de saúde aumentaram no período estudado. Este aumento foi influenciado pela melhora do acesso nas regiões mais desenvolvidas, comparativamente com as menos desenvolvidas. Nos dois anos, as pessoas residentes nas regiões Sul e Sudeste, com restrição de atividades rotineiras por motivo de saúde nos 15 dias que antecederam a entrevista, apresentaram maiores chances de uso dos serviços de saúde do que as residentes nas outras regiões. A chance de uso de serviços na Região Norte foi quase a metade da observada nas regiões Sul e Sudeste (45\% menos chance). Já nas regiões Nordeste e Centro-Oeste as chances foram $40 \%$ e $23 \%$ menores, respectivamente. Na análise desagregada por regiões, persistiu o padrão de desigualdades, influenciadas particularmente pela renda e escolaridade. A Região Sul foi a que apresentou maiores desigualdades sociais. Os moradores do sul do país, e que pertencem à classe social mais alta, apresentaram chance $95 \%$ maior de uso de serviços quando comparados com os de renda mais baixa. Somente as regiões Sudeste e Norte não apresentaram diferenças significativas no uso de serviços por classe de renda, entretanto nestas regiões a escolaridade foi a variável mais associada com desigualdades.

Quanto à assistência à saúde das mulheres, o estudo de Novaes, Braga e Schout (2006), de base nacional, encontrou um gradiente de aumento do acesso ao exame de Papanicolau correspondente ao aumento da renda e da escolaridade, sendo a cobertura desse exame mais elevada nas mulheres de maior renda e escolaridade, quando comparadas às mulheres com renda inferior a um salário mínimo e aquelas analfabetas ou com primeiro grau incompleto. Quadros, Victora e Da Costa (2004), em Pelotas, encontraram que 70\% das mulheres analfabetas não realizaram exame de Papanicolau nos últimos três anos, enquanto apenas $11,8 \%$ das mulheres com doze ou mais anos de estudo não o fizeram. O estudo de Quadros, Victora e Da Costa (2004) também apontou para o menor conhecimento sobre o exame de Papanicolau entre as mulheres de menor escolaridade, com cerca de 30\% dessas mulheres demonstrando ausência de conhecimento sobre esse exame, enquanto que para as mulheres de melhor nível educacional esse valor foi inferior a 5\%. Pinho et al. (2003), em São Paulo, demonstraram menor retorno do resultado do exame de Papanicolau em mulheres de classe social mais baixa e menor escolaridade, revelando um pior seguimento dessas mulheres. Martins, Thuler e Valente (2005) apresentam extensa revisão bibliográfica sobre o tema.

Dois estudos recentes (Oliveira et al., 2006; Pereira et al., 2007) avaliaram desigualdades no diagnóstico e tratamento das lesões pré-malignas de câncer cervical. O primeiro estudo comparou mulheres de renda mais alta, atendidas em clínicas particulares e mulheres de baixa renda, atendidas no serviço público, encontrando que as mulheres de renda alta têm 
acesso mais rápido e mais fácil ao tratamento antes que se desenvolvam lesões pré-malignas. O segundo estudo identificou a prevalência de HPV (human papilomavirus) e outros fatores de risco para câncer cervical. Idade da primeira relação sexual, paridade, idade e tabagismo foram fatores associados, sendo que os mediadores para a progressão das lesões pré-malignas até o câncer foram a idade e o nível de escolaridade, comprovando a importância das desigualdades sociais na detecção e no desenvolvimento do câncer cervical.

Quanto aos exames para rastreamento do câncer de mama, três inquéritos nacionais (Leal et al., 2005; Novaes, Braga \& Schout; 2006; Lima-Costa \& Matos, 2007) avaliaram o acesso ao exame de mamografia em mulheres de diferentes faixas etárias e com diferentes intervalos de tempo (dois ou três anos). Todos encontraram coberturas abaixo do recomendado, com menor acesso em mulheres com menor escolaridade e nível econômico, seja ele medido pela renda ou pela classe social. Lima-Costa e Matos (2007) apontam para um progressivo aumento da realização da mamografia com o aumento da escolaridade e renda familiar per capita, independentemente de todas as demais variáveis consideradas no estudo, sendo essa associação ainda mais forte nas mulheres de 50 a 59 anos. Leal et al. (2005) e Novaes, Braga \& Schout (2006) afirmam que para o exame de mamografia, o gradiente observado segundo escolaridade e nível socioeconômico é ainda maior do que o observado em relação ao exame de Papanicolau, sendo a cobertura de $22 \%$ para mulheres com menos de quatro bens de consumo e de $75 \%$ para aquelas com oito ou mais (Leal et al., 2005). Todos os trabalhos demonstram iniqüidades no acesso a esse exame, associadas a menor escolaridade, poder aquisitivo do usuário e acesso a serviços de saúde.

Com relação a intervenções para contracepção, Vieira et al. (2001) avaliaram o uso de métodos contraceptivos no período 1986-1996, tomando por base dados da Pnad 1986 e da Pesquisa Nacional de Demografia e Saúde (PNDS) realizada em 1996. Encontraram maior proporção de laqueadura tubária nas mulheres de menor escolaridade (37,9\% em analfabetas para 26,0\% nas mulheres com mais de 12 anos de estudo). Padrão inverso foi observado na esterilização masculina, com aumento progressivo do uso desse método conforme aumento da escolaridade, passando de zero em parceiros de mulheres analfabetas a $13,7 \%$ entre os parceiros de mulheres com mais de 12 anos de estudo.

\section{Acesso à Informação}

Um determinante social da saúde, cuja importância nem sempre é reconhecida com o destaque que merece é o acesso à informação. De fato, o acesso a fontes e fluxos de informação em saúde aumenta o conhecimento e a capacidade de ação, permitindo a adoção de comportamentos saudáveis e a mobilização social para a melhoria das condições de vida. Em contrapartida, a falta de acesso de grandes setores da população ao conhecimento e à informação diminui significativamente sua capacidade de decidir e atuar em favor de sua saúde e da coletividade. As iniqüidades de informação são, portanto, especialmente graves, pois, ao reforçar a exclusão, têm o poder de gerar e ampliar outras iniqüidades (Pellegrini Filho, 2002). 
O acesso à informação em saúde está hoje grandemente facilitado pelas novas tecnologias de informação e comunicação (TIC), particularmente a Internet, as quais podem exercer uma grande influência sobre a situação de saúde e, em particular, sobre as iniqüidades em saúde, por meio de diversos mecanismos.

Em primeiro lugar, por sua capacidade de incidir sobre outros importantes determinantes da saúde, como as relações sociais, os processos culturais e outros aspectos fortemente relacionados com o bem-estar físico, mental e social. Em segundo lugar, as novas TIC estão redefinindo o próprio conceito de comunidade, liberando-a dos limites geográficos. As pessoas podem, hoje, estar em constante contato com seus familiares, amigos e colegas, através do mundo, utilizando telefones celulares, e-mails e outras tecnologias. Estas comunidades virtuais estão mudando a maneira como entendemos a criação e manutenção do capital social e, concretamente, podem oferecer importante apoio, principalmente para os que estão isolados pela idade, por deficiência física ou mesmo os que vivem em lugares demasiado distantes.

Em terceiro lugar, as TIC exercem um importante impacto sobre as iniqüidades em saúde, na medida em que permitem ampliar o acesso à informação por parte de grupos excluídos dos processos de tomada de decisões de qualquer tipo, trazendo como conseqüência seu "empoderamento", sua constituição como atores sociais e, em ultima instância, o fortalecimento da sociedade civil e do próprio processo democrático. As TIC permitem a esses grupos aumentar seu conhecimento dos problemas locais e globais, tomar decisões, estreitar suas relações com outros grupos e fortalecer sua organização e inserção em ações coletivas, aumentando a coesão e a cooperação para benefício mútuo.

Entretanto, todo este potencial das TIC está ameaçado se não se resolvem as iniqüidades de acesso a essas tecnologias, também chamadas de brecha digital ou digital divide. Segundo o Ibope/Netratings, no terceiro trimestre de 2007, os usuários de Internet no Brasil, apesar de um crescimento de cerca de $21 \%$ em relação ao ano passado, são atualmente cerca de 39 milhões, uma minoria da população total, que através deste meio consegue acesso a bens e oportunidades para ascender socialmente. Os Gráficos 29 e 30, confeccionados com dados da Pnad 2006, mostram as enormes desigualdades no acesso à Internet desde qualquer local (residência, trabalho, escola, cibercafé etc.), segundo escolaridade, renda e região de moradia, com gradientes que chegam a mais de 60 ou 70 vezes de diferença entre os dois grupos situados nos extremos de renda e escolaridade. 
Gráfico 29 - Percentual das pessoas que utilizaram a Internet, nos últimos três meses, na população de 10 anos ou mais de idade, por grandes regiões, segundo anos de estudo. Brasil - 2005

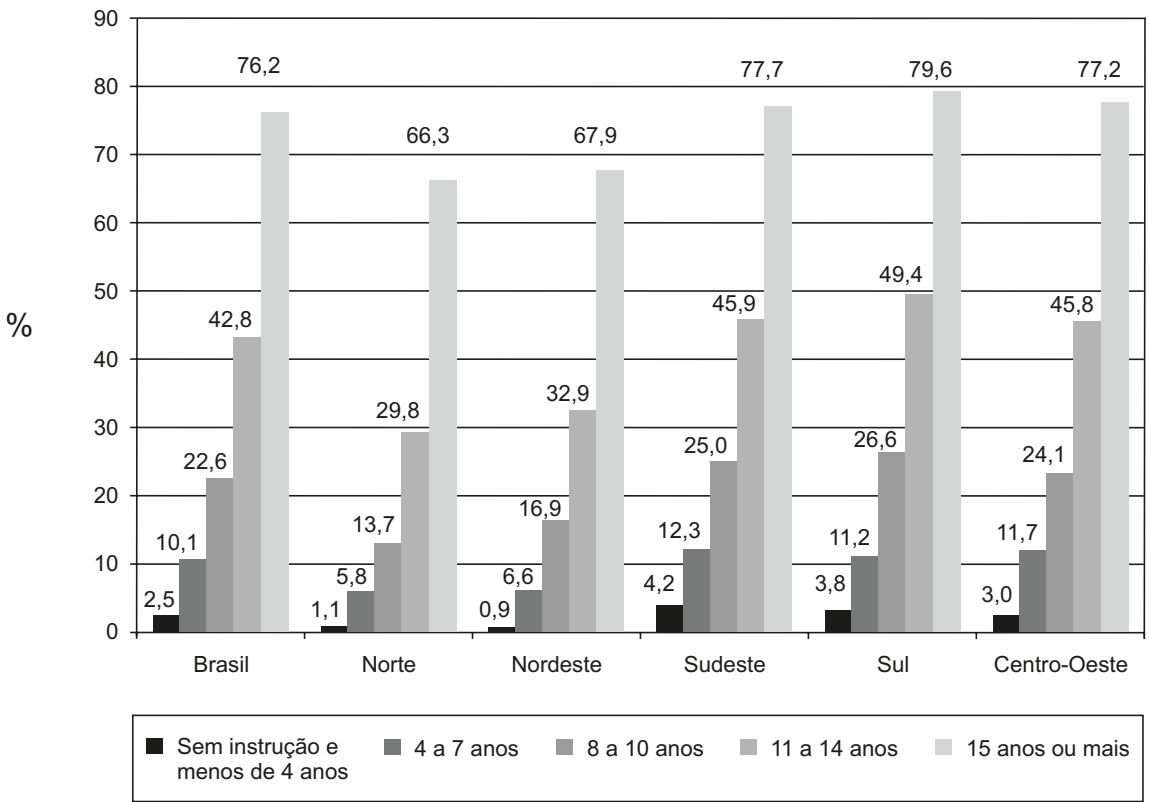

Fonte: Diretoria de Pesquisas, Coordenação de Trabalho e Rendimento, Pesquisa Nacional por Amostra de Domicílios 2005. Instituto Brasileiro de Geografia e Estatística (IBGE).

Gráfico 30 - Percentual das pessoas que utilizaram a Internet, nos últimos três meses, na população de 10 anos ou mais de idade, por grandes regiões, segundo o rendimento mensal domiciliar per capita. Brasil - 2005

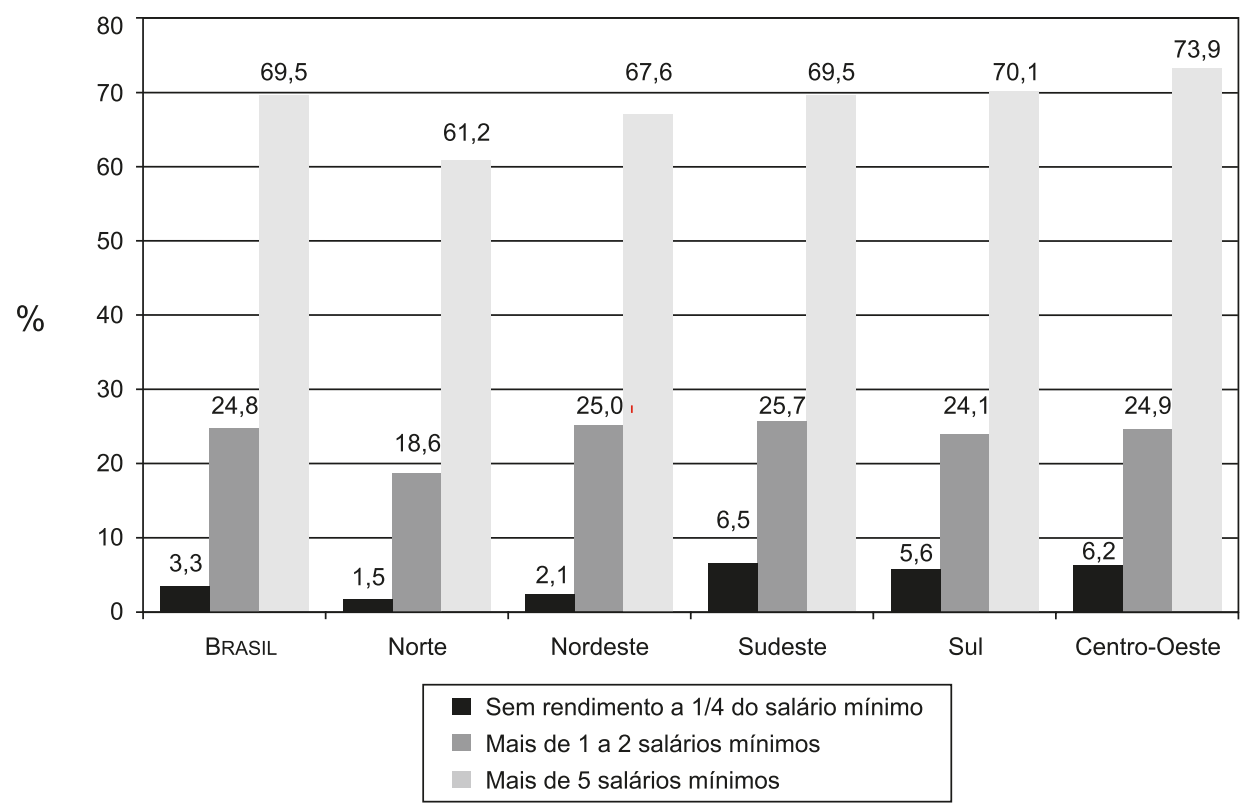

Fonte: Diretoria de Pesquisas, Coordenação de Trabalho e Rendimento, Pesquisa Nacional por Amostra de Domicílios, 2005. Instituto Brasileiro de Geografia e Estatística (IBGE). 
Segundo dados da comScore Networks (www.comscore.com), uma empresa dedicada a coletar dados para medir o avanço das tecnologias digitais, em janeiro de 2007, cerca de 747 milhões de pessoas maiores de 15 anos tinham acesso à Internet em todo o mundo, um aumento de $10 \%$ em relação ao ano anterior. Enquanto o trem e a eletricidade levaram décadas para difundir-se nos países em desenvolvimento, as TIC estão avançando nestes países a uma velocidade bem maior do que nos países desenvolvidos. Entre os 15 países com maior número de usuários, a Índia, a Rússia e a China foram os que tiveram maior incremento, (respectivamente, 33\%, 21\% e 20\%). O Brasil está em quinto lugar em percentual de crescimento, com 16\%. A China é, atualmente, o segundo país em acesso à Internet no mundo, com 86,8 milhões de usuários, atrás apenas dos Estados Unidos, que vem crescendo cerca de $2 \%$ ao ano, alcançando atualmente 153,4 milhões de usuários acima de 15 anos de idade, conforme mostra a Tabela 22.

Tabela 22 - Os quinze países com maior número de usuários de Internet acima de 15 anos de idade*

\begin{tabular}{l|ccc}
\hline \multicolumn{1}{c|}{ Países } & $\begin{array}{c}\text { Jan-06 } \\
(000)\end{array}$ & $\begin{array}{c}\text { Jan-07 } \\
(000)\end{array}$ & $\begin{array}{c}\text { \% de } \\
\text { Mudança }\end{array}$ \\
\hline TotAL MUNDIAL & 676.878 & 746.934 & $10 \%$ \\
\hline Estados Unidos & 150.897 & 153.447 & $2 \%$ \\
China & 72.408 & 86.757 & $20 \%$ \\
Japão & 51.450 & 53.670 & $4 \%$ \\
Alemanha & 31.209 & 32.192 & $3 \%$ \\
Reino Unido & 29.773 & 30.072 & $1 \%$ \\
Coréia do Sul & 24.297 & 26.350 & $4 \%$ \\
França & 23.712 & 24.560 & $33 \%$ \\
Índia & 15.867 & 21.107 & $11 \%$ \\
Canadá & 18.332 & 20.392 & $13 \%$ \\
Itália & 15.987 & 18.106 & $16 \%$ \\
Brasil & 12.845 & 14.964 & $4 \%$ \\
Espanha & 12.206 & 12.710 & $21 \%$ \\
Rússia & 10.471 & 12.707 & $3 \%$ \\
Holanda & 10.772 & 11.077 & $18 \%$ \\
México & 8.624 & & \\
& & 149 & \\
\hline
\end{tabular}

* Exclui acesso desde locais públicos como Internet e cafés ou desde telefone celular 
A própria revolução eletrônica pode contribuir para fazer desaparecer ou diminuir essas diferenças de acesso entre países e no interior dos mesmos. Para aumentar sua rede de comunicação, os países em desenvolvimento não precisam necessariamente reproduzir os mesmos caminhos e os grandes investimentos feitos pelos desenvolvidos. Podem, por exemplo, utilizar diretamente novas tecnologias por satélite, que exigem menos investimentos e manutenção e de fato o estão fazendo. Os telefones celulares permitem estender a comunicação a lugares onde os fios de cobre demorariam muitos anos para alcançar. Novos produtos de baixo custo, como minicomputadores que se ajustam à palma da mão, permitem o acesso à Internet em qualquer lugar e não seria absurdo imaginar que, em alguns anos, os estudantes de baixa renda poderão levá-los às escolas como fazem hoje com as calculadoras manuais que, até há não muito tempo, também tinham preços proibitivos.

Entretanto, o aproveitamento destas e outras oportunidades para superar o problema das iniqüidades de informação depende do estabelecimento de políticas explicitamente desenhadas para tal. Estas políticas devem basear-se no reconhecimento de que o conhecimento, a informação e a Internet são bens públicos e devem, portanto, ser objeto de políticas públicas.

O acesso à Internet está condicionado à existência e disponibilidade de uma infra-estrutura de tecnologia de informação e de telecomunicações. Para possibilitar o acesso a essa infra-estrutura, especialmente àqueles indivíduos que não contam com recursos próprios, é necessário o estabelecimento de uma política de inclusão digital por parte da esfera governamental que, entre outras estratégias, favoreça o acesso em espaços públicos como escolas, bibliotecas e quiosques. Além de facilitar o acesso, as políticas governamentais devem também promover a produção de informação de qualidade. Quando a "explosão da informação" se limita ao predomínio da quantidade sobre o conteúdo pode estimular a passividade dos sujeitos e comprometer o exercício de sua cidadania. Dessa forma, não é o acesso a mais bases de dados, a mais informações, nem a redes mundiais, que por si só irá proporcionar mais conhecimento, se essa informação não está estruturada para incentivar o raciocínio crítico que permite interpretá-la (Branco, 2006).

Segundo Eng et al. (1998), as causas responsáveis pelas diferenças de acesso à Internet estão relacionadas ao custo, barreiras geográficas, nível educacional, características culturais e outros fatores relacionados à capacidade das pessoas para usar serviços de maneira adequada. O autor classifica as barreiras de acesso em três grupos: as relacionadas com a infra-estrutura e hardware; as relacionadas com o tipo de informação e de software; as características dos próprios não-usuários. Para superar estas barreiras, sugere uma série de estratégias que buscam ampliar o acesso à informação e comunicação on-line em domicílios e lugares públicos, como o desenvolvimento de programas que tenham em conta a diversidade de potenciais usuários, apoio à pesquisa sobre temas relacionados ao problema do acesso, garantia da qualidade da informação, capacitação de usuários e de intermediários (entre estes, as organizações comunitárias não-governamentais) e, finalmente, a integração do conceito de acesso universal à informação como parte da política de saúde. 


\subsection{Redes Sociais, Comunitárias E SAúde}

As redes sociais e comunitárias, incluídas no modelo de Dahlgren e Whitehead entre os determinantes sociais da saúde, são constituintes do chamado capital social, entendido este como o conjunto das relações de solidariedade e confiança entre pessoas e grupos. Além do contato com amigos e parentes, diferentes formas de participação social como pertencer a grupos religiosos, associações sindicais, associações de moradores e clubes de recreação também representam formas pelas quais grupos de pessoas mantêm-se em contato e estabelecem vínculos sociais.

O desgaste do capital social é um importante mecanismo através do qual as iniqüidades socioeconômicas impactam negativamente a situação de saúde. Países com frágeis laços de coesão social resultantes dessas iniqüidades são os que menos investem em capital humano e em redes de apoio social e são também onde há menor participação na definição de políticas públicas. Diversos estudos mostram que não são as sociedades mais ricas as que possuem melhores níveis de saúde, mas as que são mais igualitárias e com alta coesão social. Nestas sociedades, as pessoas são mais envolvidas com a vida pública, vivem mais, são menos violentas e avaliam melhor sua própria saúde (Patussi, Hardy \& Sheiham, 2006).

Um importante indicador da riqueza do capital social são as relações de confiança entre as pessoas. Segundo dados da Pesquisa Social Brasileira (PSB), que realizou 2.363 entrevistas entre julho e outubro de 2002 (Almeida, 2007), as relações de confiança no Brasil são extremamente débeis, praticamente limitando-se à confiança em familiares. Como mostra a Tabela 23 , enquanto $84 \%$ das pessoas confiam na família, apenas $15 \%$ confiam na maioria das pessoas.

Tabela 23 - Relações de confiança no Brasil (\% de respondentes) - 2007

\begin{tabular}{l|ccccc}
\hline Resposta & $\begin{array}{c}\text { Confiança na } \\
\text { família }\end{array}$ & $\begin{array}{c}\text { Confiança } \\
\text { nos amigos }\end{array}$ & $\begin{array}{c}\text { Confiança } \\
\text { nos vizinhos }\end{array}$ & $\begin{array}{c}\text { Confiança } \\
\text { nos colegas } \\
\text { de trabalho }\end{array}$ & $\begin{array}{c}\text { Confiança na } \\
\text { maioria das } \\
\text { pessoas }\end{array}$ \\
\hline Não confia & 16 & 70 & 77 & 70 & 85 \\
Confia & 84 & 30 & 23 & 30 & 15 \\
\hline
\end{tabular}

Fonte: PSB in Almeida AC, 2007

A escolaridade está fortemente associada ao capital social. Segundo dados da mesma PSB, há uma enorme diferença entre os entrevistados que possuem nível superior completo e os que se encontram nas demais faixas de escolaridade. Como pode ser observado na Tabela 24, somando-se a confiança nos familiares e nos amigos, para os entrevistados com nível superior, essa proporção chega a 156\%, sendo que nas demais faixas varia de $96 \%$ a $114 \%$. 
Tabela 24 - Relações de confiança no Brasil, segundo escolaridade (\% de respondentes) - 2007

\begin{tabular}{l|c|c|c|c}
\hline \multirow{2}{*}{ Escolaridade } & \multicolumn{2}{|c|}{ Confiança na família } & \multicolumn{2}{c}{ Confiança nos amigos } \\
\cline { 2 - 5 } & Confia & Não confia & Confia & Não confia \\
\hline Analfabeto & 83 & 17 & 31 & 69 \\
Até a 4. série & 82 & 18 & 23 & 77 \\
Da 5. a 8. série & 78 & 22 & 21 & 79 \\
Ensino médio & 86 & 14 & 30 & 70 \\
Superior ou mais & 96 & 4 & 60 & 40 \\
\hline
\end{tabular}

Fonte: PSB in Almeida AC, 2007

Para se ter uma idéia da importância desses achados, Kawachi et al. (1999) estudaram a associação entre as relações de confiança e indicadores de saúde, comparando os diversos estados dos Estados Unidos. Verificaram uma forte associação $(r=.73)$ entre desigualdade de renda e falta de confiança social (social trust), observando que os estados com maior desigualdade de renda eram também aqueles nos quais houve maior proporção de entrevistados que concordaram com a afirmação: "a maioria das pessoas procurará tirar vantagem de você se tiver oportunidade" ("most people would try to take advantage of you if they got the chance"). Observaram também que os estados com altos níveis de falta de confiança entre as pessoas (social mistrust), expressa pela concordância com a frase mencionada, eram os que apresentavam as maiores taxas de mortalidade geral ajustada por idade $(\mathrm{r}=.77)$. Utilizando um modelo ecológico de regressão, esse autores observaram que as variações no nível de confiança social explicavam 58\% da variação da mortalidade geral entre os estados.

São poucos os estudos conduzidos na população brasileira que relacionam redes sociais e comunitárias com agravos em saúde, o que pode ser explicado, em parte, pela falta de domínio de metodologias adequadas para abordar estes objetos. A seguir, são apresentados os resultados de alguns desses estudos.

A relação entre autopercepção em saúde e a participação em atividades sociais, bem como a satisfação com redes sociais, foi estudada em 1.505 idosos em Bambuí (MG), no ano de 1997 (Lima-Costa, Firmo \& Uchôa, 2005). A distribuição da autopercepção em saúde foi de "boa/muito boa" (24,8\%), "justa" (49,2\%) e "ruim/muito ruim" (26,1\%). As análises foram conduzidas de acordo com dois estratos de renda: menor que $\mathrm{R} \$ 500,00$ e igual ou maior a $\mathrm{R} \$ 500,00$. As redes sociais investigadas foram: participação em atividades religiosas e freqüentar clubes e/ou associações. A pior autopercepção em saúde foi associada àqueles idosos insatisfeitos ou muito insatisfeitos com as suas redes sociais, tanto entre aqueles com baixa renda quanto entre aqueles com renda maior. Estes achados foram ajustados para idade, sexo, estilos de vida associados à saúde, doenças e acesso a serviços de saúde. 
Um estudo de Moraes, De Azevedo e Souza (2005) analisou os fatores associados ao envelhecimento bem-sucedido de idosos socialmente ativos da Região Metropolitana de Porto Alegre. O estudo permitiu concluir que a manutenção da independência para as atividades da vida diária, a autonomia e a satisfação com o relacionamento familiar e as amizades foram fatores preditivos independentes do envelhecimento bem-sucedido, tanto para homens como para mulheres.

Um estudo de base domiciliar, em comunidade rural da Zona da Mata de Pernambuco, com 483 adultos (maiores de 19 anos), investigou a associação entre transtornos mentais comuns e apoio social (Costa \& Ludermir, 2005). Casos suspeitos de transtornos mentais comuns foram identificados com a ajuda de um questionário padronizado auto-administrado Self Reporting Questionnaire (SRQ-20) e o apoio social foi avaliado pelo Medical Outcomes Study Questions - Social Support Survey (MOS-SSS) desenvolvido por Sherbourne e Stewart em 1985 (Sherbourne \& Stewart, 1991). Observou-se uma clara associação dos transtornos mentais comuns com o apoio social. Pessoas com baixo apoio social apresentaram maior prevalência de transtornos mentais comuns do que as com alto apoio social. 0 apoio social manteve-se associado aos transtornos mentais comuns mesmo após o ajuste por idade, escolaridade e participação no mercado de trabalho. Os resultados indicam a importância das redes de apoio social para diminuir a prevalência da doença mental, promovendo a interação dos indivíduos e aumentando a confiança pessoal e o poder de enfrentamento dos problemas. Duas hipóteses tentam explicar a ação do apoio social: uma assinala que o apoio social diminuiria os diferentes níveis de estresse (buffering hypothesis); outra considera que os relacionamentos que geram apoio promovem bem-estar mesmo na ausência de estresse (positive effects hypothesis) (Sherman, 2003).

De Antoni, Barone e Soller (2007) investigaram 20 famílias (pai, mãe e filhos) de baixo nível socioeconômico e com histórico de abuso físico parental. A pesquisa visou a conhecer a realidade dessas famílias e a forma como interagem em diferentes ambientes e contextos. Buscou-se, ainda, identificar e analisar indicadores de risco e de proteção em famílias denunciadas por abuso físico. Os indicadores de risco foram descritos como potencializadores da manifestação do abuso físico parental e os de proteção como aqueles que podem impedir ou amenizar a manifestação da violência. Foram identificados como indicadores de proteção de abuso físico parental algumas redes de apoio social e afetiva, valorização das conquistas e desejo de melhoria futura. Cerca de $60 \%$ das famílias pesquisadas citaram como indicadores de proteção a presença da rede de apoio social. A presença de graves e freqüentes indicadores de risco nas famílias pesquisadas pode revelar que o abuso físico é uma forma de manifestação da fragilidade dessas interações.

A associação entre autocuidado com a saúde, representado pela prática de auto-exame das mamas, considerado como um "comportamento marcador" do autocuidado entre mulheres e apoio social, foi investigada por Andrade et al. (2005). Apoio social incluiu cinco diferentes dimensões: material, emocional, afetivo, de informação e de interação positiva. Com este objetivo, 2.240 mulheres do Estudo Pró-Saúde (coorte de funcionários da Universidade do Estado do Rio de Janeiro, Uerj) foram investigadas, no ano de 1999. Observou-se que 44\% informaram realizar o auto-exame das mamas "todo mês" ou "quase todo mês"; 32\%, "às vezes"; e $24 \%$ informaram praticá-lo "raramente" ou "nunca". A chance de relatar prática 
mais freqüente de auto-exame das mamas foi cerca de duas vezes mais elevada entre as mulheres com maior apoio social, quando comparadas com as que contavam com menor apoio. Os resultados foram ajustados para idade, cor da pele/etnia, escolaridade, religião, local de trabalho e transtorno mental comum. Características específicas da população deste estudo, como elevada escolaridade e grande parcela constituída por funcionárias da área de saúde, podem explicar o fato de quase a metade das mulheres relatarem fazer auto-exame das mamas. Os autores sugerem a importância do apoio social no estímulo a práticas de autocuidado de saúde da mulher.

'Emponderamento' é considerado uma dimensão de capital social referente ao processo de interação social, que permite que pessoas aumentem suas habilidades individuais e coletivas, além de desempenharem maior controle sobre suas vidas. O nível de 'emponderamento' foi investigado em relação à ocorrência de cárie dental (Patussi, Hardy \& Sheihan, 2006), observando-se que a cárie dental foi menor em áreas com maiores níveis de 'emponderamento' em relação a áreas com menores níveis, após ajustes para variáveis demográficas, socioeconômicas, uso de flúor, consumo de açúcar, escovação dentária e acesso a cuidados odontológicos. Os autores destacam a importância do papel do 'emponderamento' como um potencial explicador nos níveis de cárie.

\subsection{Comportamentos, Estilos de Vida e Saúde}

Esta seção trata dos comportamentos e estilos de vida relacionados à saúde, que apesar de fortemente influenciados por fatores econômicos, culturais e outros, são entendidos como determinantes sociais proximais, por estarem mais próximos e passíveis de controle e modificação por parte dos indivíduos. De acordo com o Instituto Nacional do Câncer (Inca, 2006), os fatores relacionados a comportamentos e estilos de vida, como tabagismo, baixo consumo de frutas, de legumes e de verduras e consumo de álcool, são os principais determinantes de risco para morte por câncer em países de baixa e média renda. Estima-se que, nestes países, o tabagismo seja responsável por 18\% das mortes por câncer; o baixo consumo de frutas, legumes e verduras, por 6\%; o consumo de álcool, por 5\%. O câncer e outras doenças crônicas são resultado da exposição, ao longo da vida, a vários fatores de risco que, além de concomitantes, podem potencializar-se mutuamente, indicando a necessidade de ações de prevenção que levem em conta a simultaneidade destes fatores ao longo da vida. Esta seção está baseada na revisão da literatura recente sobre dieta, exercício físico, tabagismo e alcoolismo e sua distribuição entre os diversos grupos sociais.

\section{Dieta}

Segundo o Instituto Nacional do Câncer (Inca, 2006), a dieta é considerada como um dos fatores modificáveis mais importantes para o risco de doenças e agravos não-transmissíveis (Dant). De acordo com a Organização Mundial da Saúde (OMS), 80\% dos casos de doenças coronarianas, 90\% dos casos de diabetes tipo 2 e 30\% dos casos de câncer poderiam ser evitados com mudanças factíveis nos hábitos alimentares, níveis de atividade física e uso 
de produtos derivados do tabaco. Uma alimentação inadequada, rica em gorduras, com alimentos altamente refinados e processados, e pobre em frutas, legumes e verduras está associada ao aparecimento de diversas doenças como aterosclerose, hipercolesterolemia, hipertensão arterial, doença isquêmica do coração, infarto agudo do miocárdio, diabetes mellitus e câncer.

Estudos publicados nos últimos cinco anos buscam investigar a influência dos determinantes sociais sobre os hábitos alimentares.

O estudo de Sichieri, Castro e Moura (2003) mostra que o padrão de consumo alimentar é fortemente influenciado por renda e escolaridade, e que a região de moradia é a terceira variável explicativa, associada ao aspecto cultural do consumo. No Nordeste, predomina um padrão tradicional de consumo ("feijão e arroz") enquanto no Sudeste se observa um padrão misto, com a adição de alimentos industrializados e ricos em gorduras e açúcar, principalmente nas classes de maior escolaridade e renda. Jaime e Monteiro (2005), a partir dos dados da Pesquisa Mundial de Saúde (PMS), de 2003, encontraram consumo de frutas e verduras baixo no Brasil como um todo, observando que quanto maior a renda e a escolaridade maior o consumo destes alimentos. Na zona urbana, o consumo adequado de frutas e verduras é o dobro do que se verifica na zona rural.

Levy-Costa et al. (2005), analisando os dados da Pesquisa de Orçamentos Familiares (POF), de 2002/2003, mostram também um padrão transicional de consumo alimentar. Como característica positiva para todas as classes de renda, foi observado um aumento no consumo de proteínas de alto valor biológico; como características negativas, excesso de açúcar e insuficiência de frutas e hortaliças, além do consumo excessivo de gorduras em geral e saturadas. O limite máximo de consumo de açúcar (10\% das calorias totais) foi alcançado em todas as classes de renda, sendo o pior desempenho o das classes intermediárias (15\%). Para o consumo de gorduras, o limite máximo (30\%) foi alcançado a partir da faixa entre 2 e 5 salários mínimos, sendo que para as gorduras saturadas, o desempenho foi pior nas classes mais altas, que ultrapassaram o máximo de 10\% destes nutrientes na dieta.

Alves et al. (2006) definiram cinco tipos de padrão alimentar em mulheres do Rio Grande do Sul, sendo três padrões saudáveis e dois de risco (baixo custo e alto custo). As mulheres das classes C, D e E tiveram maior consumo de alimentos do padrão de risco de baixo custo, enquanto as das classes A e B tiveram maior consumo dos padrões saudáveis e do padrão de risco de alto custo. Os autores sugerem que o custo é um dos determinantes da escolha e consumo dos alimentos. Um estudo abordando, especificamente, a população adolescente de Pelotas, na faixa de 10-12 anos (Neutzling et al., 2007), identificou 11,6\% de obesidade, 83\% de baixo consumo de fibras e $33 \%$ de alto consumo de gorduras. A freqüência de consumo de dieta rica em gorduras foi mais alta nas famílias de classe social elevada e mães com maior escolaridade; de forma inversa, a alta escolaridade materna foi protetora para dieta pobre em fibras.

Um inquérito realizado pelo Inca (Inca, 2006) constatou que o consumo de frutas ou legumes ou verduras cinco vezes ou mais por semana foi superior a $50 \%$ em todas as capitais 
estudadas, embora em algumas delas o consumo de legumes e verduras seja muito baixo, como na Região Norte, onde menos de $25 \%$ da população consomem esses alimentos cinco vezes por semana. Quanto a diferenciais de consumo por gênero e escolaridade, as mulheres e os grupos com maior escolaridade apresentaram maiores percentuais de ingestão destes alimentos. Com relação à leitura das informações nos rótulos de alimentos embalados, os resultados deste estudo indicam que a população verifica a informação sobre prazo de validade (mais de $70 \%$ em 15 capitais), embora o mesmo não ocorra com a informação sobre o valor nutricional, o que pode ser explicado pelo fato de que este tipo de informação implica que o indivíduo tenha conhecimento prévio dos níveis adequados de nutrientes para avaliar a qualidade do produto. O sexo masculino, a população com mais de 50 anos e a de menor escolaridade apresentaram menor proporção de leitura das informações sobre prazo de validade e valor nutricional.

Com base nos resultados encontrados nesta pesquisa, os autores concluem que uma política de nutrição voltada para o incentivo de práticas alimentares saudáveis deve enfocar: o aumento do consumo de frutas, legumes e verduras, principalmente no Norte do país com especial atenção aos grupos de jovens, homens e adultos com menor escolaridade; 0 estímulo a estudos qualitativos e quantitativos sobre o consumo de legumes e verduras que permitam conhecer os fatores que interferem na seleção de alimentos; a redução do consumo de leite integral, de gordura visível da carne e de pele de frango; e a conscientização e instrumentalização dos usuários quanto à leitura de rótulos nas embalagens.

Claro et al. (2007) mostraram a participação direta da renda no padrão de consumo: a cada $1 \%$ no aumento da renda, observa-se um aumento de 0,04\% das frutas, legumes e verduras na composição da dieta; por outro lado, o decréscimo de $1 \%$ no preço destes produtos aumenta sua participação na dieta em $0,2 \%$. Este estudo aponta para a necessidade de políticas públicas voltadas para o barateamento dos alimentos saudáveis. É também interessante o estudo de Jaime et al. (2007), que mostrou, através de ensaio comunitário randomizado, que práticas de educação alimentar podem melhorar a qualidade da dieta, mesmo em populações de baixa renda, sugerindo uma estratégia factível para estas populações. Outras estratégias sugeridas são a utilização da mídia, a capacitação de professores e profissionais de saúde, as mudanças na alimentação escolar e as mudanças na regulamentação de produtos comerciais, conforme já vem sendo em parte adotado no país (Coitinho, Monteiro \& Popkin, 2002).

\section{Atividade Física}

Segundo a OMS (apud Inca, 2006), a prática de atividade física regular reduz o risco de mortes prematuras, doenças do coração, acidente vascular cerebral, câncer de cólon e mama e diabetes tipo II. Atua na prevenção ou redução da hipertensão arterial, diminui o risco de obesidade, auxilia na prevenção ou redução da osteoporose, promove bem-estar, reduz o estresse, a ansiedade e a depressão. Especialmente em crianças e jovens, a atividade física interage positivamente com as estratégias para adoção de uma dieta saudável, desestimula o uso do tabaco, do álcool, das drogas, reduz a violência e promove a integração social. O rápido crescimento das doenças crônicas associadas à inatividade física vem sendo registrado 
tanto nos países desenvolvidos como nos países em desenvolvimento, estimando-se que a inatividade física seja responsável por aproximadamente 2 milhões de mortes no mundo.

Monteiro et al. (2003) entrevistaram 11.000 pessoas do Nordeste e Sudeste do país, para avaliar a prática de atividade física no lazer (AFL). Os resultados mostraram que apenas 13\% dos entrevistados realizavam algum tipo de AFL e apenas 3,3\% cumpriam com o recomendado (30 minutos por cinco ou mais vezes na semana). Os determinantes mais importantes foram renda e escolaridade tanto para homens como para mulheres, sendo que no caso dos homens os autores encontraram maior freqüência de prática de AFL em áreas urbanas, não havendo diferença entre urbano e rural no caso das mulheres.

Vários estudos locais avaliaram fatores socioeconômicos e a prática de atividade física. Matsudo et al. (2002) relataram, para o estado de São Paulo, uma freqüência de 50\% de indivíduos ativos ou muito ativos, de acordo com o Questionário Internacional de Atividade Física (Ipaq). O sedentarismo foi maior nos extremos de classe social (A e E). No Rio de Janeiro, Salles-Costa et al. (2003) estudaram a AFL, em funcionários de uma universidade no estudo Pró-Saúde, observando um predomínio masculino na prática. A idade, a escolaridade e a renda familiar per capita estiveram diretamente associadas à prática de exercícios entre as mulheres e, entre os homens, essa associação positiva se deu com a renda familiar per capita. Os homens se engajaram mais em atividades físicas coletivas e de caráter competitivo e as mulheres em atividades individuais, que requerem menos força física.

Pitanga e Lessa (2005) estudaram atividade física em Salvador (BA), no ano de 2000, usando o mesmo instrumento Ipaq. As variáveis estudadas foram: sexo, idade, estado civil e escolaridade. Tanto para homens como mulheres a baixa escolaridade se mostrou diretamente associada com sedentarismo, com um efeito dose-resposta: fixando em 1 a freqüência de sedentarismo para as pessoas com alta escolaridade, esse valor foi de 1,43 para as de escolaridade média e 1,79 para as com baixa escolaridade. Masson et al. (2005) analisaram mulheres da cidade de São Leopoldo (RS), no ano de 2003. Foi encontrada uma prevalência de sedentarismo de $37 \%$, sem que se verificasse uma associação estatisticamente significativa com renda, escolaridade ou cor da pele. Dias-da-Costa et al. (2005) estudaram adultos de 20-69 anos na cidade de Pelotas em 2000 e relataram 80\% de inatividade física. Baretta, Barreta e Peres (2007) investigaram sedentarismo no município de Joaçaba (SC) e, ao contrário de outros estudos, encontraram associação com renda elevada.

Azevedo et al. (2007) estudaram a prática de AFL em Pelotas, observando que os homens tiveram maior AFL que as mulheres, com uma associação positiva do nível socioeconômico com esta prática em ambos os sexos. Uma associação dose-resposta positiva entre idade e inatividade física foi encontrada nos homens, mas não nas mulheres.

Em adolescentes de 10-12 anos em Pelotas, Hallal et al. (2006) relataram 58,2\% de sedentarismo. Oehlschlaeger et al. (2004), estudando esta mesma cidade, identificaram prevalência de sedentarismo maior nas classes sociais mais baixas, assim como uma relação inversa entre a escolaridade do adolescente e de sua mãe com o sedentarismo. 
Há uma série de lacunas do conhecimento com relação à importância dos determinantes sociais na prática da atividade física. Hallal et al. (2007), em uma recente revisão sistemática da literatura assinalam que, apesar do aumento da produção científica no Brasil acerca deste tema, não se encontram estudos de base nacional sobre o nível de atividade física no país. Esses mesmos autores encontraram muitas deficiências metodológicas, detectando, por exemplo, 26 diferentes definições operacionais de sedentarismo. Há, também, a necessidade de estudos que levem em conta variáveis de natureza qualitativa, como, por exemplo, as concepções acerca do ideal de corpo segundo o gênero, as quais influenciam comportamentos distintos de homens e mulheres no que se refere à prática de exercícios físicos. A superação dessas deficiências de conhecimento é imperativa para subsidiar a definição de políticas de conscientização e incentivo da atividade física, que devem ser diferenciadas e adequadas do ponto de vista sociocultural.

\section{Tabagismo e Alcoolismo}

O tabagismo é, hoje, amplamente reconhecido como doença crônica gerada pela dependência da nicotina, estando inserido na Classificação Internacional de Doenças (CID-10) da OMS. Segundo o Inca (2006), trata-se do mais importante fator de risco isolado de doenças graves e fatais, atribuindo-se ao consumo de tabaco 45\% das mortes por doença coronariana, $85 \%$ das mortes por doença pulmonar obstrutiva crônica, 25\% das mortes por doença cerebrovascular e 30\% das mortes por câncer. Cerca de 90\% dos casos de câncer de pulmão ocorrem em fumantes, e a mortalidade por este tipo de câncer entre fumantes é cerca de 15 vezes maior do que entre os não-fumantes. De acordo com essa mesma publicação, $90 \%$ dos fumantes começam a fumar antes dos 19 anos, sendo que 15 anos é a idade média de iniciação. Cem mil jovens começam a fumar no mundo a cada dia e $80 \%$ deles vivem em países em desenvolvimento.

Três trabalhos recentes foram realizados na cidade de Pelotas. O primeiro (Malcon, Menezes \& Chatkin et al., 2003) estudou adolescentes de 10-19 anos no período de 1999 a 2000. A prevalência de tabagismo foi $12 \%$, similar para os sexos feminino e masculino e os principais fatores associados foram: idade, irmãos e amigos fumantes e baixa escolaridade do adolescente. Em outro estudo (Menezes et al., 2006), foi investigada a coorte de nascimentos de 1993, ao chegar à faixa etária de 10-12 anos, para identificar os fatores de risco, dentre as dimensões socioeconômicas, culturais e comportamentais. Os resultados revelaram tendência linear para o nível socioeconômico: quanto mais baixo, maior a ocorrência de tabagismo precoce na adolescência, sendo duas vezes maior na classe D e três vezes maior na classe E, comparadas à classe A. Outros fatores importantes foram as relações familiares, sendo que viver com o pai biológico foi um fator protetor, enquanto relações ruins com a mãe aumentaram duas vezes a freqüência do evento. Violência familiar, consumo de álcool pelo adolescente e tabagismo materno (tanto na gravidez quanto durante os demais anos) também contribuíram de forma muito importante. Por último, na coorte de 1982, foram estudados os adolescentes do sexo masculino aos 18 anos (no momento do alistamento militar) e uma amostra de meninas, em 
2001 (Menezes, Hallal \& Horta, 2007). A freqüência de tabagismo diário foi de 15,8\% nos homens, sendo que 54,3\% haviam iniciado o hábito entre 13 e 15 anos e 11,5\% antes desta idade. Entre as mulheres, foi $15,4 \%$, com $47 \%$ das fumantes tendo iniciado entre os 13 e 15 anos e 18\% com início antes dos 13 anos. A determinação foi diferente nos sexos: os meninos cujas mães eram solteiras e aqueles com pai apresentando baixa escolaridade fumavam cerca de duas vezes mais; entre as meninas, o hábito foi seis vezes mais freqüente naquelas com famílias de baixa renda, comparadas às de alta renda. Também houve importante associação com mães que fumaram na gravidez e pais alcoólicos.

Um estudo realizado em Belém (PA), em 2005, incluindo apenas escolares menores de 19 anos, apontou prevalência de $11 \%$, sendo $14 \%$ na escola pública e $7 \%$ na privada (Pinto \& Ribeiro, 2007). Os fatores mais associados foram: curiosidade, amigos fumantes, ausência de recomendação para não fumar. Na escola privada, houve associação com classe mais elevada, enquanto na pública foi registrada maior prevalência naqueles com mau desempenho acadêmico. Estudos como este apresentam limitações quanto ao tipo de desenho (transversal) qua não permite relações de causalidade e quanto à base populacional de escolares, já que é lícito supor que os adolescentes que estão fora da escola estejam mais expostos a comportamentos de risco, entre eles, o tabagismo. Estas limitações fazem com que estes estudos não permitam estimar a real prevalência e a determinação deste hábito. Os estudos de coorte em Pelotas têm maior validade e as relações de associação com nível socioeconômico, renda e escolaridade são úteis e confiáveis para o enfrentamento do tabagismo em adolescentes.

Em relação à população adulta, Monteiro et al. (2007) estudaram as mudanças ocorridas na prevalência de tabagismo, tomando como base dois inquéritos nacionais (PNS, 1989 e PMS, 2003). Houve redução importante em todas as faixas etárias, em ambos os sexos e no meio urbano e rural. No entanto, observam-se desigualdades na intensidade da redução, de acordo com o poder aquisitivo e a escolaridade (Gráficos 31, 31.1 e 31.2). No caso do poder aquisitivo, o padrão foi semelhante em homens e mulheres: quanto menor a renda, menor a intensidade da redução; já para a escolaridade, as diferenças foram mais acentuadas nas mulheres: quanto menor a escolaridade, menor a redução. As mulheres com escolaridade igual ou menor de quatro anos apresentaram o dobro da prevalência de tabagismo, comparadas com aquelas com escolaridade entre 9 a 11 anos de estudo. Na verdade, as desigualdades se acentuaram em 2003, apesar do declínio em todas as categorias.

Peixoto, Firmo e Lima-Costa (2007) avaliaram a cessação do hábito de fumar em duas populações adultas (Bambuí, Belo Horizonte, MG). A escolaridade mostrou-se associada com maior freqüência de cessação apenas em Belo Horizonte, não tendo alcançado significância estatística em Bambuí. Em Belo Horizonte, também mostraram associação positiva a idade (maior de 40 anos) e o número de consultas. Em Bambuí, só foi observada associação positiva com a idade. 
Por último, em relação aos idosos, um estudo em Minas Gerais (Peixoto, Firmo \& LimaCosta, 2005) investigou a prevalência e os determinantes em pessoas com idade igual ou superior a 60 anos. Foi encontrada uma prevalência de 31,4\% entre os homens e 10,3\% entre as mulheres. Entre os determinantes, a escolaridade elevada (igual ou superior a 8 anos) mostrou-se protetora tanto para homens quanto para mulheres.

Gráfico 31 - Variação temporal na prevalência de tabagismo (> 18 anos), de acordo com o local de moradia. Brasil - 1989 - 2003

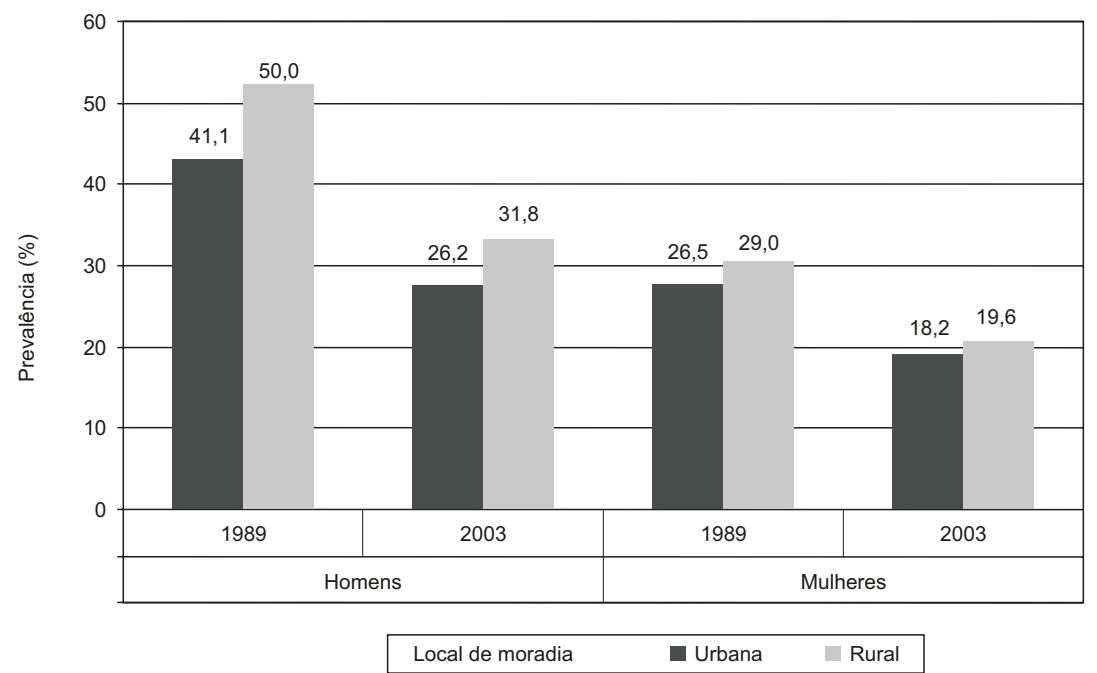

Fonte: Monteiro et al., 2007.

Gráfico 31.1 - Variação temporal na prevalência de tabagismo (> 18 anos), de acordo com os anos de estudo. Brasil - 1989 - 2003

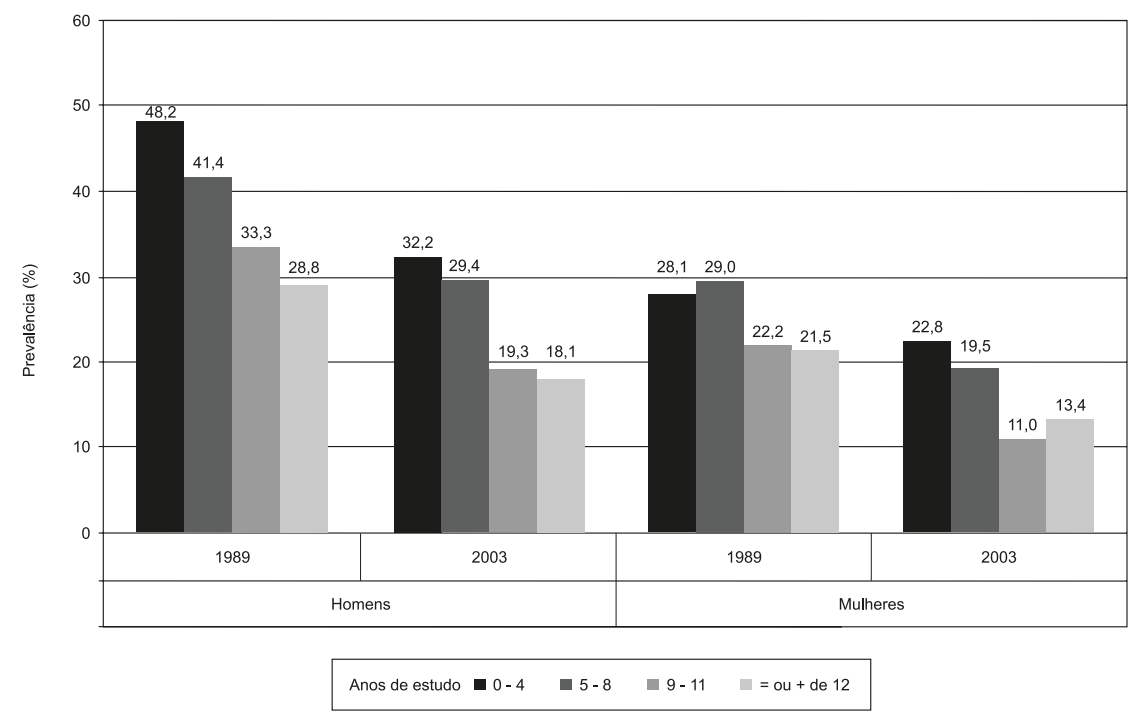

Fonte: Monteiro et al., 2007 
Gráfico 31.2 - Variação temporal na prevalência de tabagismo ( $>18$ anos), de acordo com o poder de compra do domicílio. Brasil - 1989 - 2003

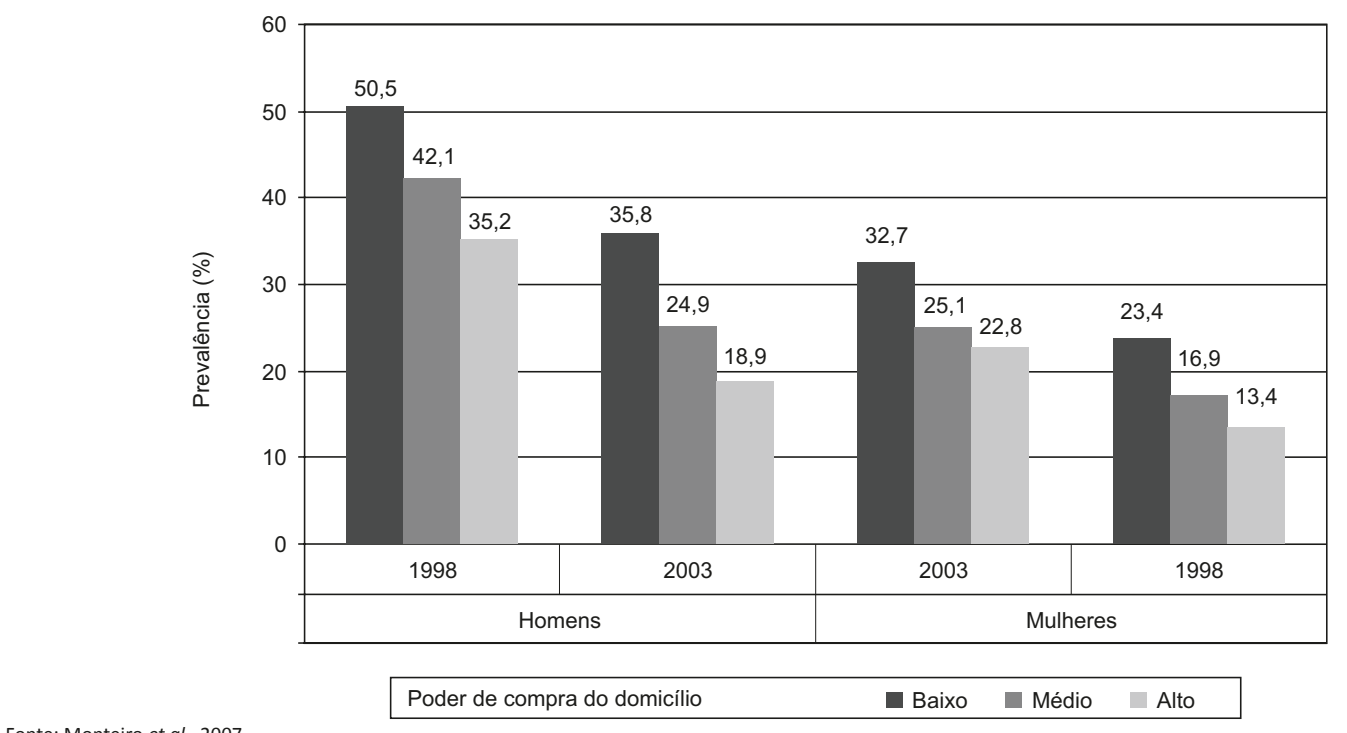

Fonte: Monteiro et al., 2007

O álcool, por sua vez, é uma das poucas drogas psicotrópicas que tem seu consumo admitido e incentivado pela sociedade. Segundo o Inca (2006), a mortalidade e a limitação da condição funcional associada ao consumo de bebidas alcoólicas superam aquelas associadas ao tabagismo. Calcula-se que, mundialmente, o álcool esteja relacionado a 3,2\% de todas as mortes e 6,2 \% das Disabilities Adjusted Life Year (DALY) dos países em desenvolvimento. Nas últimas décadas, o consumo de álcool vem aumentando no mundo todo, sendo que a maior parte deste aumento vem acontecendo em países em desenvolvimento. Embora o consumo moderado de determinadas bebidas alcoólicas possa trazer benefícios para a saúde, o consumo excessivo pode provocar cirrose, pancreatite, acidente cerebrovascular, demência, polineuropatia, miocardite, desnutrição, hipertensão arterial, infarto e certos tipos de cânceres, estando também intimamente associado a causas externas de morbimortalidade, como acidentes de trânsito e violência (WHO, 2007). A estas patologias, deve somar-se o impacto social e familiar do alcoolismo (Meloni \& Laranjeira, 2004), sendo também já bastante conhecida a associação do início precoce do alcoolismo com sua manutenção e severidade na vida adulta (Hingston, Heeren \& Winter, 2006; Bonomo et al., 2004).

Soldera et al. (2004) estudaram os alunos do curso fundamental e de ensino médio de Campinas, em 1998. As escolas foram classificadas em três categorias: públicas localizadas na periferia, públicas localizadas no centro e particulares. A média de idade foi de 15 anos, variando de 11 a 26 anos (os autores não informam o percentual de não adolescentes). A variável de interesse foi o alcoolismo pesado (consumo em 20 dos 30 dias anteriores ao inquérito). Os resultados mostraram uma prevalência de 15,9\% entre os meninos e 7,7\% entre as meninas. Considerando as escolas, o consumo pesado foi maior nas públicas centrais (14,8\%), seguidas das particulares (12,3\%) e das públicas periféricas $(8,6 \%)$. $\mathrm{Na}$ análise multivariada, o fator de maior associação positiva foi já estar trabalhando, 
enquanto o suporte dos pais foi protetor. As classes sociais A e B tiveram maior prevalência. A avaliação destes resultados fica, em parte, prejudicada pela inclusão de participantes maiores de 18 anos.

Souza, Areco e Silveira (2005) também valorizaram o trabalho como variável relacionada com alcoolismo. Avaliaram 2.718 estudantes das escolas públicas de Cuiabá, abrangendo a faixa etária de 10 a 20 anos, dos quais 993 trabalhavam e 1.725 não. Os trabalhadores tinham prevalência de consumo de álcool de $81 \%$, enquanto os não-trabalhadores de $65,8 \%$, sendo esta diferença estatisticamente significante. Na análise multivariada, os fatores associados para ambos os grupos foram: idade (maior nos de 15-20 anos), nível socioeconômico (maior nas classes A, B, C), história de consumo de álcool na família e não morar com os pais.

Em um estudo na Universidade de São Paulo (Silva et al., 2006), foram abordados adolescentes e adultos jovens (15-24 anos), matriculados nos cursos da área da Saúde. O consumo de álcool em qualquer momento nos últimos doze meses foi relatado por 84,7\% dos 926 participantes. Os fatores associados foram: renda familiar elevada e não praticar religião. Não houve análise multivariada neste estudo.

Em estudo sobre a gênese da dependência de drogas e álcool, De Micheli e Formigoni (2004) identificaram três grupos, de acordo com a intensidade do padrão de dependência. Pertencer à classe média baixa aumentou 3,5 vezes a chance de dependência, atraso escolar elevou 4,4 vezes e presença apenas da mãe no lar aumentou 22 vezes este comportamento.

Em inquérito realizado pelo Inca (2006), a prevalência de consumo de bebida alcoólica, nas 15 capitais brasileiras e no Distrito Federal, variou de 32,4\% a 58,6\%. Estas taxas são semelhantes às encontradas em outros países da América Latina, como Colômbia (59,8\%), Costa Rica (40,3\%), República Dominicana (55,0\%), Jamaica (32,0\%), México $(54,0 \%)$ e Panamá (54,2\%). A prevalência de consumo, no caso dos homens, variou de $48,9 \%$ a $72,1 \%$, enquanto que entre mulheres essa variação foi de $19,7 \%$ a $47,5 \%$, devendo-se observar que mesmo a maior taxa encontrada para mulheres $(47,5 \%)$ foi inferior à menor encontrada para homens.

Em sociedades desenvolvidas, principalmente os países europeus, essas diferenças de gênero não são tão evidentes, em torno de 10\% a 20\%. Nos países em desenvolvimento, essas diferenças são maiores, sendo que, na América Latina, essas diferenças variaram de $20 \%$ a $100 \%$, dependendo do país. Esta variação pode ser explicada pelo tipo de bebida consumida com mais freqüência. Em países onde o consumo de vinho é alto, como no Chile, as diferenças entre gênero não chegam a 30\% (68,7\% entre homens e 53,6\% entre mulheres). No México, onde cervejas e destilados são muito mais populares, o percentual de consumo entre o sexo masculino é praticamente o dobro do consumo entre o sexo feminino $(73,0 \%$ entre homens e $37,0 \%$ entre mulheres). Em Porto Alegre, na Região Sul, onde se concentra a produção vinícola do país, observou-se a menor diferença por gênero (40\%).

As diferenças por gênero costumam ser ainda mais marcantes quando se avalia o consumo de risco. Entretanto, as taxas desse indicador, neste estudo, ficaram entre 4,6\% e 11,1\%. Na Região Sul, apesar das taxas de consumo terem sido altas, em comparação às encontradas 
nas outras regiões, as taxas para consumo de risco encontraram-se entre as menores, o que deve estar relacionado às diferenças regionais no tipo de bebida consumida.

Um estudo, na cidade de Rio Grande (RS), realizado em 2000, utilizou o questionário AUDIT, que identifica alcoolismo e desordens no consumo de álcool (Mendoza-Sassi \& Beria, 2004). A prevalência de consumo de álcool foi $43 \%$, sendo $31 \%$ entre mulheres e $56 \%$ entre homens. A prevalência de desordens no consumo foi 7,9\% (2,5\% para as mulheres e 14,5\% para os homens). A análise multivariada para as desordens no consumo do álcool revelou predominância do sexo masculino e relação inversa com classe social. O tabagismo esteve fortemente associado, assim como desordens psiquiátricas menores. Esta última associação mostrou interação com o sexo, sendo bem mais intensa nas mulheres do que nos homens.

Almeida-Filho et al. (2004) realizaram inquérito domiciliar no município de Salvador (BA), com amostra de 2.302 adultos, para avaliar consumo de alto risco, definido como uso diário ou semanal mais episódios de embriaguez, além de qualquer uso de bebidas alcoólicas com embriaguez freqüente (pelo menos uma vez por semana). A prevalência anual de consumo de alto risco foi de $7 \%$, seis vezes maior entre homens do que entre mulheres. Foi encontrada uma associação positiva de prevalência de consumo de alto risco com educação e classe social. Nenhuma relação foi encontrada entre etnicidade e consumo de alto risco, porém bebidas como cachaça e destilados tiveram maior consumo entre pardos e pretos.

Um estudo em Pelotas (Dias-da-Costa et al., 2004), sobre consumo pesado de álcool (>30g/ dia), mostrou prevalência de $14,3 \%$ (29\% nos homens e 3,7\% nas mulheres). Na análise multivariada, foi observada associação do consumo pesado com: sexo masculino (prevalência dez vezes maior entre os homens), idade mais avançada (idade entre 60-69 cerca de 2,5 vezes maior que idade entre 20-29), cor da pele preta ou parda (duas vezes maior que branca), classe social (classe E cerca de 3 vezes maior que classe A), tabagismo (grandes fumantes 4,5 vezes maior que não-fumantes).

Outro aspecto importante, tanto em relação ao alcoolismo quanto ao tabagismo, é a relação destes hábitos com desigualdades sociais. Segundo relatórios da OMS (Monteiro et al., 2007), o tabagismo sofreu uma transição dos países desenvolvidos para aqueles em desenvolvimento, com projeção de aumento para 2020, quando se espera que, de cada dez mortes relacionadas ao tabaco, sete ocorram nestes países. No caso do alcoolismo, a relação é menos evidente; havendo mesmo associação do consumo de álcool com maior renda. Os padrões na distribuição das desigualdades sociais não são universais, podendo diferir por gênero, país, tipo de bebida e classificação de consumo de álcool (Bloomfield et al., 2006). Para os adolescentes, uma revisão sistemática na América Latina (Malcon, Menezes \& Chatkin, 2003) encontrou como principais fatores para o tabagismo: tabagismo entre irmãos e amigos, baixo desempenho escolar, idade, sexo masculino, trabalho remunerado e pais separados.

o enfrentamento destes importantes problemas de saúde depende do conhecimento do padrão de acesso e de consumo dos cigarros e das bebidas alcoólicas, principalmente entre os jovens. 
Para o tabagismo, ficam evidenciadas as desigualdades sociais no início, na redução e na cessação do hábito, em todas as faixas etárias e em ambos os sexos. O artigo de Monteiro et al. (2007), ao descrever o declínio ocorrido na prevalência de tabagismo no Brasil, ressalta o papel das campanhas e medidas adotadas pelo Ministério da Saúde. Tanto a educação da população em relação aos efeitos nocivos do tabaco quanto medidas coercitivas, em relação a preços, proibições de locais para fumo e publicidade, parecem ter efetividade.

Para o mesmo autor, no caso dos adolescentes, é importante atuar ainda mais intensamente em relação aos preços, já que os cigarros no Brasil têm um dos preços mais baixos do mundo. Como mostraram os estudos de Pelotas, os fatores familiares e socioculturais têm enorme influência na aquisição do hábito, requerendo estratégias centradas na família e a participação da escola e da comunidade. Os serviços de saúde devem contribuir com ações educativas em nível de atenção primária, envolvendo a comunidade e tendo o adolescente como alvo. Estes autores propõem ações conjuntas entre governo, entidades educacionais, família e sociedade como um todo.

No caso das mulheres, onde a redução tem sido mais lenta, as estratégias devem levar em conta o apelo estético, psicológico e "glamoroso" do tabagismo. A preocupação com o emagrecimento, o efeito ansiolítico e a aura de modernidade já se cristalizaram como "benefícios" do cigarro para as mulheres (Scarinci et al., 2007).

No caso das populações mais desfavorecidas, a questão do tabagismo é mais grave, pois além de serem mais atingidas, também sofrem mais com as conseqüências danosas do cigarro. A elevação dos preços é uma das medidas mais efetivas neste grupo.

Em pesquisa realizada em quatro capitais brasileiras (Rio de Janeiro, São Paulo, Recife e Porto Alegre), Gigliotti e Laranjeira (2005) mostraram que os fumantes brasileiros estavam motivados a cessar o hábito, com 85\% manifestando o desejo de parar de fumar. As razões estavam ligadas ao conhecimento dos malefícios do cigarro e a preocupações com tabagismo passivo e exemplo para os filhos. Apesar do número reduzido de entrevistados, os resultados são coerentes com o declínio observado no estudo de Monteiro et al. (2007), apontando a boa resposta da população às medidas contra o tabaco.

No caso do alcoolismo, a relação entre desigualdades sociais e adição ao hábito é menos evidente, havendo mesmo discordância entre os estudos quanto à relação entre alcoolismo e classe social (ou renda e escolaridade). Em alguns estudos, a relação é positiva e em outros é inversa. Uma possível explicação é a heterogeneidade de definições, instrumentos e pontos de corte para definir alcoolismo.

Apesar destas discordâncias, pode-se concluir que é necessária uma mínima renda para adquirir bebida alcoólica e, quanto maior a disponibilidade de renda, maior a facilidade do consumo. No entanto, comportamentos mais abusivos ou problemas relacionados com o consumo parecem ocorrer mais nas classes mais desfavorecidas, como mostrou o estudo de Pelotas, de Dias-da-Costa et al. (2004). 
Outro aspecto metodológico é a transversalidade dos estudos, o que limita a inferência de causalidade. Uma última questão se refere à abordagem da análise multivariada. No estudo de Dias-da-Costa et al. (2004), onde o nível socioeconômico foi adequadamente hierarquizado, encontrou-se uma relação inversa com o consumo pesado de álcool. Em outros estudos, onde não há essa adequada hierarquização, o efeito causal dos fatores socioeconômicos pode ser subestimado.

Parece estar bem estabelecida a colinearidade entre tabagismo e alcoolismo. Tanto o alcoolismo é facilitador do hábito de fumar quanto o tabagismo favorece o consumo de álcool.

No caso dos adolescentes, a questão do alcoolismo é bastante complexa, parecendo haver uma grande influência das relações familiares e do meio sociocultural. Existe grande diferença na atitude de 'experimentar' de acordo com as regiões (54\% no Sul e 9\% no Norte e Nordeste). Em relação ao uso regular, a cidade de Porto Alegre (RS) lidera com 15\%. Estas diferenças são explicadas tanto por fatores socioeconômicos quanto pelos hábitos culturais das diferentes nacionalidades que colonizaram o país (Pechansky, Szobot \& Scivoletto, 2004).

Outro aspecto importante, encontrado em vários estudos, foi a relação com o trabalho. Parece que o padrão de comportamento que mimetiza o do adulto, isto é, sair para trabalhar e ter renda própria, pode ser distorcido e reproduzir também o hábito do consumo de álcool.

Para a definição e aperfeiçoamento das estratégias de prevenção, deve-se ainda levar em conta o apelo publicitário em torno do hábito de beber, além de questões culturais e do caráter 'lícito' do consumo de álcool. A prevenção do uso de álcool dependeria, então, da revisão da legislação sobre propaganda de bebidas alcóolicas, cumprimento da legislação que proíbe a venda a menores, ações de saúde e educação para a população escolar adolescente, além de uma abordagem diferenciada para o suporte social e familiar.

\subsection{Saúde Materno-Infantil}

Esta seção consta de dois componentes. O primeiro deles analisa os determinantes da mortalidade na infância no Brasil, destacando entre eles a renda e a escolaridade da mãe. o segundo está baseado em uma revisão da literatura científica sobre diversos aspectos da saúde materno-infantil no Brasil.

\section{Alguns Determinantes da Mortalidade na Infância, no Brasil ${ }^{4}$}

A divulgação do Censo 2000 e das Pesquisas Nacionais por Amostra de Domicílios (Pnads), realizadas no início da presente década, tornaram possível a atualização das estimativas da mortalidade infantil e na infância, viabilizando maior confiabilidade e exatidão dos valores desses indicadores, ao permitir comparações com os derivados do censo de 1991.

É possível, então, refazer e atualizar as estimativas da mortalidade na infância e retomar análises realizadas em trabalho divulgado pela Opas/OMS (Simões, 2002), considerando, não mais as Pnads 1992 e 1999, mas os censos de 1991, 2000 e a Pnad 2005, tendo como controles a escolaridade da mãe e quintis de renda familiar per capita. 
Apesar de alguns avanços na cobertura das políticas públicas ao longo dos anos, ainda persistem fortes desigualdades econômicas e sociais no país, com reflexos negativos nas condições de vida de contingentes importantes de crianças, principalmente, aquelas residentes em áreas e regiões onde o desenvolvimento econômico não se deu na mesma intensidade daquele observado em áreas, como do Centro-Sul do país. A reprodução de estruturas sociais, nas quais a pobreza é predominante, situação típica da Região Nordeste, continua tendo fortes impactos nas precárias condições de vida e de saúde das crianças, refletindo-se nos indicadores de mortalidade infantil e na infância que permanecem elevados, apesar da tendência de declínio observada nos anos mais recentes.

É bem verdade que, a situação social e de saúde dessas crianças poderia estar pior, caso não se estivesse verificando no país uma profunda transformação no padrão demográfico, com impactos nas estruturas etárias. Estas alterações vêm agindo no sentido de reduzir a proporção de crianças menores de 5 anos, sendo, portanto, um facilitador na solução de um conjunto de problemas, a exemplo das questões relacionadas à saúde infantil e na infância, ao elevar os níveis de sua sobrevivência, particularmente nos estratos sociais mais carentes e em regiões menos desenvolvidas.

Indispensável mencionar que os dados de mortalidade fornecem elementos de suma importância no conhecimento dos níveis de saúde da população, além de proverem subsídios para o planejamento das ações das políticas de atenção à saúde dos distintos segmentos populacionais.

A mortalidade na infância ${ }^{5}$ tem sido utilizada como um bom indicador de avaliação das condições de saúde e de vida da população. Em sua fase mais recente (1990/2005), a mortalidade na infância, no Brasil, passa de 53,7 óbitos de menores de 5 anos por 1.000 nascidos vivos, para 28,8\%, ou seja, um decréscimo de 46,4\% (Tabela 25 e Gráfico 32).

Tabela 25 - Taxa de mortalidade na infância, segundo região. Brasil - 1990, 1991, 2000, 2005

\begin{tabular}{l|ccccc}
\hline \multicolumn{1}{c|}{ Região } & 1990 & 1991 & 2000 & 2005 & $\begin{array}{c}\text { Diferença } \\
\text { relativa (\%) }\end{array}$ \\
\hline BRASIL & 53,7 & 50,6 & 35,1 & 28,8 & $-46,4$ \\
Norte & 52,9 & 49,9 & 34,1 & 28,3 & $-46,5$ \\
Nordeste & 87,3 & 81,6 & 50,9 & 38,9 & $-55,4$ \\
Sudeste & 36,6 & 34,7 & 25,3 & 19,2 & $-47,5$ \\
Sul & 35,2 & 33,3 & 22,0 & 18,1 & $-48,8$ \\
Centro-Oeste & 41,0 & 38,7 & 26,2 & 22,6 & $-44,8$ \\
\hline
\end{tabular}

Fonte: Censos Demográficos, 1991-2000 e Pesquisa Nacional por Amostra de Domicílios (PNAD), 2005. Instituto Brasileiro de Geografia e Estatística (IBGE).

${ }^{5} \mathrm{~A}$ taxa de mortalidade na infância (menores de 5 anos) é definida como o número de óbitos de menores de cinco anos de idade, por mil nascidos vivos, em determinado espaço geográfico, no ano considerado. Estima o risco de morte dos nascidos vivos durante os cinco primeiros anos de vida. 
Apesar dos avanços alcançados no indicador, persistem, ainda, profundos contrastes regionais. Durante o período, a Região Nordeste apresentou declínios na mortalidade na infância de aproximadamente 55\%, ou seja, 10 pontos percentuais acima da média nacional. Todavia, merece consideração ressaltar que o valor da taxa, nessa região, em 2005 (38,9\%), ainda representa o dobro da observada para as regiões Sudeste e Sul do país, significando uma melhoria, tendo em vista que, em 1990, essa relação era de 2,5.

Chamam também a atenção os valores da mortalidade na infância da Região Norte, cujos índices são levemente inferiores à média nacional. Esta tem sido, inclusive, uma tendência que se vem notando historicamente e, provavelmente, está correlacionada a fatores positivos decorrentes não só da existência de uma economia de subsistência na área, mas também do fluxo importante de migrantes oriundos do Sul do país, que já apresentavam um padrão de mortalidade relativamente baixo, na época de seu deslocamento para a região.

Gráfico 32 - Mortalidade na infância, segundo região. Brasil - 1990, 1991, 2000, 2005

(\%)

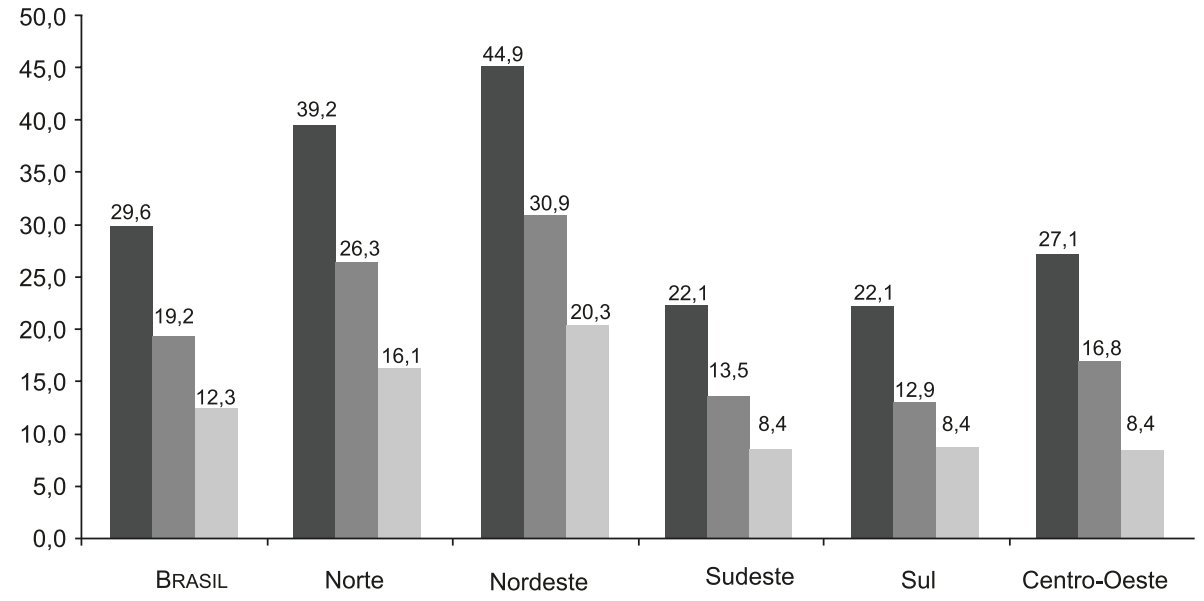

Fonte: Censos Demográficos, 1991-2000 e Pesquisa Nacional por Amostra de Domicílios (PNAD), 2005 Instituto Brasileiro de Geografia e Estatística (IBGE).

Vale apontar também a similaridade entre as taxas de mortalidade na infância das regiões Sudeste, Sul e Centro-Oeste, com valores em torno de $20 \%$. Portanto, se considerarmos a classificação da OMS, essas regiões e, em decorrência, seus estados, já se enquadram na categoria de baixa mortalidade.

As desigualdades educacionais e de renda na mortalidade na infância

Nos estudos dos diferenciais, a educação da mãe tem sido uma das principais variáveis socioeconômicas que tem originado impactos altamente positivos na redução dos índices de mortalidade infantil e na infância, em decorrência da maior percepção que a mãe adquire no trato e cuidado da saúde dos filhos. 
Apesar dos avanços alcançados nos últimos anos na inserção de novas gerações no sistema escolar, quando se considera o grupo de mulheres em idade fértil (15 a 49 anos) verificase que, em algumas regiões, ainda é bastante elevada a proporção dessas mulheres com baixa escolaridade (Tabela 26 e Gráfico 33). Trabalhando com o conceito da Unesco sobre analfabetismo funcional (menos de 4 anos de instrução), constata-se que a Região Nordeste apresenta, historicamente, as mais elevadas proporções de mulheres nesta categoria, cujos valores, que eram de 44,9\% em 1991, vêm declinando ao longo dos anos (39,1\%, em 2000, e 20,3\%, em 2005). Ou seja, no período 1990/2005, ocorre uma redução de 54,8\%, na proporção de mulheres de 15 a 49 anos analfabetas funcionais, similar à média nacional. Entretanto, é importante destacar que, considerando o país como um todo, essa proporção, em 2005, era de $12,3 \%$, sendo que as regiões Sul, Sudeste e Centro-Oeste apresentam valores bem abaixo desse parâmetro (8,4\%). Na Região Norte, esse valor - 16,1\% - é levemente inferior ao observado no Nordeste $(20,3)$.

Tabela 26 - Proporção de mulheres em idade fértil (15 a 49 anos) por anos de estudo, segundo região. Brasil - 1991, 2000, 2005

\begin{tabular}{|c|c|c|c|c|}
\hline \multirow{2}{*}{ Região } & \multirow{2}{*}{ TOTAL } & \multicolumn{3}{|c|}{ Anos de estudo da mulher } \\
\hline & & Menos de 4 & 4 a 7 & 8 ou mais \\
\hline \multicolumn{5}{|c|}{1991} \\
\hline BRASIL & 100,0 & 29,6 & 35,3 & 35,1 \\
\hline Norte & 100,0 & 39,2 & 33,4 & 27,4 \\
\hline Nordeste & 100,0 & 44,9 & 28,9 & 26,3 \\
\hline Sudeste & 100,0 & 22,1 & 37,1 & 40,8 \\
\hline Sul & 100,0 & 22,1 & 41,4 & 36,5 \\
\hline Centro-Oeste & 100,0 & 27,1 & 36,4 & 36,5 \\
\hline \multicolumn{5}{|c|}{2000} \\
\hline BRASIL & 100,0 & 19,2 & 32,0 & 48,8 \\
\hline Norte & 100,0 & 26,3 & 33,5 & 40,2 \\
\hline Nordeste & 100,0 & 30,9 & 31,8 & 37,3 \\
\hline Sudeste & 100,0 & 13,5 & 30,8 & 55,7 \\
\hline Sul & 100,0 & 12,9 & 34,4 & 52,7 \\
\hline Centro-Oeste & 100,0 & 16,8 & 33,4 & 49,8 \\
\hline \multicolumn{5}{|c|}{2005} \\
\hline BRASIL & 100,0 & 12,3 & 24,8 & 62,9 \\
\hline Norte & 100,0 & 16,1 & 26,8 & 57,0 \\
\hline Nordeste & 100,0 & 20,3 & 28,0 & 51,7 \\
\hline Sudeste & 100,0 & 8,4 & 22,1 & 69,4 \\
\hline Sul & 100,0 & 8,4 & 25,1 & 66,4 \\
\hline Centro-Oeste & 100,0 & 8,4 & 25,1 & 66,4 \\
\hline
\end{tabular}

Fonte: Censos Demográficos, 1991-2000 e Pesquisa Nacional por Amostra de Domicílios (Pnad), 2005. Instituto Brasileiro de Geografia e Estatística (IBGE). 
Gráfico 33 - Mulheres de 15 a 49 anos analfabetas funcionais (menos de 4 anos de estudo), segundo região. Brasil - 1991, 2000, 2005

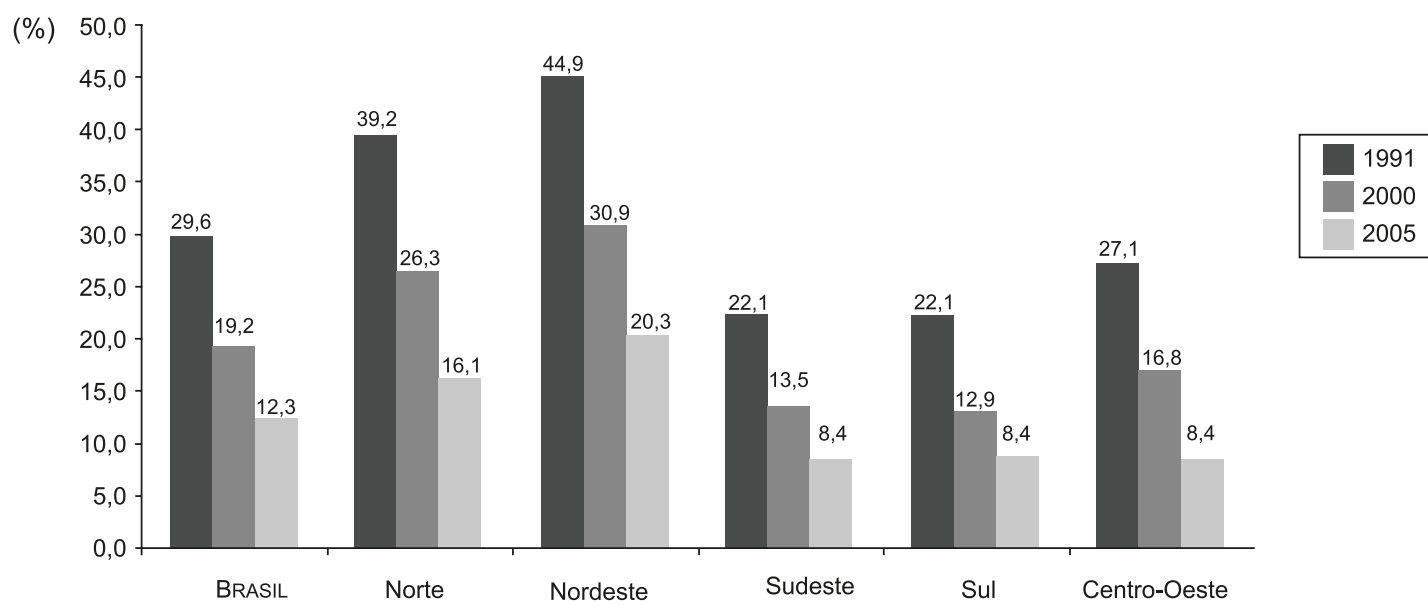

Fonte: Censos Demográficos, 1991-2000 e Pesquisa Nacional por Amostra de Domicílios (PNAD), 2005

Instituto Brasileiro de Geografia e Estatística (IBGE).

O esperado é que a melhora nos indicadores educacionais, notada em todas as regiões brasileiras, durante os últimos 15 anos, tenha repercutido positivamente nos níveis da mortalidade na infância. Este fato é plenamente comprovado com os resultados apresentados na Tabela 27. Existe uma relação inversa entre o nível de educação da mãe e a mortalidade na infância, ou seja, à medida que aumenta a escolaridade materna, diminui de forma intensa a mortalidade de menores de 5 anos. Nesse sentido, para o Brasil como um todo, em 1990, esta mortalidade, que era de $89,7 \%$ em crianças cujas mães tinham menos de quatro anos de instrução, se reduz para 30,3\%, em crianças com mães com nível de instrução superior a oito anos, representando um diferencial de 196,6\%. Este valor é um forte indicativo de que as desigualdades entre os estratos sociais no que diz respeito à mortalidade na infância, no início da década de 1990, eram extremamente elevados.

A Região Nordeste se destacava como a área onde a mortalidade na infância, de filhos de mulheres analfabetas funcionais era a mais elevada dentre as regiões brasileiras, com cifras superiores a $120 \%$, mais que o dobro do estimado, para o mesmo estrato nas demais regióes.

Durante o período foco da análise, 1990/2005, constatam-se quedas nos diferenciais de mortalidade entre os estratos sociais, principalmente, no caso específico da Região Nordeste, decorrentes, possivelmente, da melhora do nível educacional das mulheres em idade fértil, que, durante os últimos 15 anos, acarretou reduções acentuadas na proporção de mulheres enquadradas na categoria de analfabetas funcionais.

Entretanto, a situação continua sendo ainda preocupante nessa região, que permanece apresentando as taxas de mortalidade na infância mais elevadas para crianças com mães de 
baixa instrução. Em 2000, os valores se situavam em 70 óbitos de menores de 5 anos por 1.000 nascidos vivos, o dobro do observado para as regiões Sudeste e Sul. Entre 2000 e 2005, verificase redução nessas diferenças - 56\% contra 30\%, em média - reflexo, provável, de um conjunto de programas que vem sendo implementado no país, particularmente na Região Nordeste.

Tabela 27 - Taxa de mortalidade na infância por anos de estudo da mãe, segundo região. Brasil - 1990, 2000, 2005

\begin{tabular}{|c|c|c|c|c|c|}
\hline \multirow{2}{*}{ Região } & \multirow{2}{*}{ TOTAL } & \multicolumn{3}{|c|}{ Anos de estudo da mãe } & \multirow{2}{*}{ Razão a/b } \\
\hline & & Menos de 4 (a) & 4 a 7 & 8 ou mais (b) & \\
\hline \multicolumn{6}{|c|}{1990} \\
\hline BRASIL & 53,7 & 89,7 & 47,6 & 30,3 & 2,9 \\
\hline Norte & 52,9 & 66,1 & 51,8 & 32,9 & 2,0 \\
\hline Nordeste & 87,3 & 123,5 & 75,8 & 39,9 & 3,1 \\
\hline Sudeste & 36,6 & 56,6 & 34,9 & 22,3 & 2,5 \\
\hline Sul & 35,2 & 57,5 & 33,5 & 18,8 & 3,0 \\
\hline Centro-Oeste & 41,0 & 59,5 & 36,2 & 20,7 & 2,8 \\
\hline \multicolumn{6}{|c|}{2000} \\
\hline BRASIL & 35,1 & 53,7 & 31,5 & 22,9 & 2,3 \\
\hline Norte & 34,1 & 45,6 & 30,0 & 23,4 & 1,9 \\
\hline Nordeste & 50,9 & 70,2 & 41,7 & 28,8 & 2,4 \\
\hline Sudeste & 25,3 & 35,4 & 27,9 & 18,0 & 1,9 \\
\hline Sul & 22,0 & 33,5 & 22,3 & 16,3 & 2,0 \\
\hline Centro-Oeste & 26,2 & 38,1 & 25,2 & 19,4 & 1,9 \\
\hline \multicolumn{6}{|c|}{2005} \\
\hline BRASIL & 28,8 & 39,9 & 25,8 & 18,4 & 2,1 \\
\hline Norte & 28,3 & 37,9 & 24,9 & 18,7 & 2,0 \\
\hline Nordeste & 38,9 & 56,2 & 31,9 & 20,3 & 2,7 \\
\hline Sudeste & 19,2 & 30,2 & 21,2 & 13,7 & 2,2 \\
\hline Sul & 18,1 & 29,2 & 18,3 & 13,3 & 2,2 \\
\hline Centro-Oeste & 22,6 & 33,5 & 21,7 & 16,7 & 2,0 \\
\hline
\end{tabular}

Fonte: Censos Demográficos, 1991-2000 e Pesquisa Nacional por Amostra de Domicílios-PNAD, 2005. 
Apesar dessas melhorias e das conseqüentes reduções nas desigualdades da mortalidade na infância entre o Nordeste e as demais regiões, principalmente neste estrato social específico, há que ressaltar que uma taxa de mortalidade na infância daquela magnitude não deixa de ser inquietante. É importante destacar também as diferenças inter-regionais relativamente baixas entre os níveis de mortalidade na infância no estrato de maior escolaridade. A mortalidade um pouco mais elevada no Nordeste, de certo modo, leva à conclusão de que existem outros fatores, além da educação, que podem estar explicando essa maior mortalidade. Tais fatores podem estar relacionados, por exemplo, às precárias condições socioambientais ainda prevalecentes na região, com fortes impactos sobre as condições de sobrevivência das crianças, mesmo daquelas pertencentes a estratos não tão carentes.

A mesma situação de desigualdade na sobrevivência de crianças se repete quando se considera o impacto de outra variável socioeconômica importante, como é o caso da renda (Tabela 28 e Gráfico 34). Esta variável, quando desagregada por quintis de renda familiar per capita, mostra que a mortalidade na infância é sempre superior para os quintis de renda familiar per capita mais pobre. De modo geral, nota-se que as diferenças entre os três primeiros quintis de renda familiar per capita são pequenas, acentuando-se nos dois últimos quintis, independentemente da unidade espacial analisada.

Ao longo dos últimos 15 anos, verifica-se uma clara tendência de queda da mortalidade na infância em todos os quintis de renda, independentemente da região. Na média nacional, a mortalidade na infância associada ao primeiro quinto era de $72,7 \%$, em 1990, caindo para $40,7 \%$ em 2000 e 33,9\% em 2005. Ou seja, uma queda de aproximadamente $114 \%$. Este fato vai se refletir positivamente na comparação entre o primeiro e último quintis de renda. A diferença, que era de 126\% em 1990, cai para 96\% em 2005.

A Região Nordeste, como esperado, apresenta as maiores taxas de mortalidade na infância em todos os quintis de renda, particularmente, no primeiro quinto, embora a tendência histórica seja também de queda no decorrer dos anos. Se, em 1990, a taxa era de 107,6\%, em 2000 declinou para $64 \%$ e em 2005 para $56,4 \%$. É importante destacar que, ao se comparar esse estrato com o das regiões do Centro-Sul, constata-se diminuição nos diferenciais, no decorrer dos anos.

Tem-se uma visão da tendência da mortalidade na infância, comparando o primeiro com o último quinto de renda familiar per capita. Fica clara a tendência de queda, mas se destaca o último estrato da Região Nordeste, onde a mortalidade na infância, em 2005, não é das mais baixas (24\%) quando comparada com a das regiões do Centro-Sul, que apresentam valores levemente superiores a $10 \%$, reflexo do maior desenvolvimento social e econômico dessas áreas e, conseqüentemente, da oferta mais elevada de serviços, seja de saúde, educação, saneamento e outros. 
Tabela 28 - Taxa de mortalidade na infância, por quintis de renda familiar per capita, segundo região. Brasil - 1990, 2000, 2005

\begin{tabular}{|c|c|c|c|c|c|c|c|}
\hline \multirow[b]{2}{*}{$\begin{array}{c}\text { Grandes } \\
\text { regiões }\end{array}$} & \multirow[b]{2}{*}{ TOTAL } & \multicolumn{5}{|c|}{ Quintis de renda familiar per capita } & \multirow[b]{2}{*}{$\begin{array}{l}\text { Diferença } \\
\text { relativa (\%) }\end{array}$} \\
\hline & & $\begin{array}{c}10 \\
\text { Quintil }\end{array}$ & $\begin{array}{c}20 \\
\text { Quintil }\end{array}$ & $\begin{array}{c}30 \\
\text { Quintil }\end{array}$ & $\begin{array}{c}40 \\
\text { Quintil }\end{array}$ & $\begin{array}{c}50 \\
\text { Quintil }\end{array}$ & \\
\hline \multicolumn{8}{|c|}{1990} \\
\hline BRASIL & 53,7 & 72,7 & 63,5 & 47,6 & 38,4 & 32,2 & 125,8 \\
\hline Norte & 52,9 & 60,8 & 58,4 & 56,3 & 54,2 & 41,8 & 45,6 \\
\hline Nordeste & 87,3 & 107,6 & 99,2 & 93,1 & 75,7 & 46,0 & 133,8 \\
\hline Sudeste & 36,6 & 44,5 & 38,4 & 33,3 & 28,9 & 22,9 & 94,3 \\
\hline Sul & 35,2 & 43,3 & 35,7 & 32,2 & 25,9 & 22,7 & 90,5 \\
\hline Centro-Oeste & 41,0 & 44,0 & 38,6 & 35,5 & 32,4 & 27,8 & 58,1 \\
\hline \multicolumn{8}{|c|}{2000} \\
\hline BRASIL & 35,1 & 40,7 & 31,9 & 29,0 & 23,6 & 19,5 & 108,6 \\
\hline Norte & 34,1 & 38,0 & 37,6 & 36,6 & 31,9 & 24,5 & 55,0 \\
\hline Nordeste & 50,9 & 64,0 & 58,3 & 53,9 & 49,4 & 30,3 & 111,5 \\
\hline Sudeste & 25,3 & 27,1 & 25,0 & 22,0 & 20,0 & 14,4 & 88,1 \\
\hline Sul & 22,0 & 25,4 & 22,4 & 21,1 & 17,4 & 12,6 & 100,7 \\
\hline Centro-Oeste & 26,2 & 26,5 & 24,4 & 23,4 & 20,4 & 17,2 & 53,8 \\
\hline \multicolumn{8}{|c|}{2005} \\
\hline BRASIL & 28,8 & 33,9 & 30,0 & 26,3 & 20,7 & 17,3 & 95,9 \\
\hline Norte & 28,3 & 33,3 & 31,1 & 30,4 & 26,5 & 22,3 & 49,2 \\
\hline Nordeste & 38,9 & 56,4 & 44,5 & 41,2 & 37,2 & 23,9 & 136,5 \\
\hline Sudeste & 19,2 & 23,1 & 19,0 & 18,0 & 15,2 & 11,0 & 110,9 \\
\hline Sul & 18,1 & 21,4 & 18,4 & 17,3 & 14,3 & 10,1 & 111,5 \\
\hline Centro-Oeste & 22,6 & 22,9 & 21,1 & 20,2 & 17,6 & 14,9 & 54,0 \\
\hline
\end{tabular}

Fonte Censos Demográficos, 1991 e 2000 e Pesquisa Nacional por Amostra de Domicílios (PNAD), 2005. Instituto Brasileiro de Geografia e Estatística (IBGE). 
Gráfico 34 - Taxa de mortalidade na infância, por quintis de renda familiar per capita, segundo região. Brasil - 1990, 2000, 2005

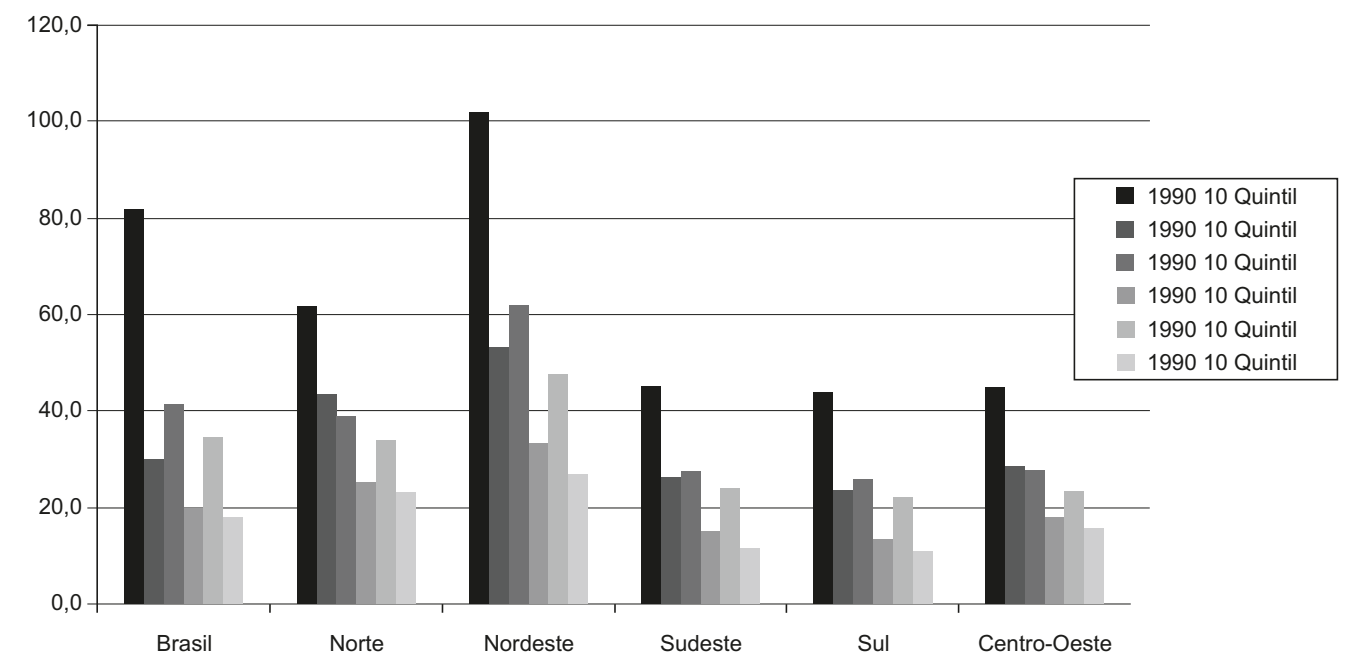

Fonte: Censos Demográficos, 1991-2000 e Pesquisa Nacional por Amostra de Domicílios (Pnad), 2005. Instituto Brasileiro de Geografia e Estatística (IBGE

\section{Revisão da Literatura sobre Saúde Materno-Infantil ${ }^{6}$}

A revisão da produção científica brasileira e internacional sobre os diferenciais em saúde de mães e crianças menores de cinco anos no Brasil, aqui realizada, cobre o período de 1990 até meados de 2007, incluindo publicações que tenham desagregado os desfechos de interesse segundo grupos socioeconômicos.

Os aspectos revisados incluíram:

1. Diferenciais em mortalidade, morbidade, amamentação, situação nutricional (incluindo baixo peso ao nascer, subnutrição e sobrepeso/obesidade), desenvolvimento cognitivo;

2. Diferenciais de acesso, utilização e cobertura de serviços e programas de saúde;

3. Análise de programas ou intervenções com objetivo de superar iniqüidades neste grupo populacional.

\section{Baixo peso ao nascer e nascimentos pré-termo}

O Ministério da Saúde, com dados do Sistema de Informação sobre Nascidos Vivos (Sinasc), estimou em 8,2\% a prevalência de baixo peso ao nascer (BPN), ${ }^{7}$ no Brasil, para o ano de 2004 (Brasil, 2006). Chama a atenção que esta prevalência seja maior no Sul $(8,6 \%)$ e no Sudeste $(9,1 \%)$ do que no Nordeste $(7,4 \%)$, o que também acontece com a prevalência 
de nascimentos pré-termo (menos de 37 semanas completas de gestação). Os diferenciais de baixo peso entre Nordeste e Sudeste também foram descritos em outras publicações (Silva et al., 2005, 2006).

Além da referida publicação do Ministério da Saúde, que assinala diferenças regionais, mas não avalia diferenciais socioeconômicos, dez outras publicações foram identificadas sobre esse tema, sendo nove estudos sobre BPN, cinco sobre nascimentos pré-termo e quatro sobre retardo de crescimento intra-uterino (RCIU) ${ }^{8}$

A maior parte dos estudos mostrou associação entre BPN e baixo nível socioeconômico, embora em vários deles os diferenciais tenham sido discretos. Alguns estudos recentes revelam um aumento de BPN na classe alta, talvez associado a interrupções da gravidez (Silva et al., 2006; Barros et al., 2007). Nascimentos pré-termo e RCIU também estiveram associados com pior situação socioeconômica.

As tendências temporais destes indicadores, pelo menos no Sudeste do país, foram de aumento das prevalências de BPN e pré-termo. Com relação às desigualdades sociais, as prevalências de BPN, em São Paulo, se mantiveram estáveis entre 1984-1985 e 1995-1996, para os recémnascidos do tercil mais baixo de renda familiar - ao redor de $10 \%-$, mas aumentaram no tercil mais alto, de 6,3\% para 8,6\% (Monteiro et al., 2000a). Em Ribeirão Preto, a prevalência de BPN aumentou marcadamente entre 1978-1979 e 1994, tanto entre os recém-nascidos de famílias de baixa renda - de 8,6\% para 13,8\% - como naqueles de famílias mais ricas - de 3,4\% para 9,1\% (Silva et al., 1998). Em Pelotas, o BPN se manteve estável entre os recém-nascidos de renda familiar até um salário mínimo mensal, mas aumentou marcadamente entre aqueles das famílias mais abastadas - de 5,4\% para 11,6\% (Barros et al., 2007). Nesta cidade, os nascimentos pré-termo tiveram um impressionante aumento entre 1982 (6,3\%), 1993 (11,4\%) e 2004 (14,7\%). Entre os recém-nascidos mais pobres, a prevalência de pré-termo aumentou de $7,7 \%$, em 1982 , para $19,8 \%$, em 2004 , enquanto que para os recém-nascidos de famílias ricas este aumento foi de 5,7\%, em 1982, para 13,5\%, em 2004.

Em resumo, os estudos demonstram desigualdades sociais para BPN, RCIU e nascimentos pré-termo, com maiores prevalências sendo observadas entre os recém-nascidos mais pobres. Em contrapartida, o país vem enfrentando um aumento progressivo de nascimentos prétermo e de BPN de proporções epidêmicas, que afeta todos os grupos sociais e que requer cuidadosa investigação.

\section{Amamentação}

A duração mediana da amamentação, no Brasil, tem aumentado progressivamente nas últimas décadas, de 2,5 meses (em 1975) para 9,9 meses (em 1999) (Brasil, 2000). Quanto às desigualdades sociais, foram identificados quatro estudos. Dois analisaram dados de todo o país, sendo um para 1989, baseado na Pesquisa Nacional sobre Saúde e Nutrição -

${ }^{8}$ Retardo de crescimento intra-uterino (RCIU), corresponde a um peso ao nascer para a idade gestacional abaixo do percentil 10 de uma curva de referência. 
PNSN (Venancio \& Monteiro, 1998) e outro para 1996, com base na Pesquisa Nacional sobre Demografia e Saúde - PNDS (Gwatkin et al., 2007). Os dois outros estudos são inquéritos locais, realizados em Pernambuco, em 1997 (Vasconcelos et al., 2006), e em Pelotas (RS), entre 1982 e 2004 (Victora et al., 2007).

A análise do PNSN de 1989 mostrou que, aos seis meses de idade, a prevalência de amamentação entre as crianças do quartil inferior de renda per capita era de $59 \%$, sendo de $53 \%$ para o quartil mais alto. Aos 12 meses, a prevalência para as mais pobres era de $46 \%$, sendo de $24 \%$ para as mais ricas (Venancio \& Monteiro, 1998).

Na PNDS, realizada em 1996, a prevalência de amamentação exclusiva em crianças menores de três meses foi de 40,6\%, sendo $32,7 \%$ no quintil de renda mais baixo e 59,9\% no quintil de maior renda (Gwatkin et al., 2007). Um problema metodológico no questionário utilizado faz com que estes dados provavelmente estejam superestimados, mas de qualquer forma a comparação entre ricos e pobres é válida. Outro indicador disponível na PNDS é o percentual de crianças de 6 a 9 meses que recebiam leite materno mais alimentos complementares, igual a $30,6 \%$, variando de $29,2 \%$ no quintil inferior a $37,2 \%$ no superior.

No estado de Pernambuco, em 1997, em um estudo de crianças menores de dois anos, a mediana da amamentação foi mais alta naquelas com renda familiar per capita superior a dois salários mínimos mensais (201 dias) do que nas de menor renda (108 dias) (Vasconcelos et al., 2006).

Com relação às tendências temporais mais recentes, o estudo das coortes de Pelotas mostrou aumento na duração mediana da amamentação, de 3,1 meses em 1982 para 4,0 em 1993 e 6,8 em 2004. Nas três coortes, as crianças das famílias mais ricas apresentaram maiores prevalências de aleitamento até os seis meses de idade, mas as crianças mais pobres mostraram maiores prevalências a partir desta idade.

Em resumo, os dados sobre amamentação sugerem que esta prática está aumentando em nosso país, sendo que, atualmente, as mães de nível socioeconômico alto tendem a amamentar mais freqüentemente do que as pobres, pelo menos nos primeiros meses de vida de seus filhos.

\section{Estado nutricional}

A desnutrição inclui, por um lado, os déficits de crescimento ou subnutrição, e por outro, o sobrepeso e a obesidade. Foram identificados 15 estudos sobre esse tema, sendo dois deles de abrangência nacional: o de Monteiro et al. (2000a, 2000b, 2000c, 2000d) baseado na PNSN1989 e o de Gwatkin et al. (2007), com base na PNDS-1996. Os outros 13 estudos foram regionais, analisando déficits de peso para idade (P/I), altura ou comprimento para idade (A/I) e peso para altura (P/A), e, no caso de sobrepeso, o excesso de peso para altura.

Na PNSN de 1989, a prevalência de déficit de P/I foi de 7,1\%, sendo 13,6\% para as crianças do quartil mais baixo de renda e $1,4 \%$ para as do quartil mais alto. Portanto, a diferença entre 
os grupos extremos foi de cerca de dez vezes. Na PNDS de 1996, a prevalência de déficit de altura/idade para o país foi de $10,4 \%$, sendo $23,4 \%$ no quintil mais baixo e $2,4 \%$ no mais alto. Todos os outros 13 estudos confirmaram a associação entre pobreza e subnutrição, sendo esta marcadamente mais freqüente no grupo mais pobre do que em todos os demais. Os diferenciais foram sempre superiores para déficits de altura do que de peso.

Além da comparação entre PNSN e PNDS, há apenas dois estudos sobre tendências temporais nas desigualdades sociais em subnutrição. Em São Paulo, a prevalência de déficit de comprimento para idade nas crianças do tercil mais baixo de renda familiar reduziu-se de 30,5\% em 1974-1975 para 3,6\% em 1995-1996. Para as crianças do tercil mais alto, a queda no período foi de $10,1 \%$ para $1,5 \%$. Houve, portanto, uma discreta redução na brecha entre pobres e ricos.

Em Pelotas, uma comparação entre 1982 e 2004 mostrou uma marcada redução nas desigualdades. Em 1982, as crianças do grupo de menor renda familiar tinham uma prevalência de déficit de comprimento para idade de $16,9 \%$, enquanto que entre as mais ricas esta prevalência era de $2,4 \%$, uma razão de sete vezes entre pobres e ricos. Já em 2004 , as prevalências foram de $8,0 \%$ entre as crianças mais pobres e 3,1\% entre as mais ricas, com uma razão entre pobres e ricos de 2,6. Cabe notar que a prevalência de subnutrição é expressa como o percentual de crianças abaixo da média menos dois escores $\mathrm{Z}$ de uma população de referência com adequado estado nutricional. Estatisticamente, espera-se que 2,3\% de uma população bem nutrida esteja abaixo deste ponto de corte. Portanto, nos estudos de São Paulo e Pelotas, a população mais rica já se encontra nesse patamar mínimo, sendo esperado que as diferenças se reduzam na medida em que o estado nutricional da população como um todo melhora.

Dois estudos avaliaram sobrepeso por grupos de renda e sua tendência temporal. Em São Paulo (1995-1996), o sobrepeso (definido por P/A > 2 escores Z) foi de 5,1\% nas crianças de maior renda e 1,9\% nas mais pobres. Avaliando as tendências temporais desta população entre 1974-1975 e 1995-1996, as crianças do tercil inferior de renda apresentaram aumento de $1,6 \%$ para $2,8 \%$, enquanto que entre as pertencentes ao tercil mais alto o sobrepeso caiu de 6,1\% para 5,4\%. Em Pelotas, em uma comparação entre 1982 e 2004, o sobrepeso aumentou de $4,0 \%$ para $8,1 \%$ entre as mais pobres, enquanto que nas mais ricas a prevalência de sobrepeso reduziu de $13,1 \%$ para 9,5\%. Portanto, em ambas as populações - ao contrário da maioria dos desfechos revisados -, o sobrepeso foi maior entre crianças ricas do que entre as pobres. No entanto, as desigualdades estão diminuindo ao longo do tempo, pela redução observada entre as crianças mais ricas e o aumento entre as mais pobres.

Em resumo, persistem os diferenciais socioeconômicos em subnutrição, afetando especialmente as crianças mais pobres, e, no caso de sobrepeso e obesidade, afetando as mais ricas. No entanto, há evidências de que estes diferenciais estejam sendo reduzidos ao longo do tempo. 


\section{Deficiências de micronutrientes}

Seis estudos foram identificados com informações sobre anemia, para distintos grupos socioeconômicos; três do Sul, dois do Nordeste e um do Sudeste. A prevalência global em crianças menores de cinco anos (ou menores de três anos, em alguns estudos) foi muito elevada: 54\% em Criciúma (SC) (Neuman et al., 2000), 48\% na Bahia (Assis et al., 2007), 48\% em Porto Alegre (RS) (Silva et al., 2001), 47\% em São Paulo (SP) (Monteiro et al., 2000d), 41\% em Pernambuco (Araújo et al., 2006) e 30\% em Pelotas (RS) (Assunção et al., 2007). Ademais, todos os estudos mostraram uma associação direta entre a prevalência de anemia e pobreza.

Em relação às tendências temporais, a prevalência de anemia aumentou de 35,6\%, em 19841985, para 46,9\%, em 1995-1996, em São Paulo (Monteiro et al., 2000d). Este aumento ocorreu em todos os grupos sociais, sendo mais marcado entre as crianças do tercil mais pobre da população (de 40,8\% para 55,1\%) do que entre as do tercil mais alto (31,9\% para $38,7 \%$ ).

Além da deficiência de ferro subjacente à maioria dos casos de anemia, em nosso país, outros micronutrientes como vitamina A e zinco também estão associados à saúde e desenvolvimento infantis. Somente um estudo foi localizado (Assis et al., 2007), no qual foram medidos os consumos de retinol e zinco na dieta de crianças baianas menores de 5 anos. A ingesta destes dois micronutrientes foi significativamente menor nas crianças do tercil inferior de nível socioeconômico.

Em resumo, os estudos demonstram altas taxas de anemia em todos os grupos sociais, mas prevalências ainda mais elevadas entre as crianças mais pobres. Desigualdades sociais também foram observadas no estudo que avaliou a ingesta de retinol e zinco em crianças.

\section{Morbidade}

Dez publicações sobre morbidade infantil foram localizadas, todas utilizando dados primários. Duas delas, de abrangência nacional, utilizaram dados da PNDS (Sastry \& Burgard, 2005; Gwatkin et al., 2007) e avaliaram diarréia e infecções respiratórias agudas; dois estudos de casos e controles avaliaram fatores de risco para diarréia (Zona da Mata, Pernambuco) (Silva et al., 2004) e pneumonia (Porto Alegre-RS) (Victora et al., 1994) e um estudo transversal em São Paulo avaliou diarréia, parasitoses intestinais e doença respiratória, além de hospitalizações por diarréia (Benicio et al., 2000; Benicio \& Monteiro, 2000; Ferreira et al., 2000). Três estudos avaliaram hospitalizações, dois no Rio Grande do Sul, nos primeiros cinco anos de idade (Issler et al., 1996) e no primeiro ano de vida (Matijasevich et al., 2007), e um na Bahia, com crianças menores de cinco anos (Assis et al., 2007).

Diferenciais socioeconômicos claros foram observados em todos os desfechos estudados, com exceção do estudo da Bahia, onde a proporção de crianças hospitalizadas no último ano foi semelhante para os três grupos socioeconômicos. Os estudos de tendências temporais demonstraram reduções na prevalência de morbidade para toda a população ao longo do tempo, com exceção do estudo de doença respiratória em São Paulo, onde houve um marcado aumento entre 1984-1985 e 1995-1996. Com relação à evolução das desigualdades sociais, a análise dos estudos não mostra resultados homogêneos. O inquérito de São Paulo mostrou 
uma redução das desigualdades (expressas como a razão da prevalência entre pobres e ricos) em termos de diarréia, mas um aumento das mesmas para doenças respiratórias baixas, assim como um discreto aumento para parasitoses intestinais.

As tendências temporais de hospitalização das coortes de Pelotas mostraram resultados distintos: enquanto entre as crianças mais pobres a prevalência de hospitalização no primeiro ano de vida foi similar entre 1982 e 2004 (26,8\% e 24,5\%, respectivamente), para as mais ricas a prevalência de hospitalização aumentou significativamente no período (3,5\% e 12,6\%, respectivamente). Portanto, nesta população, a brecha entre ricos e pobres diminuiu, não por redução nas mais pobres, mas por aumento entre as mais ricas.

\section{Desenvolvimento cognitivo}

Foram identificados três estudos sobre desenvolvimento cognitivo, todos utilizando o teste de Bailey, um instrumento de triagem capaz de detectar suspeita de atraso de desenvolvimento a ser posteriormente confirmado por outros instrumentos. As crianças avaliadas tinham entre um e dois anos de idade. Um dos estudos foi realizado em Salvador (BA) (Andrade et al., 2005), outro na Zona da Mata de Pernambuco (Grantham-McGregor et al., 1998) e o terceiro em Pelotas (RS) (Halpern et al., 2007). No estudo baiano, a prevalência de suspeita de problemas de desenvolvimento esteve inversamente associada à qualidade de estímulo familiar, que, por sua vez, esteve fortemente relacionado ao nível educacional da mãe. Em Pernambuco, o desenvolvimento cognitivo esteve positivamente associado com melhor situação socioeconômica familiar. Em Pelotas, a prevalência de suspeita de atraso de desenvolvimento foi de $37,1 \%$ em 1993, caindo para 21,4\% em 2004. Com relação às tendências temporais de desigualdades nesta cidade, as prevalências de suspeita de atraso apresentaram queda discretamente maior entre as crianças mais pobres (36\%) do que entre as mais ricas (30\%), e a razão entre pobres e ricos reduziu-se de 1,6 em 1993 para 1,4 em 2004.

Em resumo, os estudos avaliados demonstram maiores prevalências de problemas cognitivos entre as crianças de famílias mais pobres.

Acesso, utilização e cobertura de serviços e programas de saúde

Aqui são examinados os diferenciais socioeconômicos em termos de atenção pré-natal e parto, e assistência médica para crianças menores de cinco anos.

Atenção pré-natal e ao parto

Quatro publicações nacionais e oito estudos locais, três no Sul e cinco no Sudeste, foram localizados, avaliando a cobertura pré-natal e a atenção ao parto, incluindo cesarianas.

A atenção pré-natal foi analisada na base de dados da PNDS de 1996, em duas publicações (Barros et al., 2005; Gwatkin et al., 2007). Para toda a população, a prevalência de pré-natal inadequado foi de $38,4 \%$, sendo $70,7 \%$ no quintil mais pobre e $13,6 \%$ no mais rico (Barros et al., 2005). O percentual de mulheres com uma ou mais consultas variou entre $72,2 \%$ no quintil inferior de bens e 98,1\% no quintil mais rico (Gwatkin et al., 2007). 
Uma publicação recente do Ministério da Saúde, utilizando dados do Sinasc, considerou como pré-natal inadequado a realização de menos do que sete consultas; $74 \%$ das grávidas sem escolaridade apresentaram pré-natal inadequado, em comparação com $21 \%$ daquelas com 12 ou mais anos de estudo (Brasil, 2006). Todos os outros estudos analisados confirmaram a forte associação entre o número de consultas pré-natais ou o início precoce do pré-natal com a situação socioeconômica e educacional das mães.

Em relação à atenção ao parto, a PNDS de 1996 mostrou que 52,5\% das mães do quintil inferior de bens tiveram seu parto atendido por médico, comparadas com $97,6 \%$ no quintil superior (Gwatkin et al., 2007).

Em termos de tendências temporais, o estudo das coortes de nascimento de Pelotas mostrou que a proporção de mães das famílias de menor renda cujos partos foram atendidos por médicos aumentou de 69,4\%, em 1982, para 86,1\%, em 2004. Entre as mães das famílias mais ricas, o percentual aumentou de 93,2\%, em 1982, para 98,2\%, em 2004 (Cesar et al., 2007).

Todos os estudos analisados demonstram o mesmo padrão de maior freqüência de cesarianas entre mulheres de nível socioeconômico elevado. Na PNDS, o índice global foi de 36,4\%, variando de $16,4 \%$ no quintil inferior a $67,6 \%$ no quintil superior (Ronsmans et al., 2006).

Entre os estudos de cesarianas que permitem a avaliação de tendências temporais, o realizado em São Paulo, comparando a atenção em 1984-1985 e 1995-1996 (Monteiro et al., 2000), não mostrou um aumento entre as parturientes do tercil superior de renda. No entanto, esta tendência foi claramente observada entre 1982 e 2004 em Pelotas, onde a prevalência para mulheres com renda familiar superior a 10 salários mínimos mensais aumentou de 46,7\%, em 1982, para 79,1\%, em 2004 (Cesar et al., 2007).

Em resumo, existem fortes diferenciais em atendimento pré-natal e ao parto entre os grupos sociais. Ao mesmo tempo, a falta de atendimento adequado no grupo mais pobre é preocupante e há também evidências de excesso de medicalização entre as mulheres mais ricas, expostas aos riscos de cesarianas desnecessárias.

Atenção à criança

Para o país, três publicações analisaram a atenção de saúde com dados da PNDS de 1996 (Barros et al., 2005; Victora et al., 2005; Gwatkin et al., 2007).

Uma análise de co-cobertura avaliou a utilização de oito intervenções materno-infantis: quatro direcionadas à criança (vacinas BCG, DPT e sarampo e suplemento de vitamina A), três à mãe (toxóide tetânico, atenção pré-natal e atenção do parto por pessoal qualificado) e uma em nível domiciliar (acesso à água potável). As famílias foram estratificadas conforme quintis de índice de bens. A proporção de crianças que receberam seis ou mais destas intervenções variou de $47 \%$ no quintil mais pobre a $90 \%$ no quintil mais rico. Foi observado, ademais, que o quintil inferior apresentou cobertura marcadamente inferior a do segundo grupo mais pobre, no qual a prevalência de cobertura com seis ou mais intervenções já atingiu quase $80 \%$ (Victora et al., 2005). 
Outra análise de dados da PNDS mostrou que, em crianças entre 12-59 meses, a proporção com esquema vacinal incompleto variou de $33,4 \%$ no quintil mais baixo a $15,3 \%$ no mais alto.

Diversos indicadores de acesso a intervenções preventivas e curativas estão disponíveis nas análises da PNDS de 1996 publicadas por Gwatkin et al. (2007). Crianças com vacinas completas para a idade corresponderam a 56,6\% no quintil inferior e $73,8 \%$ no quintil superior. Observou-se, ainda, que $33,4 \%$ das crianças do quintil mais pobre foram levadas a um serviço de saúde quando apresentaram suspeita de pneumonia (tosse com respiração rápida), comparadas com $65,1 \%$ no quintil mais rico. Para episódios de diarréia, estes percentuais foram de $27,2 \%$ e $51,8 \%$, respectivamente. Em contrapartida, o uso de terapia de reidratação oral para a diarréia foi mais comum em crianças pobres $(73,1 \%)$ do que nas ricas $(65,8 \%)$.

Em São Paulo, a proporção de crianças do tercil mais pobre com seis ou mais consultas preventivas no primeiro ano de vida aumentou de 68,8\% em 1984-1985 para 73,9\% em 19951996 (Monteiro et al., 2000c, 2000d). Para as do tercil de renda mais alta, este aumento foi de $87,5 \%$ para $90,2 \%$. Um quadro semelhante foi observado em Pelotas, onde, entre 1982 e 2004, o número médio de consultas preventivas no primeiro ano de vida aumentou de 7,5 para 9,3 entre as mais pobres, e de 10,4 a 11,3 entre as mais ricas (Cesar et al., 2007).

Com relação à atenção especializada neonatal e pediátrica, dois estudos analisaram a distribuição urbana de unidades de tratamento intensivo, ambos na Região Sudeste. No estado do Rio de Janeiro, em 1997-1998, foi realizada uma análise das 74 UTIs disponíveis (Barbosa et al., 2002). O número de leitos intensivos neonatais e pediátricos por habitante mostrou ser adequado para a população como um todo (cerca de 1:3000 crianças), mas 94\% destes se encontram na região metropolitana, que possui $74 \%$ da população infantil. Uma análise restrita à cidade do Rio de Janeiro também mostra distorções, pois áreas mais pobres, onde vive grande parte das crianças, não contam com nenhum leito intensivo.

Em São Paulo (SP) em 2000-2002, 107 UTIs neonatais e pediátricas foram avaliadas (Souza et al., 2004). O número de leitos intensivos por população foi de 1:2700 crianças, mas oscilou, dependendo do núcleo estudado, de 1 leito/600 a 1 leito/6.000 crianças. Os núcleos regionais de saúde com maior população pediátrica apresentaram o menor número de UTIs, e os mais centrais, com menor população pediátrica, apresentaram a maior concentração destas unidades. Cabe aqui ressaltar que, com um bom serviço de referência, estas desigualdades dentro de um município ou região metropolitana não seriam tão importantes.

Em resumo, diversos estudos sobre cobertura de intervenções e utilização de serviços de saúde indicam importantes diferenciais entre crianças ricas e pobres, sempre em detrimento destas últimas.

\section{Mortalidade}

Os estudos brasileiros sobre mortalidade de crianças podem ser divididos em dois grandes grupos: os de base individual, nos quais a informação sobre o desfecho e/ou a situação 
socioeconômica foi coletada de cada família, e os de delineamento ecológico, baseados em informações de desfechos e/ou situação socioeconômica - renda, escolaridade, situação de água e/ou saneamento, índice de qualidade de vida - de bairros ou outros agregados geográficos.

Os estudos em nível individual evidenciaram forte relação inversa entre situação socioeconômica e mortalidade, seja esta do período perinatal, neonatal, pós-neonatal, infantil ou de menores de cinco anos. Diferenciais bastante amplos foram observados entre os grupos socioeconômicos extremos, que chegaram até a sete vezes para mortalidade infantil em um estudo de Pelotas, ao comparar os $20 \%$ mais pobres com os $5 \%$ mais ricos (Victora et al., 1988, 2000). Em Pelotas, os diferenciais entre grupos sociais se mantiveram nas três coortes estudadas em 1982, 1993 e 2004, embora a mortalidade para toda a população tenha caído.

A maioria dos trabalhos sobre mortalidade infantil ou de menores de cinco anos, no Brasil, apresenta delineamento ecológico baseado em áreas geográficas. Esta revisão localizou 23 análises com este delineamento - 12 da Região Sudeste, oito do Nordeste, dois do Sul e um do Centro-Oeste. Com exceção de um estudo conjunto das regiões Sudeste e Nordeste, realizado com dados da PNDS de 1996 (Wagstaff, 2000), as outras publicações analisaram dados de mortalidade para estados, regiões metropolitanas ou municípios de porte médio. Em sua maioria, estes estudos demonstram uma relação inversa entre situação socioeconômica e mortalidade perinatal, neonatal, pós-neonatal, infantil e de menores de cinco anos, mas com diferenciais menos marcados do que os observados em estudos individuais. Este fato é esperado, uma vez que os estudos ecológicos consideram de forma homogênea todas as famílias residentes em uma mesma região ou bairro, desconsiderando importantes diferenças socioeconômicas entre estas. No grupo populacional pertencente ao estrato geográfico mais pobre, portanto, algumas famílias não são tão pobres, o mesmo ocorrendo entre as famílias do estrato mais rico.

Em resumo, estudos epidemiológicos e demográficos com diversos delineamentos confirmam uma forte associação inversa entre nível socioeconômico e mortalidade.

\section{Avaliação de programas e intervenções para superação de iniqüidades em saúde infantil}

Intervenções ou programas visando a reduzir iniqüidades em saúde infantil podem ser avaliados de diferentes formas. A avaliação mais simples consiste em verificar se o programa realmente atingiu os mais pobres. Isto pode ser avaliado a partir de estimativas da cobertura (que percentual das crianças pobres é atendido pelo programa?) e foco (que percentual das crianças atendidas pelo programa são pobres?) (Habicht, Mason \& Tabatabai, 1984). O cálculo do foco - como o próprio nome indica - é particularmente útil para programas focalizados. Avaliações mais complexas incluem medir se o programa reduziu desigualdades sociais, seja em termos de indicadores de processo (como cobertura vacinal ou uso de serviços de saúde), seja de impacto (como mortalidade ou subnutrição). 
Além do Sistema Único de Saúde (SUS), o Brasil possui um grande número de intervenções com possível impacto sobre iniqüidades em saúde e nutrição infantil, como o Programa de Saúde da Família (PSF), os Agentes Comunitários de Saúde (ACS), o Programa Bolsa Família (PBF), a Pastoral da Criança, as Ações Integradas de Combate às Doenças Prevalentes da Infância (AIDPI), além de programas estaduais, como o Viva Criança, no Ceará.

No entanto, a maior parte destes programas, quando avaliados, o foram em relação a seu impacto global sobre a saúde materno-infantil como um todo e não sobre as desigualdades em saúde. Esta avaliação é dificultada pelo fato de que os programas não foram planejados ou implementados de forma a facilitar a medição de seu impacto. Programas de dimensões nacionais, como o Bolsa Família ou o PSF, por exemplo, são difíceis de avaliar, pois não há grupos-controle adequados. Isso não foi o caso, por exemplo, do programa mexicano similar ao Bolsa Família - Progresa, depois reformulado como Oportunidades -, para o qual um processo inicial de aleatorização determinou a ordem de implementação geográfica (Rivera et al., 2004). A avaliação do Progresa revelou que o programa esteve associado a uma melhora na situação nutricional global, sobretudo entre as crianças mais pobres, contribuindo, portanto, para reduzir as desigualdades.

Se a avaliação destes programas em termos de seu impacto global é problemática, mais difícil ainda é a de seu impacto sobre desigualdades em saúde, uma vez que esta última requer tamanhos de amostra maiores e mensuração do nível socioeconômico na população-alvo.

Treze publicações sobre avaliações de programas e intervenções brasileiros com possível impacto sobre desigualdades em saúde materna e infantil foram localizadas, incluindo quatro avaliações do programa Bolsa Família (Andrade et al., 2007a; Andrade et al., 2007b; Conde, Konno \& Monteiro, 2006; Santos et al., 2007), uma do programa Bolsa Alimentação (Morris et al., 2004) e duas da Pastoral da Criança (Cesar, 2005; Neumann et al., 1999). Já o impacto do PSF sobre a mortalidade infantil foi investigado, em nível nacional, em três estudos (Macinko et al., 2006, 2007; Pereira, 2006). Um outro estudo avalia o efeito sobre as iniqüidades em saúde infantil de diversos programas, incluindo o PSF, a Pastoral da Criança, o Programa Nacional de Imunização (PNI) e o programa de Atenção Pré-Natal (Barros et al., 2005). Finalmente, uma análise investigou o impacto sobre desigualdades em saúde de um programa estadual, o Viva Criança (Victora et al., 2000), e outro estudo avaliou o AIDPI (Victora et al., 2006).

Não foram incluídos na revisão estudos sobre melhorias na saúde infantil em um único município, sem grupo de comparação.

\section{Bolsa família}

Duas publicações sobre o impacto global do Programa Bolsa Família (PBF) foram originadas de um estudo realizado na região do semi-árido (que inclui todos os estados nordestinos, com exceção do Maranhão, assim como o norte e nordeste de Minas Gerais), a partir da 
avaliação nutricional das crianças que participaram do Dia Nacional de Vacinação em 2005 (Conde, Konno \& Monteiro, 2006; Santos et al., 2007). O primeiro fato que chama a atenção é a surpreendentemente baixa prevalência de déficits nutricionais nesta população de crianças tão pobres: 6,6\% para A/I (altura/idade), 5,6\% para P/I (peso/idade) e 2,8\% para P/A (peso/ altura). Como esperado, as crianças que participavam do PBF eram bem mais pobres do que não participantes, o que confirma estar o programa focalizado nas famílias pobres. A avaliação dos déficits antropométricos, após ajuste para o número de bens no domicílio e para a escolaridade do chefe de família e da mãe da criança, sugeriu que a participação no PBF reduziu o risco de déficit de A/I em 30\% - de 6,5\% para 4,8\%. O maior benefício do programa parece ter ocorrido com crianças entre 6 e 11 meses de idade, entre as quais a redução do déficit de A/I foi da ordem de $62 \%$ - de 5,3\% para 2,0\%.

O impacto do PBF sobre a nutrição e cobertura vacinal de crianças entre 6 e 60 meses foi avaliado em 2005, com uma amostra restrita a famílias com renda per capita inferior a $\mathrm{R} \$ 200,00$. Não foram encontradas diferenças, em nível nacional ou regional, na situação nutricional e vacinal de crianças participantes do programa, quando comparadas com crianças-controle de famílias não participantes, após emparelhamento por situação socioeconômica (Andrade et al., 2007a, 2007b). Um problema importante desta pesquisa é a falta de informação sobre o tempo de permanência no programa entre as famílias participantes.

O precursor do PBF - Programa Bolsa Alimentação - foi também alvo de avaliação de impacto. Um estudo inicial comparou crianças admitidas no programa com outras que, por motivos administrativos, não foram incluídas apesar de serem elegíveis. Após seis meses, crianças incluídas no programa apresentaram peso inferior ao grupo-controle, o que os autores interpretaram como sendo devido ao temor das mães de que, caso seus filhos ganhassem peso, perderiam o benefício (Morris et al., 2004). Dados não publicados, produzidos pelos mesmos autores, com uma amostra maior de crianças após seis meses de utilização do programa, revelaram que as crianças incluídas no programa ganharam, em média, 27g por mês a mais do que aquelas não incluídas (World Health Organization and Commission on Social Determinants of Health, 2007).

Em resumo, as avaliações do PBF e seu precursor confirmam que estes programas estiveram efetivamente focalizados nos mais pobres. Os achados sobre o impacto global na nutrição infantil não são consistentes, com alguns estudos sugerindo impacto e outros não. Finalmente, nenhum estudo avaliou se houve redução das desigualdades no estado nutricional (ou qualquer outro indicador) como resultado do programa.

Programa de Saúde da Família (PSF)

Três estudos de avaliação do impacto do PSF sobre o coeficiente de mortalidade infantil (CMI) utilizaram delineamentos ecológicos. O primeiro teve como unidades de análise os estados brasileiros, mostrando que o aumento na cobertura do PSF esteve associado com uma redução no CMI, após ajuste para outros determinantes, como água, saneamento, renda familiar, educação feminina, fertilidade, número de médicos e enfermeiras e número de leitos 
hospitalares (Macinko et al., 2006). O mesmo grupo de autores repetiu estas análises usando como unidades de estudo as microrregiões brasileiras, com conclusões similares (Macinko et al., 2007). Estas análises são prejudicadas pelo uso, nas regiões mais pobres do país, de estimativas indiretas de mortalidade infantil, para compensar o sub-registro de óbitos. Tais estimativas, no entanto, resultam da projeção para anos recentes de tendências observadas no passado, não sendo particularmente úteis para investigar o impacto de programas recentes. A avaliação realizada por Pereira (2006) contornou este problema restringindo a análise a municípios com alta cobertura de registro civil, sem depender de estimativas indiretas. Esta autora mostrou que o PSF foi bem focalizado nos municípios mais pobres, sendo que sua implementação esteve associada a reduções na mortalidade infantil, após ajuste para diversos fatores de confusão.

Assim, apesar de limitações metodológicas, há alguma evidência de que o PSF estaria associado a uma redução global da mortalidade infantil nas áreas cobertas, mas não existem evidências sobre seu impacto em termos de desigualdade dentro destas áreas.

\section{Pastoral da criança}

A Pastoral da Criança é um programa de abrangência nacional que visita mensalmente mais de 2 milhões de crianças e gestantes, em 43.000 comunidades de 4.063 municípios brasileiros. As ações de saúde promovidas pela Pastoral priorizam problemas de saúde enfrentados pelas populações mais pobres, como a diarréia, a subnutrição e as infecções respiratórias. As intervenções promovidas incluem diversas medidas de baixo custo e alta efetividade, como a reidratação oral, as imunizações, o controle pré-natal e o aleitamento materno, entre outras. Avaliações independentes mostram aumentos em vários, mas não em todos, os indicadores de cobertura. Em um estudo realizado em Sergipe, em algumas comunidades rurais pobres, a Pastoral era a principal fonte de informações e aconselhamento sobre saúde materno-infantil (Cesar, 2005). Apenas um estudo avaliou especificamente se a Pastoral estava efetivamente alcançando os mais pobres. Esta pesquisa, realizada em Criciúma (SC), mostrou maiores coberturas nos $40 \%$ mais pobres da população, embora revelasse também a dificuldade de manter altas coberturas nos $20 \%$ mais pobres, que são mais difíceis de atingir do que o quintil imediatamente superior (Neumann et al., 1999).

\section{Outros programas}

Uma análise da cobertura de diversos programas (Barros et al., 2005) revelou que os programas nacionais de imunização e de atenção pré-natal apresentam alta cobertura global, mas cobertura inferior entre os pobres, ao contrário do PSF, que mostrou uma alta cobertura entre estes últimos.

A comparação de dois inquéritos populacionais no Ceará, antes (1987) e depois da implementação do programa Viva Criança (1994), mostrou importantes melhoras em vários indicadores de cobertura e nutrição para a população infantil como um todo, mas não houve progresso na redução de desigualdades entre ricos e pobres (Victora et al., 2000). 
A implantação do programa AIDPI, na Região Nordeste, mostrou que o mesmo foi preferencialmente implementado em municípios com maior índice de desenvolvimento humano e localizados mais próximos às capitais estaduais, e não naqueles de alta mortalidade, que mais se poderiam beneficiar do programa (Victora et al., 2006).

Concluindo, observa-se a escassez de avaliações de programas visando a melhorar a saúde das crianças brasileiras em termos de seu impacto sobre a eqüidade. Poucos programas foram avaliados sobre se estavam ou não atingindo os mais pobres, e menos ainda em termos de seu impacto sobre as desigualdades em indicadores de saúde.

\section{Conclusões}

Os estudos sobre saúde materna e infantil estão fortemente concentrados na Região Sudeste, foco de 38 dos 113 estudos incluídos nesta revisão. Vinte e sete publicações tiveram como área de estudo o Nordeste do país, com um número expressivo de análises ecológicas de mortalidade e estudos sobre situação nutricional. A Região Sul foi tema de 23 publicações, observando-se uma distribuição mais homogênea dos indicadores estudados. Chama a atenção a total ausência de estudos dirigidos especificamente à Região Norte, assim como a pobreza de informações sobre a Região Centro-Oeste, alvo de apenas duas publicações. Vinte e três estudos de âmbito nacional foram localizados, poucos deles publicados após o ano 2000. Espera-se que a publicação da recente Pesquisa Nacional sobre Demografia e Saúde da Mulher e da Criança (PNDS-2006), assim como novas publicações do Ministério da Saúde e do IBGE, e investigações de grupos acadêmicos - promovidas por recente edital incentivado pela Comissão Nacional sobre Determinantes Sociais da Saúde (CNDSS) - atualizem as informações sobre desigualdades de saúde materno-infantil.

Alguns temas têm sido alvo de poucos estudos, como as desigualdades socioeconômicas em termos de sobrepeso e obesidade, desenvolvimento cognitivo, amamentação, anemia e atenção à criança. Chama ainda a atenção a quase total ausência de estudos sobre a qualidade da atenção médica recebida por crianças de distintos níveis sociais. Maiores pesquisas sobre estes temas devem ser incentivadas.

A presente revisão apresenta algumas limitações. As desigualdades foram analisadas conforme indicadores de estratificação socioeconômica (renda, índice de bens, escolaridade dos pais e combinações destes), enquanto que os determinantes sociais da saúde incluem outras dimensões, como características culturais e ambientais, redes sociais e comunitárias, entre outras. Mesmo em termos de diferenciais socioeconômicos, as diferentes classificações adotadas nos estudos revisados dificultam a comparação direta entre seus resultados. Em termos metodológicos, as principais deficiências observadas na revisão foram quanto aos estudos ecológicos, que muitas vezes utilizam de forma acrítica dados secundários cuja cobertura e qualidade deixa a desejar.

Apesar dessas limitações, os resultados da revisão não deixam dúvidas sobre a presença de marcadas iniqüidades sociais em saúde e nutrição infantil em todo o país, evidenciadas nos indicadores de mortalidade, morbidade, situação nutricional e utilização de serviços 
de saúde. De todos os indicadores estudados, os pobres quase sempre apresentam situação menos favorável em termos de atenção pré-natal, peso ao nascer (tanto por RCIU como por parto pré-termo), amamentação exclusiva, cobertura vacinal, consultas preventivas, morbidade, subnutrição, deficiências de micronutrientes, desenvolvimento cognitivo, e, conseqüentemente, mortalidade. O Gráfico 35 mostra alguns indicadores selecionados, baseados na PNDS-1996. Observa-se que, para a maioria desses indicadores, o quintil inferior apresenta cobertura notadamente menor do que todos os demais quintis, o que está de acordo com as análises de co-cobertura mencionadas anteriormente (Victora et al., 2005). Este tipo de padrão, descrito como "exclusão marginal" (World Health Organization, 2005), é normalmente observado em países onde a cobertura global é relativamente alta.

Gráfico 35 - Cobertura de intervenções selecionadas conforme os quintis de índice de bens. Brasil - 1996

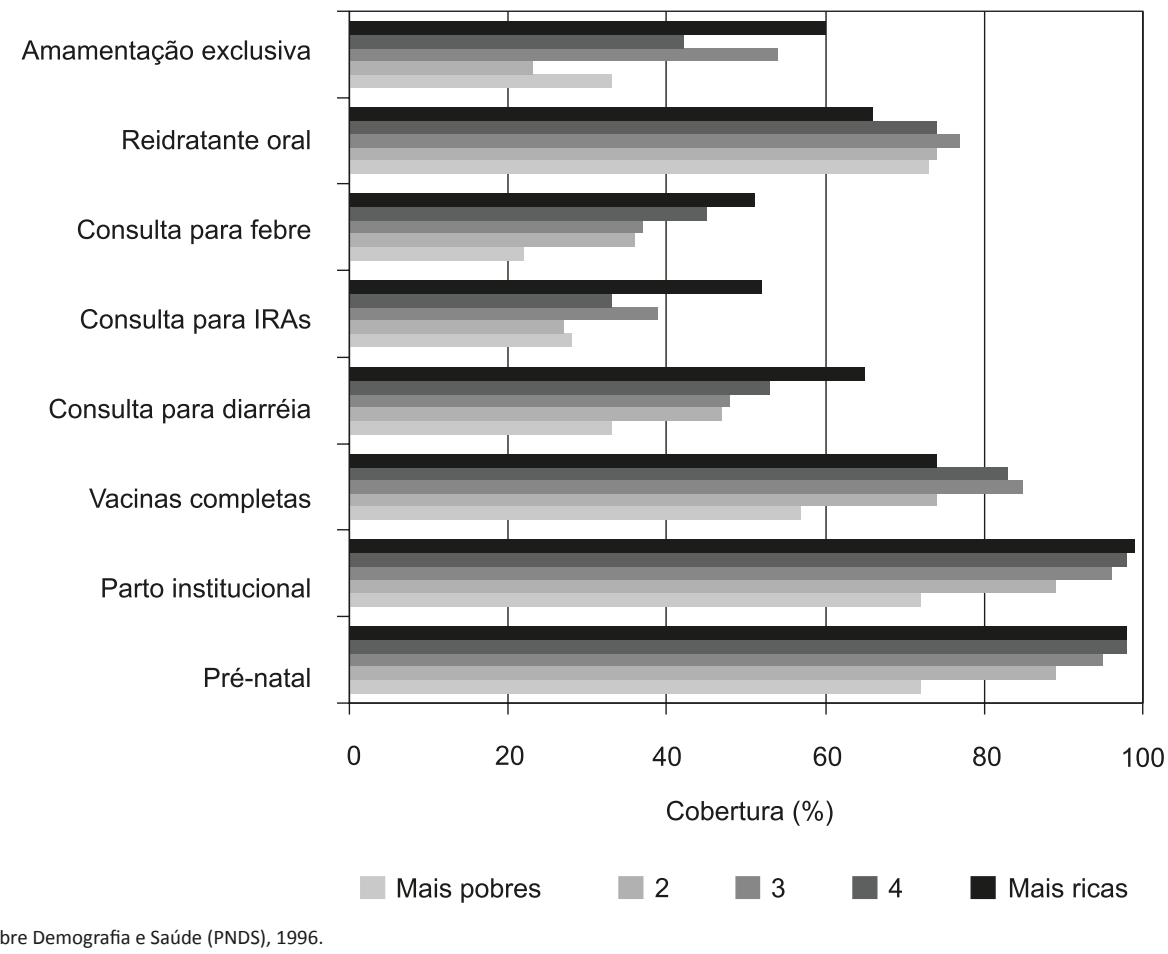

Fonte: Pesquisa Nacional sobre Demografia e Saúde (PNDS), 1996

Os poucos indicadores que são piores entre as mães e crianças de famílias ricas incluem o parto por cesarianas, sobrepeso/obesidade e o uso de terapia de reidratação oral (TRO) durante episódios de diarréia. O padrão de uso de TRO pode ser explicado por ser este tipo de tratamento considerado freqüentemente como "remédio de pobre" (Behague et al., 2002), pois famílias ricas tendem a tratar diarréia em seus filhos com produtos comerciais percebidos como sendo mais sofisticados. Como já foi comentado, pesquisas recentes sobre amamentação mostram que esta prática, que antes era mais comum entre as crianças de famílias pobres, agora é mais comum entre as de nível socioeconômico mais elevado, pelo menos para os primeiros seis meses de vida. 
De maneira geral, os principais indicadores de saúde infantil, mortalidade e desnutrição, têm melhorado substancialmente em todos os estratos da população. Outros indicadores, como o baixo peso ao nascer e o nascimento pré-termo, assim como a anemia, parecem estar aumentando. Embora seja possível documentar tendências temporais para alguns indicadores na população como um todo, são pouquíssimos os estudos que permitem evidenciar tendências em desigualdades sociais - em especial os inquéritos de Monteiro e colaboradores em São Paulo (1984-1985 e 1995-1996), os estudos do Ceará (1987 e 1994) e as coortes de nascimentos de Ribeirão Preto (1978-1979 e 1994) e de Pelotas (1982, 1993 e 2004). Em uma análise baseada nas séries temporais do Ceará e de Pelotas (Victora et al., 2000), foi proposta uma hipótese de que as novas intervenções para redução de morbimortalidade atingiriam, inicialmente, as crianças mais ricas, levando em curto prazo a um aumento nas desigualdades relativas; posteriormente, à medida que as crianças mais ricas atingissem um alto nível de cobertura (ou baixo nível de morbimortalidade), as crianças mais pobres continuariam a melhorar e a desigualdade seria reduzida.

Alguns exemplos da revisão anterior apóiam esta hipótese. A amamentação exclusiva, uma intervenção comportamental disseminada a partir dos anos 90, já é mais comum entre ricos do que pobres. O sobrepeso e a obesidade, tradicionalmente mais comuns entre crianças ricas, já se encontram em declínio neste grupo, mas seguem aumentando entre crianças pobres. A subnutrição já está praticamente erradicada entre crianças ricas, e as desigualdades estão diminuindo, pois continua a cair entre as crianças pobres. Estes exemplos evidenciam a complexa natureza das tendências seculares em indicadores de saúde e nutrição infantis nos diferentes grupos sociais.

Como discutido na revisão das tendências de mortalidade, não há evidências convincentes de que as desigualdades em mortalidade de crianças estejam diminuindo no Brasil. Em contrapartida, alguns estudos sobre a situação nutricional - embora restritos às regiões Sul e Sudeste - sugerem uma redução das disparidades entre crianças pobres e ricas. Kelly et al. (2007: 11) enfatizam que

os fatores que levam a uma melhora geral da saúde - progressos ambientais, bom saneamento e água limpa, melhor nutrição, bons níveis de imunização, melhores moradias - não reduzem as iniqüidades em saúde. Isto ocorre porque os determinantes de uma boa saúde não são os mesmos determinantes das iniqüidades em saúde.

Portanto, a atual queda da mortalidade infantil no Brasil não significa, necessariamente, que as diferenças sociais estejam sendo reduzidas, até porque a mortalidade mesmo no quintil mais rico ainda apresenta ampla margem para redução, quando comparada aos níveis - de 5 por mil ou menos - atingidos pelos países mais avançados (United Nations Children's Fund, 2007).

No que se refere às intervenções e programas de combate às iniqüidades em saúde e nutrição infantil, uma limitação óbvia é a escassez de informações de boa qualidade para sua avaliação. O país conta com um elenco de programas que têm como foco as populações mais pobres, mas a avaliação de seus efeitos sobre a saúde infantil ainda é incipiente. o padrão de exclusão social discutido anteriormente, com coberturas notadamente inferiores em crianças 
do quintil mais pobre, justifica a opção por programas focalizados como o Bolsa Família. Para este programa e seu antecessor (o Bolsa Alimentação), os resultados dos estudos de avaliação de impacto nutricional são conflitantes, e não há estudos de impacto sobre mortalidade, tampouco de seu efeito sobre desigualdades. São necessárias, também, maiores avaliações de programas de grande abrangência com agentes comunitários voluntários, como a Pastoral da Criança, que podem ser de grande importância para corrigir a dificuldade em alcançar as famílias mais excluídas. O PSF já conta com algumas avaliações que sugerem um impacto positivo sobre a saúde infantil como um todo, embora sem informações sobre seu efeito em termos de desigualdades. Finalmente, nota-se a completa ausência de estudos sobre o impacto da implantação do Sistema Único de Saúde (SUS) sobre as desigualdades em mortalidade.

Em resumo, existem marcadas desigualdades socioeconômicas em praticamente todos os indicadores de saúde e nutrição de crianças menores de cinco anos. Estas desigualdades configuram um quadro de iniqüidade, por serem evitáveis e injustas, impedindo que todas as crianças atinjam seu potencial de saúde, crescimento e desenvolvimento.

A solução definitiva das desigualdades socioeconômicas requer amplas transformações na sociedade como um todo, por meio de ações multisetoriais. Não obstante, a documentação destas desigualdades, particularmente no que diz respeito ao acesso, utilização e cobertura de programas de saúde, indica que intervenções médico-sanitárias podem contribuir para sua redução em curto prazo. O setor saúde, em muitas situações, parece estar contribuindo para acentuar ao invés de reduzir as iniqüidades. As persistentes desigualdades evidenciadas nesta revisão devem ser utilizadas no sentido de subsidiar as ações do setor público para reverter este cenário perverso.

A sociedade brasileira atravessa uma fase de rápidas mudanças, com uma redução - embora discreta - na concentração de renda e com quedas rápidas na mortalidade e subnutrição de crianças. Ao mesmo tempo, o SUS amplia o acesso de todos os brasileiros aos procedimentos médico-sanitários, e programas focalizados como o Bolsa Família são direcionados especificamente às populações excluídas. Dentro deste quadro, é lícito esperar que reduções nas iniqüidades em saúde infantil sejam alcançadas em um futuro próximo.

A pesquisa em saúde direcionada para a investigação de desigualdades, assim como o monitoramento permanente das disparidades e a avaliação de programas sob a ótica da eqüidade, são essenciais para que todas as crianças brasileiras alcancem seu potencial de saúde, crescimento e desenvolvimento. 


\section{Addendum*}

Em julho de 2008, foram divulgados os dados da Pesquisa Nacional de Demografia e Saúde da Criança e da Mulher (PNDS-2006), que traça um perfil da população feminina em idade fértil e das crianças menores de 5 anos no Brasil. Trata-se da terceira edição desta pesquisa, realizada pela primeira vez no Brasil em 1986 e reeditada em 1996. A equipe, de cerca de 20 pesquisadores e consultores de diversas instituições, teve coordenação geral de Elza Berquó. A execução do trabalho de campo esteve a cargo do Ibope e o DECIT/MS foi responsável pelo financiamento da pesquisa. Mais detalhes sobre os resultados da pesquisa podem ser encontrados no seguinte endereço: <http://bvsms.saude.gov.br/bvs/pnds/index.php>.

A população-alvo do estudo foram mulheres de 15 e 49 anos de idade e filhos menores de 5 anos. A amostra com representativa nacional, das 5 macrorregiões e dos extratos urbano-rural constou de 14.617 domicílios, tendo sido entrevistadas 15.575 mulheres e incluídas no estudo 5.056 crianças menores de 5 anos (4.957 vivas no momento da entrevista). O trabalho de campo foi realizado de novembro de 2006 a maio de 2007.

Os métodos de coleta de dados incluíram entrevistas domiciliares, mensurações antropométricas (altura e peso de mulheres e crianças e circunferência da cintura de mulheres), coleta de amostras de sangue para dosagens de vitamina A e hemoglobina e informações sobre 0 teor de iodo disponível no sal consumido nos domicílios. Os tópicos pesquisados foram os seguintes: fecundidade e aspectos reprodutivos; planejamento da fecundidade; anticoncepção, gravidez, parto e puerpério; conjugalidade e atividade sexual; saúde da criança; amamentação e alimentação; avaliação antropométrica do estado nutricional de crianças e mulheres; segurança alimentar; acesso a medicamentos; micronutrientes.

Apresenta-se a seguir uma série de tabelas e gráficos com alguns dados comparativos da PNDS-2006 e PNDS-1996.

\section{Fecundidade e Aspectos Reprodutivos}

Taxas de fecundidade por idade e taxa de fecundidade total (TFT)

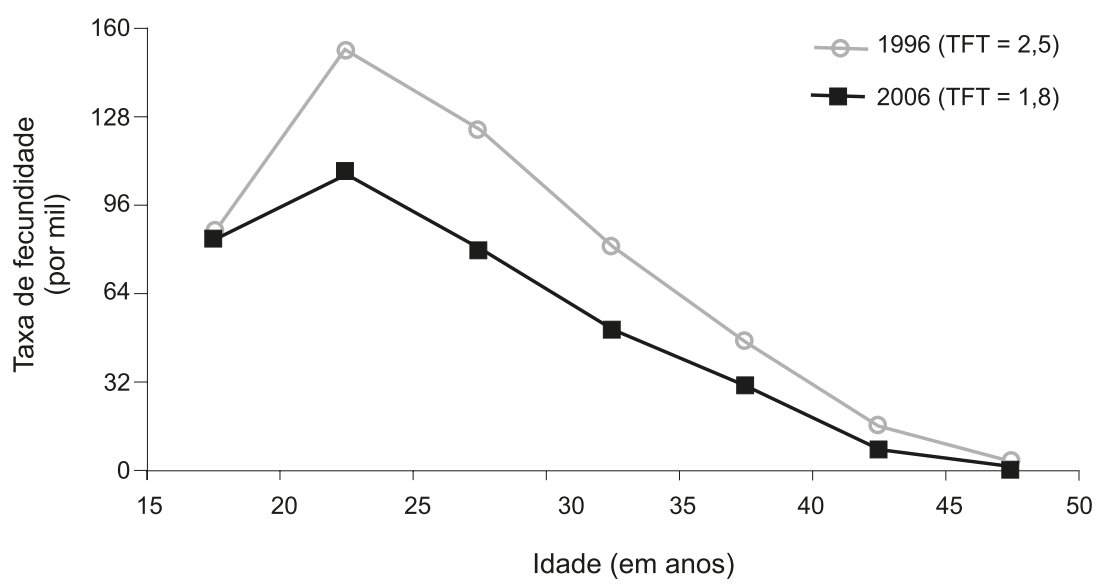

* Resumo de apresentação feita pela dra. Elza Berquó em 3 de julho de 2008 ao Ministério da Saúde. 
Taxas de fecundidade total, segundo as características sociodemográficas

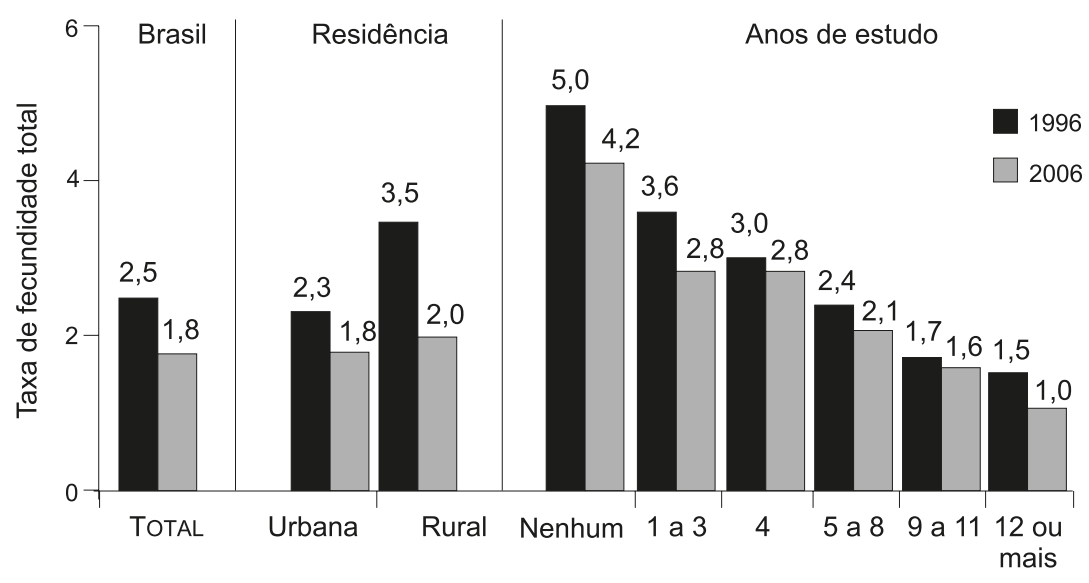

A Pesquisa revelou um rejuvenescimento do processo reprodutivo. A proporção de mulheres de 15 a 19 anos que já são mães aumentou de $14 \%$ para $16 \%$. A idade mediana ao ter o primeiro filho (para mulheres 25 a 49 anos) passou de 22,4 para 21,0 anos. Esta redução ocorreu segundo região, situação de residência e anos de estudo. A fecundidade das mulheres de 15 a 24 anos, que representava $47 \%$ da fecundidade total, passou a representar 53\% em 2006. Em contrapartida, a fecundidade das mulheres de 35 a 49 anos, declinou de $13 \%$ para $11 \%$.

\section{Assistência ao Parto}

Percentual de partos hospitalares e de partos assistidos por médicos ou enfermeiras, nos cinco anos anteriores à entrevista. Brasil, rural e regiões Norte e Nordeste.

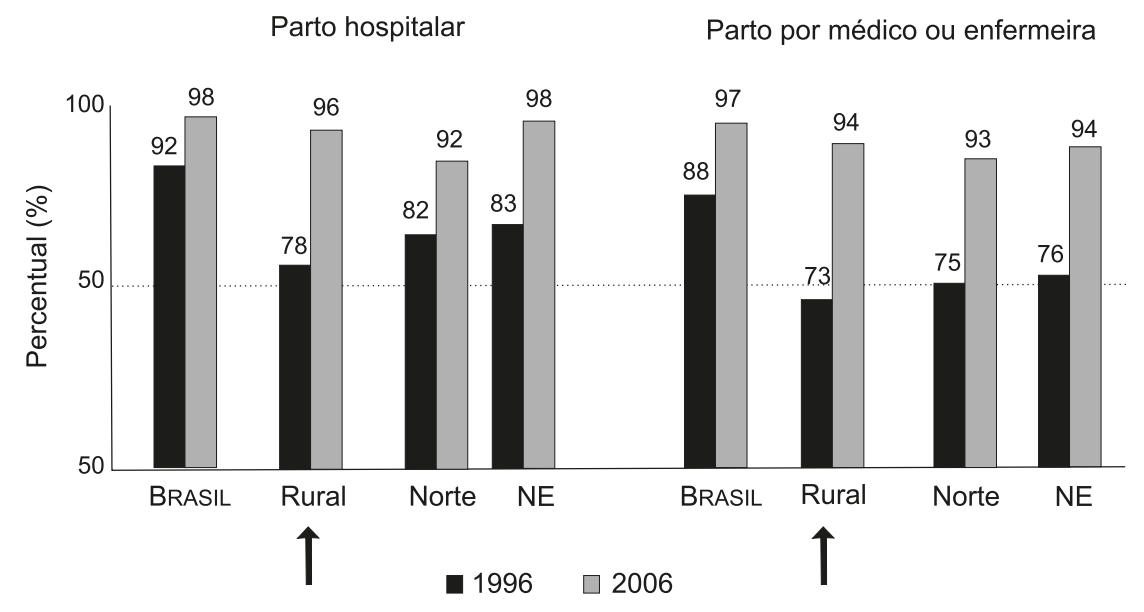


Porcentagem de partos cesáreos nos cinco anos anteriores à entrevista, segundo residência e tipo de serviço de saúde utlizado.

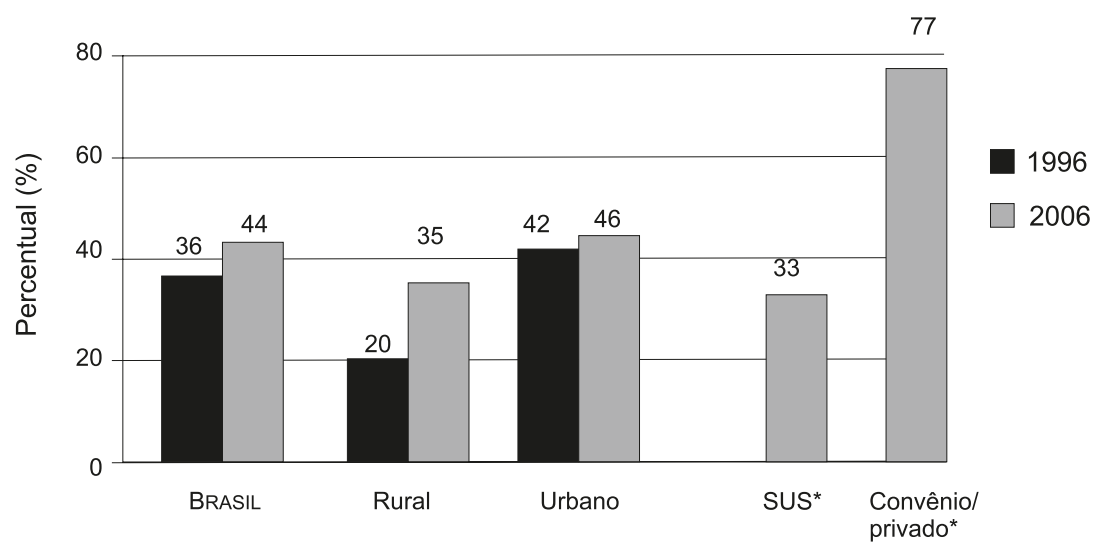

* Dado não disponivel em 1996

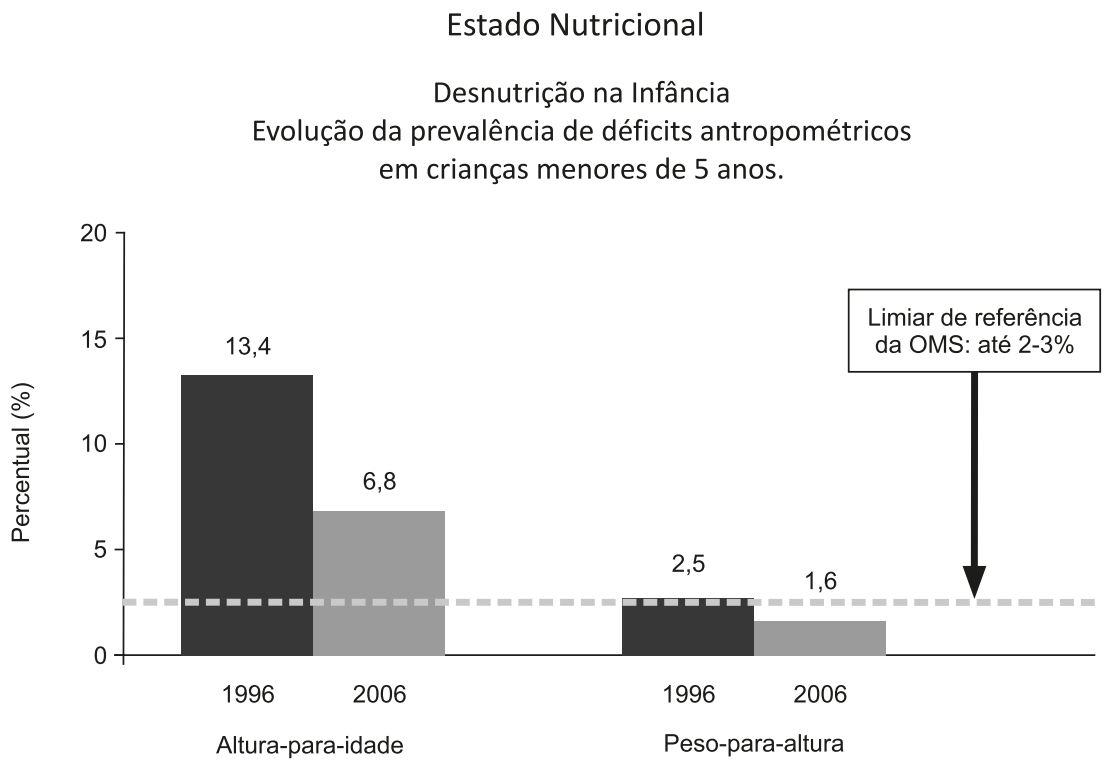


Evolução da prevalência de déficit de altura-para-idade em crianças menores de 5 anos, segundo região.

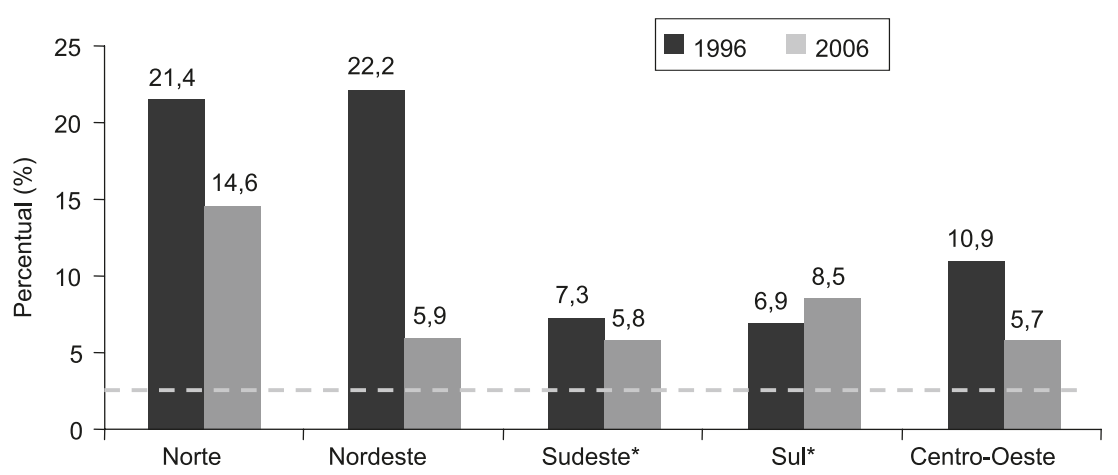

*Variação não significativa.

Evolução da prevalência de déficit de peso-para-altura em crianças menores de 5 anos, segundo região.

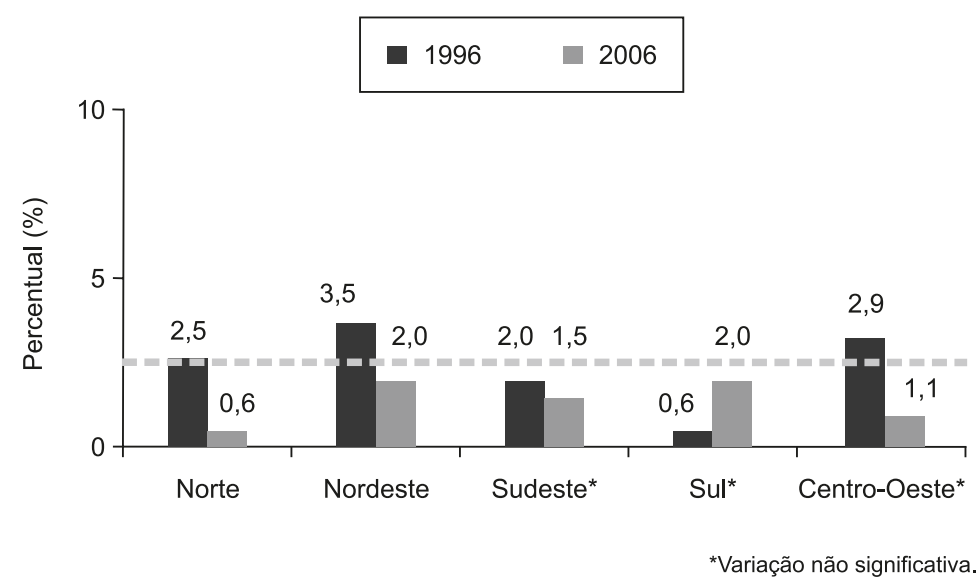




\section{Obesidade na Infância}

Evolução da prevalência de excesso de peso-para-altura em crianças menores de 5 anos, segundo região.

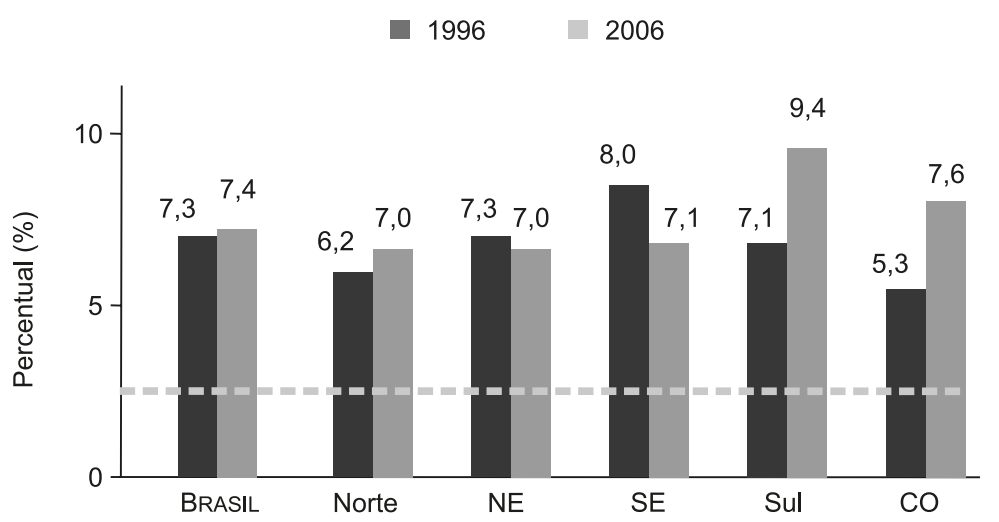

Obs: Variação entre os anos não significativa.

\section{Amamentação}

Percentual de crianças menores de 60 meses alguma vez amamentadas, segundo residência e região.

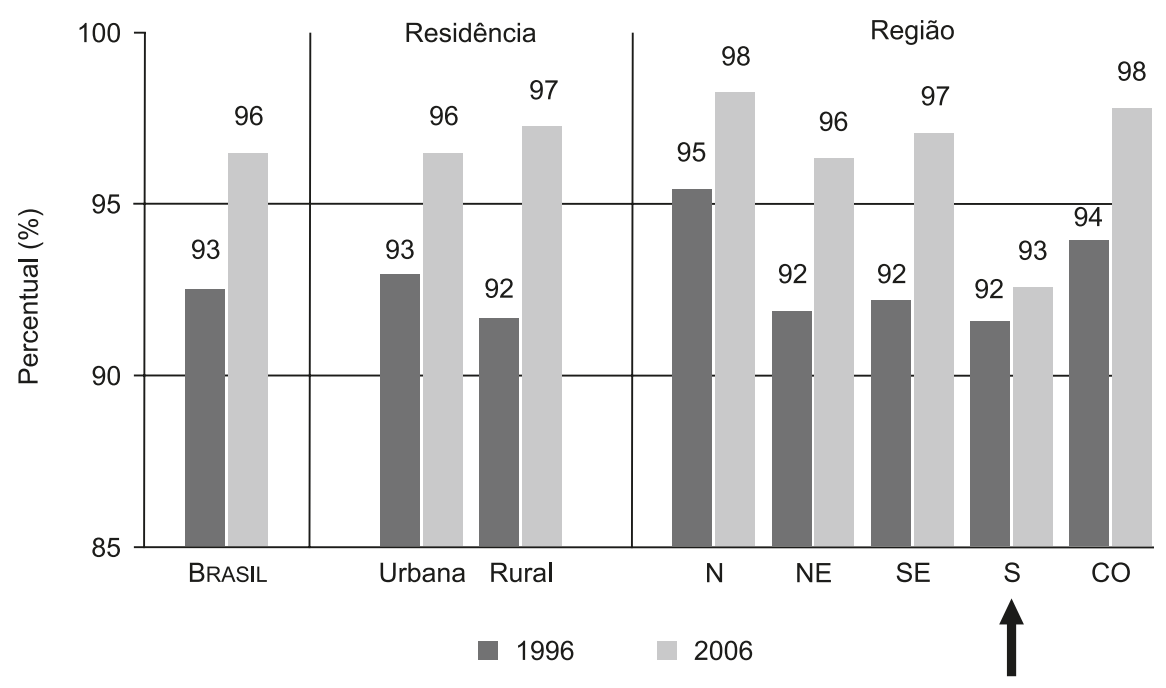


Duração mediana do aleitamento materno (em meses), entre menores de 36 meses de idade, segundo residência e região.

\begin{tabular}{lcccc}
\hline & \multicolumn{2}{c}{$\begin{array}{c}\text { Aleitamento } \\
\text { exclusivo }\end{array}$} & \multicolumn{2}{c}{$\begin{array}{c}\text { Aleitamento } \\
\text { TOTAL }\end{array}$} \\
& 1996 & 2006 & 1996 & 2006 \\
\hline BRASIL & 1,1 & 2,2 & 7,0 & 9,4 \\
Residência & & & & \\
Urbano & 1,3 & 2,2 & 6,7 & 9,3 \\
$\quad$ Rural & 0,7 & 2,1 & 8,9 & 9,7 \\
Região & & & & \\
$\quad$ Norte & 1,4 & 2,1 & 10,3 & 9,7 \\
$\quad$ Nordeste & 0,7 & 2,2 & 9,8 & 9,6 \\
Sudeste & 1,9 & 2,0 & 6,0 & 9,4 \\
Sul & 1,7 & 2,6 & 7,1 & 9,6 \\
$\quad$ Centro-Oeste & 0,7 & 2,5 & 7,0 & 8,6 \\
\hline
\end{tabular}

Prevalência domiciliar de Segurança/Insegurança Alimentar, segundo escolaridade da pessoa de referência. PNDS-2006.

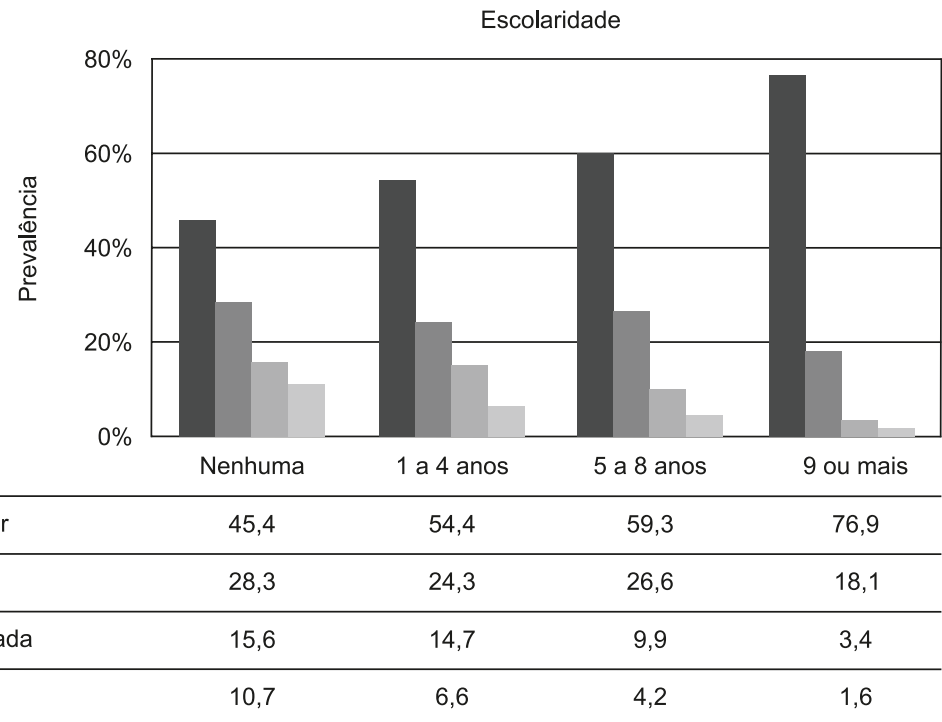




\subsection{SaÚde IndíGenA ${ }^{9}$}

Os povos indígenas no Brasil apresentam um complexo e dinâmico quadro de saúde, diretamente relacionado a processos históricos de mudanças sociais, econômicas e ambientais atreladas à expansão e à consolidação de frentes demográficas e econômicas da sociedade nacional nas diversas regiões do país (Coimbra Jr., Santos \& Escobar, 2003; Coimbra Jr. \& Santos, 2004; Garnelo, Macedo \& Brandão, 2003; Santos et al., 2008). Ao longo dos séculos, tais frentes exerceram importante influência sobre os determinantes dos perfis da saúde indígena, quer seja por meio da introdução de novos patógenos ocasionando graves epidemias; usurpação de territórios; dificultando ou inviabilizando a subsistência; e/ou a perseguição e morte de indivíduos ou mesmo comunidades inteiras. No presente, emergem outros desafios à saúde dos povos indígenas, que incluem doenças crônicas não-transmissíveis, contaminação ambiental, crescente urbanização e dificuldades de sustentabilidade alimentar, para citar uns poucos exemplos.

o perfil de saúde dos povos indígenas é muito pouco conhecido, o que decorre da exigüidade de investigações, da ausência de inquéritos e censos, assim como da precariedade dos sistemas de informações sobre morbidade e mortalidade (Coimbra Jr. et al., 2002; Coimbra Jr., Santos \& Escobar, 2003; Garnelo, Macedo \& Brandão, 2003; Santos \& Escobar, 2001; Santos et al., 2008). Qualquer discussão sobre o processo saúde/doença dos povos indígenas precisa levar em consideração, além das dinâmicas epidemiológica e demográfica, a enorme sociodiversidade existente. São aproximadamente 220 etnias, falantes de algo em torno de 180 línguas e que têm experiências de interação com a sociedade nacional as mais diversas. As estimativas quanto ao total da população indígena no país variam entre 400 a 730 mil pessoas, a depender da fonte, o que perfaz menos de $1 \%$ da população brasileira.

Um documento do Ministério da Saúde, intitulado "Política nacional de atenção aos povos indígenas", não somente explicita a condição de ausência de dados, como também aponta para a magnitude das desigualdades entre a saúde dos povos indígenas e de outros segmentos da sociedade nacional:

Não se dispõe de dados globais fidedignos sobre a situação de saúde... [dos povos indígenas], mas sim de dados parciais, gerados pela Funai [Fundação Nacional do Índio], pela Funasa [Fundação Nacional de Saúde] e diversas organizações não-governamentais ou ainda por missões religiosas que, por meio de projetos especiais, têm prestado serviço de atenção à saúde dos povos indígenas. Embora precários, os dados disponíveis indicam, em diversas situações, taxas de morbidade e mortalidade três a quatro vezes maiores que aquelas encontradas na população brasileira geral. O alto número de óbitos sem registro ou indexados sem causas definidas confirmam a pouca cobertura e baixa capacidade de resolução dos serviços disponíveis. (Funasa, 2002: 10)

${ }^{9}$ Esta seção foi elaborada por Ricardo Ventura Santos e Carlos E. A. Coimbra Jr. 
Com base nos dados disponíveis, não é possível caracterizar de forma satisfatória as condições de saúde dos povos indígenas, dado que estão ausentes os elementos quantitativos necessários para embasar análises abrangentes e sofisticadas. Em geral, é difícil ir além da compilação de estudos de casos específicos, muitos dos quais oriundos da Amazônia. Em anos recentes, foi iniciada a implantação de um sistema de informação específico sobre a saúde indígena (Sistema de Informação da Atenção à Saúde Indígena - Siasi), mas que infelizmente ainda não funciona a contento. Não obstante, restam poucas dúvidas de que as condições de saúde dos povos indígenas sinalizam para uma considerável situação de vulnerabilidade, colocando-as em desvantagem em relação a outros segmentos da sociedade nacional (Coimbra Jr., Santos \& Escobar, 2003; Garnelo, Macedo \& Brandão, 2003; Santos et al., 2008).

A partir dos resultados do mais recente censo demográfico (2000) evidenciou-se que os níveis de escolaridade dos indígenas permanecem muito baixos e que há diferenças importantes nas taxas de fecundidade total das mulheres indígenas urbanas (2,7 filhos) e rurais (5,7 filhos). Os dados censitários mostram também uma taxa de mortalidade infantil para os indígenas em 2000 (51,4 por mil) significativamente mais elevada que a taxa nacional (de 30,1 por mil). A mortalidade infantil indígena é muito superior a dos demais grupos de cor/raça, inclusive das crianças 'pretas' e 'pardas' (34,9 e 33,0 por mil, respectivamente). Chamam atenção também as elevadas taxas de mortalidade infantil dos indígenas nas regiões socioeconomicamente mais desenvolvidas do país (Sudeste e Sul) (IBGE, 2005).

As doenças infecciosas e parasitárias persistem como as principais causas de adoecimento e morte de indígenas no país. A tuberculose se destaca como uma das principais endemias nessas populações. A malária constitui outra endemia amplamente presente nas terras indígenas, sobretudo na Amazônia, onde tem ocasionado surtos que resultam em elevadas taxas de mortalidade. Concomitantemente, as infecções respiratórias agudas e as diarréias são as principais causas de adoecimento e morte nas crianças menores de cinco anos (Coimbra Jr., Santos \& Escobar, 2003; Garnelo, Macedo \& Brandão, 2003; Funasa, 2003, 2006; Santos et al., 2008).

Atualmente, a questão alimentar e nutricional indígena tem adquirido grande visibilidade. Estudos recentes destacam que, de modo geral, a desnutrição atinge mais de um quarto das crianças menores de cinco anos e, não raro, mais da metade delas. A anemia por deficiência de ferro constitui a principal doença carencial verificada nas populações indígenas, afetando principalmente crianças menores de 10 anos e mulheres em idade reprodutiva, com prevalências que chegam a 70-80\% desse segmento populacional (Leite et al., 2007).

Condições precárias de saneamento e habitação, aliadas à baixa cobertura e qualidade dos serviços de saúde, interagem, levando ao agravamento e deterioração das condições nutricionais das crianças indígenas. Sem água potável e tratamento adequado dos dejetos nas aldeias, aumenta a incidência de diarréias e de outras doenças infecciosas e parasitárias. 
A questão da terra constitui outra variável fundamental para a compreensão das condições de saúde e nutrição dos povos indígenas. Um aspecto crucial é que as dimensões das terras indígenas, sobretudo nas regiões Sul, Sudeste e Nordeste do Brasil, e em parte do CentroOeste, são bastante reduzidas em relação às necessidades das comunidades. Um exemplo é aquele dos Guarani-Kaiowá de Mato Grosso do Sul, que vivem uma situação de extrema restrição territorial, com graves conseqüências sobre a situação alimentar.

Outra dimensão particularmente pouco conhecida da epidemiologia dos povos indígenas diz respeito à emergência de doenças crônicas não-transmissíveis, como obesidade, hipertensão arterial, diabetes mellitus e câncer. O surgimento desse grupo de doenças está estreitamente associado a modificações na subsistência, dieta e atividade física, dentre outros fatores, acopladas a mudanças socioculturais e econômicas. No bojo dessas alterações, verifica-se que, concomitante à emergência de doenças crônicas não-transmissíveis, há um crescente número de relatos sobre a ocorrência de suicídio, alcoolismo e drogadicção em diferentes povos indígenas. Observa-se, ainda, aumento importante das mortes por causas externas, sejam estas ocasionadas por acidentes automobilísticos ou uso de maquinário agrícola, como também por violência (Coimbra Jr. et al., 2002; Coimbra Jr., Santos \& Escobar, 2003; Garnelo, Macedo \& Brandão, 2003; Santos et al., 2008).

O conhecimento do perfil epidemiológico em transição dos povos indígenas no Brasil, considerando a grande diversidade étnica que os caracteriza, reveste-se de suma importância para orientar a organização, planejamento e melhoria da qualidade dos serviços de saúde. Em geral, esses serviços encontram-se voltados para lidar com determinados grupos de doenças, sobretudo as infecciosas e parasitárias, que, historicamente, têm (ou tiveram) maior peso na morbidade e mortalidade indígena.

Até o final da década de 1990, os serviços de saúde destinados ao atendimento dos povos indígenas eram geridos pela Fundação Nacional do Índio (Funai). Em larga medida, baseavam-se em atuações eminentemente curativas. A continuidade da atenção básica à saúde nas áreas indígenas não ocorria de forma satisfatória. Mesmo nas décadas de 1960 e 1970, quando já se dispunham de vacinas, antibióticos e outros recursos, não se conseguiu evitar que epidemias de malária, tuberculose ou mesmo de sarampo dizimassem centenas de indígenas recém-contatados no Brasil Central e Amazônia.

A partir de 1999, a responsabilidade pela provisão de serviços de saúde aos povos indígenas passou para a Fundação Nacional de Saúde (Funasa), vinculada ao Ministério da Saúde, concretizando a implantação de um serviço de saúde voltado para os povos indígenas e estruturado segundo divisão territorial em distritos (os chamados "Distritos Sanitários Especiais Indígenas” - DSEIS), vinculados ao Sistema Único de Saúde (SUS). No presente, há 34 distritos implantados em todo o país. Esse novo modelo pauta-se na perspectiva da atenção diferenciada, reconhecendo, ao menos em tese, as especificidades dos povos indígenas. Não obstante, após meia década de implantação, é perceptível que as ações ainda estão bastante distantes quanto a reduzir as enormes disparidades em saúde dos indígenas se comparados aos não-indígenas (Garnelo, Macedo \& Brandão, 2003; Santos et al., 2008). 